
JACYR VIANNA DE QUADROS JR.

Estudo da reação de epoxidação do óleo de soja em condição de remoção de calor máxima 

JACYR VIANNA DE QUADROS JR.

Estudo da reação de epoxidação do óleo de soja em condição de remoção de calor máxima

Tese apresentada à Escola Politécnica da Universidade de São Paulo para obtenção de título de Doutor em Ciências

São Paulo 

JACYR VIANNA DE QUADROS JR.

Estudo da reação de epoxidação do óleo de soja em condição de remoção de calor máxima

Tese apresentada à Escola Politécnica da Universidade de São Paulo para obtenção de título de Doutor em Ciências

Área de concentração: Engenharia Química

Orientador: Prof. Dr. Reinaldo Giudici, Professor Titular, Escola Politécnica USP

São Paulo 
Este exemplar foi revisado e corrigido em relação à versão original, sob responsabilidade única do autor e com a anuência de seu orientador.

São Paulo, de de

Assinatura do autor:

Assinatura do orientador:

\section{Catalogação-na-publicação}

Quadros Junior, Jacyr Vianna de

Estudo da reação de epoxidação do óleo de soja em condição de remoção de calor máxima / J. V. Quadros Junior. -- versão corr. -- São Paulo, 2015.

$97 \mathrm{p}$.

Tese (Doutorado) - Escola Politécnica da Universidade de São Paulo. Departamento de Engenharia Química

1.Reações químicas 2. Transporte de calor 3.Modelos matemáticos I.Universidade de São Paulo. Escola Politécnica. Departamento de Engenharia Química II. t. 


\section{AGRADECIMENTOS}

Agradeço, antes de mais nada, à Escola Politécnica da Universidade de São Paulo, seus professores, pesquisadores, funcionários administrativos e técnicos, por sua dedicação e presteza, contribuindo de diversas formas para este doutorado que aqui encerro com esta tese.

Gostaria também de registrar aqui meus sinceros agradecimentos às seguintes pessoas:

- Ao meu orientador, Reinaldo Giudici, por sua paciência, disponibilidade e contribuição intelectual para o trabalho. Além de seu impressionante conhecimento de engenharia química, de processos e de modelagens matemáticas, demonstrou uma capacidade extraordinária de entender as dificuldades experimentais e teóricas do tema em estudo, propondo soluções criativas e cientificamente sólidas.

- Aos professores Ardson dos Santos Vianna Junior, Antonio Carlos S. C. Teixeira e João Guilherme R. Poço pelas importantes contribuições e sugestões dadas para aperfeiçoamento dos ensaios e do texto desta tese.

- Aos colegas de mestrado e doutorado que contribuíram com sua experiência e conhecimento.

- À minha esposa, Adriana Carranca Correa, pelo incentivo e pela paciência.

- Aos meus pais, Neusa Di Franco Quadros e Jacyr Vianna de Quadros (in memorian) por me motivarem desde cedo a buscar respostas para as perguntas mais difíceis e confiar na ciência. 



\section{RESUMO}

Óleo de soja epoxidado (OSE) é um produto químico há muito tempo utilizado como co-estabilizante e plastificante secundário do poli (cloreto de vinila) (PVC), ou seja, como um material que tem limitações na quantidade máxima que pode ser usada no composto de PVC. A sua aplicação como plastificante primário, ou seja, como o principal elemento plastificante no composto de PVC, e como base para outros plastificantes de fontes renováveis, tem aumentado nos últimos anos, principalmente devido a melhorias de desempenho e à redução do custo do OSE em comparação com plastificantes tradicionais. A reação de epoxidação do óleo de soja é bem conhecida e ocorre em duas fases líquidas, com reações em ambas as fases, e transferência de massa entre as fases. O processo industrial mais utilizado conta com formação "in-situ" do ácido perfórmico, através da adição gradativa do principal reagente, o peróxido de hidrogênio a uma mistura agitada de ácido fórmico e óleo de soja refinado. Industrialmente, o processo é realizado em batelada, controlando a adição do reagente peróxido de hidrogênio de forma que a geração de calor não ultrapasse a capacidade de resfriamento do sistema. O processo tem um ciclo que pode variar entre 8 e 12 horas para atingir a conversão desejada, fazendo com que a capacidade de produção seja dependente de investimentos relativamente pesados em reatores agitados mecanicamente, que apresentam diversos riscos de segurança. Estudos anteriores não exploram em profundidade algumas potenciais áreas de otimização e redução das limitações dos processos, como a intensificação da transferência de calor, que permite a redução do tempo total de reação. Este trabalho avalia experimentalmente e propõe uma modelagem para a reação de epoxidação do óleo de soja em condições de remoção de calor máxima, o que permite que os reagentes sejam adicionados em sua totalidade no início da reação, simplificando o processo. Um modelo foi ajustado aos dados experimentais. $O$ coeficiente de troca térmica, cuja estimativa teórica pode incorrer em erros significativos, foi calculado a partir de dados empíricos e incluído na modelagem, acrescentando um fator de variabilidade importante em relação aos modelos anteriores. O estudo propõe uma base teórica para potenciais alternativas aos processos adotados atualmente, buscando entender as condições necessárias e viáveis em escala industrial para redução do ciclo da reação, podendo inclusive 
apoiar potenciais estudos de implementação de um reator contínuo, mais eficiente e seguro, para esse processo. 


\begin{abstract}
Epoxidized soybean oil (ESBO) has been largely used commercially, especially in the poly (vinyl chloride) (PVC) industry. For that market, until recently, ESBO was applied only as a co-stabilizer and a secondary plasticizer, where the material is considered partially compatible and presents limitations to the allowed concentration in PVC compounds. The application of this material as a primary plasticizer, where ESBO is the main plasticizer of the formulation, and also as building block for other bio-based primary plasticizers has been growing significantly in the past years, mainly due to better quality of the epoxidized products and reduced cost over traditional petroleum based materials.

The epoxidation of vegetable oils is a well know process that occurs in two liquid phases, with reactions in both phases and mass transfer between phases. The most commonly used industrial process employs mechanically agitated lengthy batch reactions, with gradual addition of hydrogen peroxide, in order to keep heat generation below maximum heat removal capacity. This process has a cycle that may vary between 8 to 12 hours to reach the desired conversion, and depends on relatively high investments, in addition to several safety concerns.

Previous studies have not explored in detail a potential optimization of the processes by heat transfer intensification, in order to maximize conversion, reduce reaction times, and improve safety.

The present research offers a better understanding of the kinetic and transport phenomena variables of the epoxidation reaction under maximum heat removal conditions, which allow complete addition of all reagents at once. The present study evaluates experimentally and proposes a reaction simulation model under these conditions. The thermal exchange coefficient, for which theoretical estimates may incur in significant errors, was calculated from empirical results and included in the model, adding an important variability factor when compared to previous models. The study also proposes the initial bases to understand the necessary conditions to reduce the reaction cycle and allow the evaluation of a continuous, more efficient and safer reaction system.
\end{abstract}





\section{LIST A DE ILUSTRAÇÕES}

Figura 2.1 - Reação de formação do ácido perfórmico ............................................23

Figura 2.2 - Esquema da reação de epoxidação do óleo de soja .......................... 24

Figura 2.3 - Esquema das reações e da transferência de massa entre fases ..... 26

Figura 2.4 - Reação de degradação do OSE (sem peróxido) …………………..... 28

Figura 2.5 - Reação de degradação do OSE (com peróxido) …………………......2 29

Figura 3.1 - Esquema do equipamento (reator e periféricos) …………………..... 39

Figura 3.2 - Fotografia do Variac e do reator ......................................................... 39

Figura 3.3 - Fotografias do controlador de rotação do agitador,do termômetro com termopares e do sistema de aquisição de dados 39

Figura 3.4 - Esquema do reator piloto, de 50 litros, termicamente isolado, usado na determinação da entalpia de reação. .44

Figura 3.5 - Aparato para medida de viscosidade cinemática 47

Figura 4.1 -

Resultados do cálculo do U para dois experimentos replicados 52

Figura 4.2 Efeito da viscosidade e velocidade de rotação sobre o coeficiente de transferência de calor. Verificação da equação (15) 57

Figura 4.3 - Viscosidades de OSE puro, e curva de tendência 59

Figura 4.4 - Evolução da viscosidade aparente (medida com o dispositivo capilar) e da temperatura durante ensaios de reação de epoxidação. 60

Figura 4.5 - Curvas experimentais de temperatura vs. tempo 61

Figura 4.6 - Comparação: adições de 1/20 e 1/10 de peróxido 62

Figura 4.7 - Comparação da elevação da temperatura 62

Figura 4.8 - Variação da temperatura para 5 adições sequenciais de peróxido .63

Figura 4.9 - Comparação da elevação de temperatura 63

Figura 4.10 - Curvas de temperatura para três adições de peróxido 64

Figura 4.11 - Curvas de temperatura para duas adições de peróxido 64

Figura 4.12 - Curva de temperatura para adição única de peróxido 65

Figura 4.13 - Primeira adição de 33 \%, 50 \% e $100 \%$ do peróxido 66

Figura 4.14 - Comparação da evolução de conversão - índice oxirânico 68

Figura 4.15 - Comparação da evolução de conversão - índice de lodo 68

Figura 4.16 - Sumário dos experimentos planejados $\left(60^{\circ} \mathrm{C}\right)$.................................. 71

Figura 4.17 - Sumário dos experimentos planejados $\left(40^{\circ} \mathrm{C}\right)$.................................73

Figura 4.18 - Comparação de modelos - U variável e U constante .76 
Figura 4.19 - Comparação entre dados experimentais e modelo - PE01 ...............77

Figura 4.20 - Comparação entre dados experimentais e modelo - PE16 ………...77

Figura 4.21 - Comparação entre modelo e dados experimentais, com ajuste .......78 


\section{LIST A DE TABELAS}

Tabela 2.1 - Composição de óleo de soja no Brasil ..................................................24

Tabela 2.2 - Características cinéticas da reação de epoxidação simplificada...... 25

Tabela 4.1 - Dados medidos e cálculos preliminares para determinação da

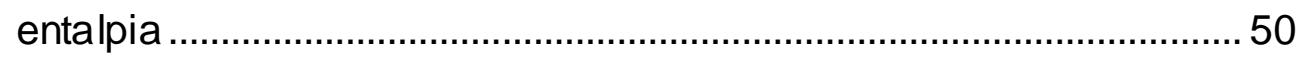

Tabela4.2 - Resultados dos ensaios planejados para determinação do U ...........55

Tabela 4.3 - Viscosidades do óleo de soja ...........................................................5

Tabela 4.4 - Viscosidades do OSE .................................................................. 58

Tabela 4.5 - Viscosidades de OSE puro, medidas experimentais ..........................58

Tabela 4.6 - Viscosidades de óleo de soja puro, medidas experimentais .............58

Tabela 4.7 - Dados comparativos e fator multiplicador .............................................59

Tabela 4.8 - I Índice oxirânico e índice de iodo do produto final. Comparação com

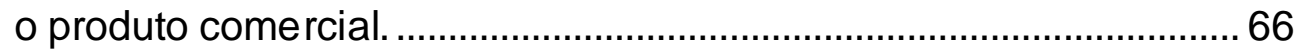

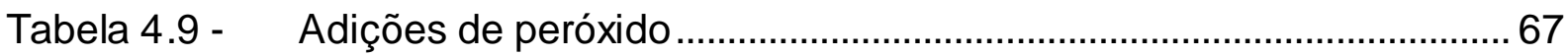

Tabela 4.10 - Planejamento de experimentos para os ensaios. …………………... 70

Tabela 4.11 - Sumário dos experimentos planejados $\left(60^{\circ} \mathrm{C}\right)$...................................70

Tabela 4.12 - Sumário dos experimentos planejados $\left(40^{\circ} \mathrm{C}\right)$....................................

Tabela4.13 - Parâmetros e propriedades do modelo simplificado .............................75

Tabela 4.14 - Comparação de ajustes dos modelos aos dados experimentais .....79 



\section{LISTA DE ABREVIATURAS E SIGLAS}

ABNT .............Associação Brasileira de Normas Técnicas

$\mathrm{AF}$....................écido fórmico

AOCS ............American Oil Chemists' Society

APF................Ácido perfórmico

E....................Energia de ativação

EFAME...........Epoxidized fatty acid methyl ester (Éster metílico de soja epoxidado)

ESBO .............Epoxidized soybean oil (Óleo de soja epoxidado)

FA .................Formic acid (Ácido fórmico)

FAME ............Fatty acid methyl ester (Éster metílico de soja)

EDTA 2Na ....Ethylenediaminetetraacetic Acid Disodium Salt (Sal disódico de etileno diamina tetracética)

OSE...............óleo de soja epoxidado

PVC ...............Poly (vinyl chloride) ou poli (cloreto de vinila) 



\section{LISTA DE SÍMBOLOS}

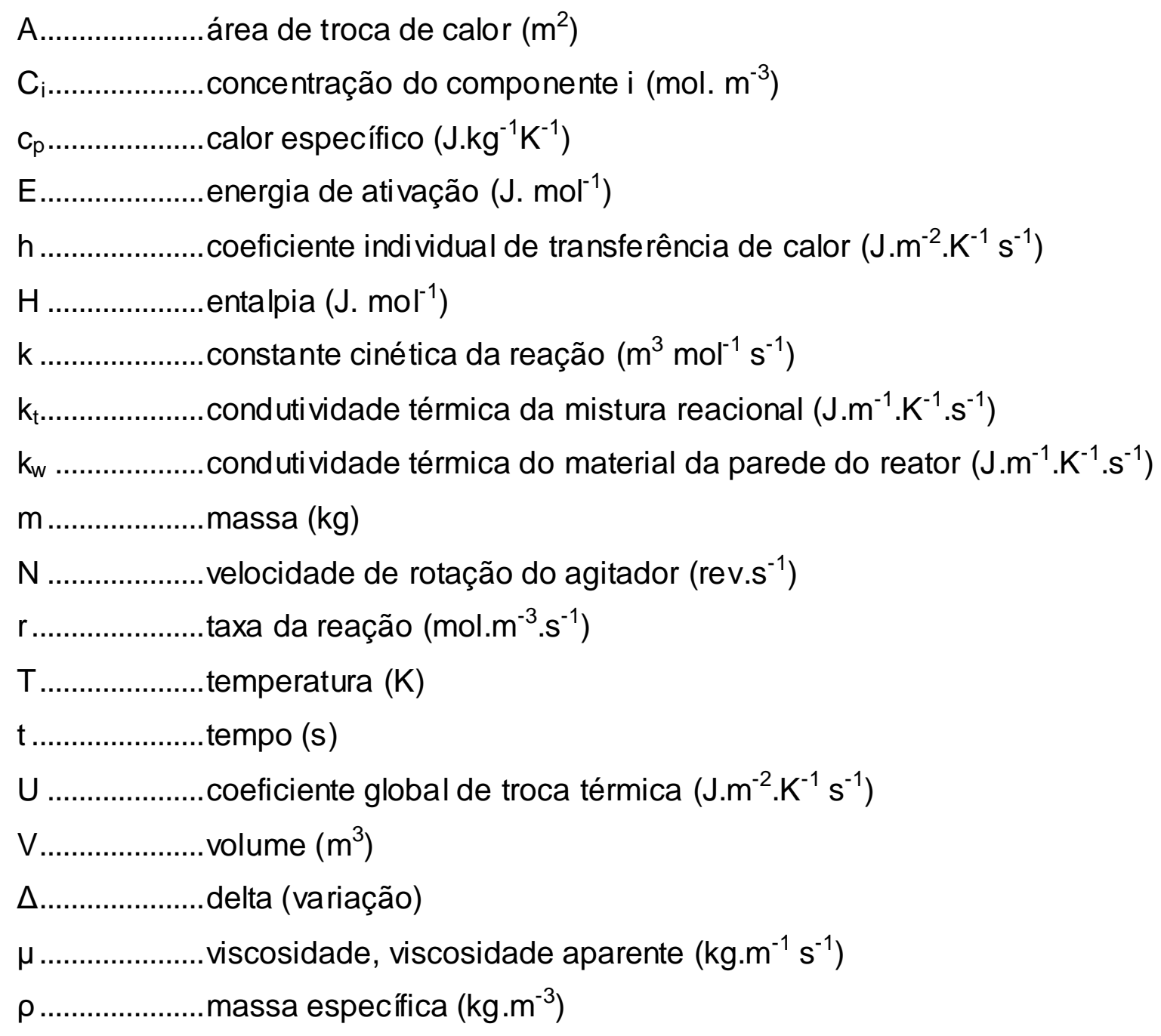





\section{SUMÁRIO}

1 INTRODUÇÃO

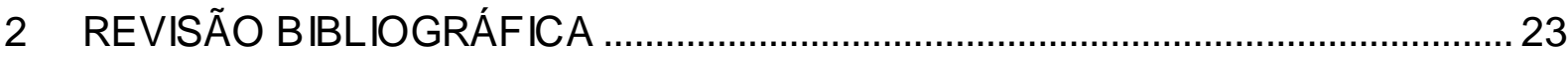

2.1 Descrição dos sistemas reacionais e cinética ................................................2 23

2.1.1 Descrição das reações principais ........................................................2 23

2.1.2 Descrição do sistema de duas fases ..................................................26

2.1.3 Descrição das reações secundárias ..................................................2

2.1.4 Outros sistemas reacionais e informações adicionais ........................30

2.2 Epoxidação: processos reacionais e entalpia da reação …………………... 31

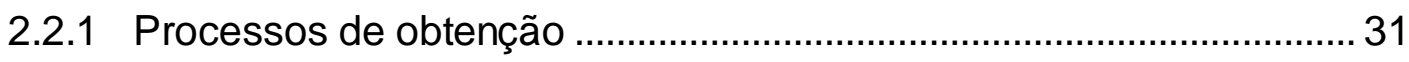

2.2.2 Entalpia de reação.............................................................................. 32

2.3 Intensificação dos processos reacionais ......................................................... 33

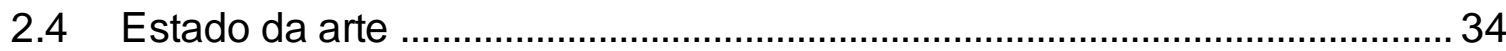

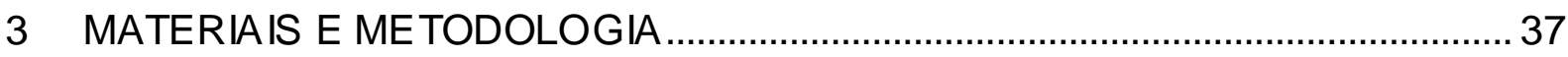

3.1 Metodologia e materiais dos ensaios experimentais ....................................3 37

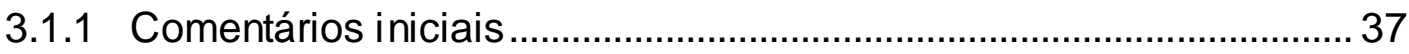

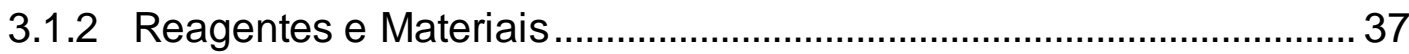

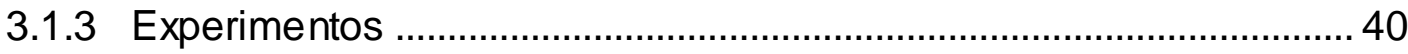

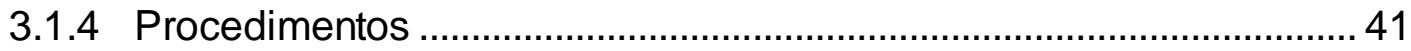

3.2 Metodologia para cálculo da modelagem ……………………………........ 47

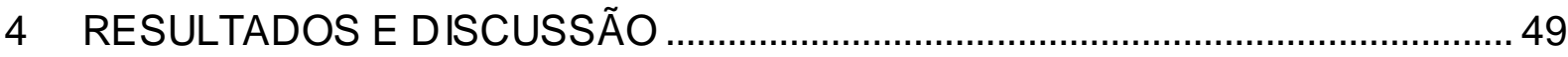

4.1 Detalhamento dos resultados dos experimentos realizados ....................... 49

4.1.1 Determinação da entalpia da reação .................................................. 49

4.1.2 Determinação de coeficiente de troca térmica $(U)$............................. 51

4.1.3 Ensaios de medição da viscosidade ………………………………....5

4.1.4 Experimentos da reação de epoxidação …………………………..... 61 


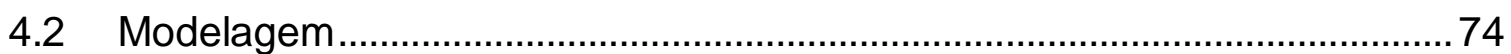

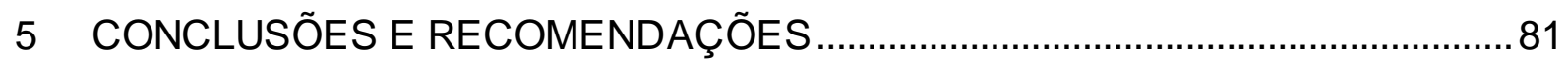

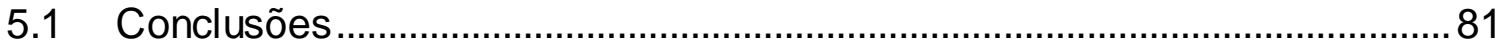

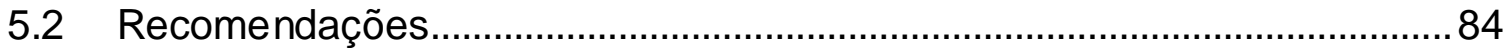

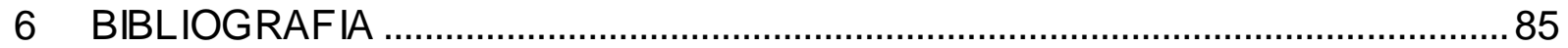




\section{INTRODUÇÃO}

Óleo de soja epoxidado (OSE) é um produto químico há muito tempo comercialmente utilizado, principalmente na indústria do poli (cloreto de vinila) (PVC). Para esse mercado o OSE vinha sendo aplicado até recentemente apenas como co-estabilizante e plastificante secundário, ou seja, como um material que tem limitações na quantidade máxima que pode ser usada no composto de PVC (SEARS; DARBY, 1982). A aplicação como plastificante primário, ou seja, como o principal elemento plastificante no composto de PVC, e como base para obtenção de outros plastificantes de fontes renováveis tem aumentado continuamente nos últimos anos (KARMALM et al., 2009), principalmente devido a melhorias de desempenho e da redução do custo do OSE em comparação com os plastificantes tradicionais (RAHMAN; BRAZEL, 2004). Especificamente no Brasil o volume de participação dos plastificantes epoxidados cresceu de $5 \%$ (1995) para $30 \%$ (2012), atingindo uma demanda total de aproximadamente 50 mil toneladas.

O processo de epoxidação consiste de diversas reações exotérmicas que ocorrem em fases líquidas distintas, com transferência de massa entre as fases. O produto final desejado é o óleo de soja epoxidado, onde as insaturações (duplas ligações) dos triglicerídeos originais do óleo de soja são substituídas por anéis oxirânicos (grupos epóxido). A conversão é determinante da qualidade do produto final e da sua viabilidade comercial, principalmente para o mercado de PVC. As especificações técnicas do produto comercial encontram-se no Anexo I.

Esta tese propõe uma avaliação experimental, não antes realizada, da reação em condição de remoção de calor máxima e adição única de todos os componentes. A proposta, ao contrário dos trabalhos existentes que focam a intensificação da reação (p.ex. via uso de diferentes catalisadores, diferentes agentes epoxidantes, métodos de agitação, etc.), é a intensificação da troca de calor, que representa um importante limitante para a redução do tempo do processo em escala industrial. Além disso, um modelo matemático simplificado para o processo é desenvolvido e validado por comparação com dados experimentais. O modelo considera a variação do coeficiente de transferência de calor do sistema, acrescentando uma variável não antes estudada experimentalmente.

Os objetivos deste trabalho de tese foram os seguintes: 1) avaliar a viabilidade da adição única de todos os componentes na reação de epoxidação de óleo de soja; 2) 
entender a cinética e questões de fenômenos de transporte da reação na condição de remoção de calor máxima, considerando diferentes parâmetros operacionais; 3) determinar experimentalmente os coeficientes de troca de calor durante o processo reacional; 4) modelar o processo e validar o modelo com dados experimentais, fornecendo assim uma ferramenta de simulação que permita avaliação de potencial e viabilidade técnica/comercial de alternativas aos processos atuais, incluindo reatores contínuos, com potenciais ganhos de produtividade, segurança e qualidade. A tese inclui uma revisão bibliográfica, onde o estado da arte e as informações relevantes ao trabalho encontradas na literatura são apresentados e discutidos. Em seguida a metodologia é apresentada, onde são descritos os materiais e métodos utilizados para desenvolver os ensaios experimentais e o desenvolvimento da modelagem do processo. Na sequência apresentam-se os resultados obtidos, incluindo a discussão das observações realizadas. Para finalizar, a última parte do trabalho mostra as conclusões obtidas a partir dos ensaios e modelagem, bem como recomendações para estudos continuados relacionados ao tema. 


\section{REVISÃo BIBLIOGRÁFICA}

A revisão bibliográfica subdivide-se em quatro partes: 1) descrição dos sistemas reacionais e cinética; 2) levantamento dos dados relevantes sobre o processo de epoxidação do óleo de soja e a geração de calor; 3) revisão dos trabalhos de intensificação da reação e processos; 4) apreciação do estado da arte e dos trabalhos que se relacionam mais diretamente com a proposta desta tese.

\subsection{Descrição dos sistemas reacionais e cinética}

A literatura existente sobre as reações de epoxidação de óleos e ésteres vegetais apresenta grande riqueza de dados sobre a cinética de reação sob diversas condições. Várias publicações apresentam dados interessantes sobre a cinética da reação avaliando fatores como concentração dos reagentes e catalisadores, diferentes tipos de catalisadores, temperatura e agitação. As descrições aqui apresentadas referem-se aos processos escolhidos para a realização dos ensaios desta tese. Outros processos são discutidos brevemente ao final desta seção.

\subsubsection{Descrição das reações principais}

O processo de epoxidação do óleo de soja ocorre em duas etapas. A primeira é a reação de formação do perácido fórmico, que ocorre na fase aquosa, como mostrado na Figura 2.1:

Figura 2.1 - Reação de formação do ácido perfórmico

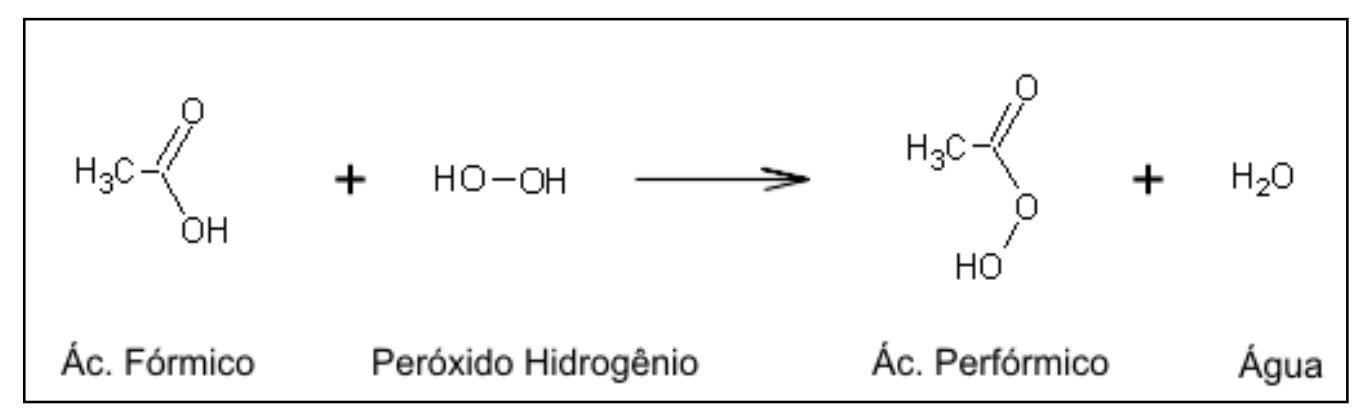

Fonte: La Scala e Wool (2002)

A segunda é a reação de epoxidação propriamente dita, que ocorre na fase oleosa.

$\mathrm{O}$ ácido perfórmico reage com as duplas ligações do óleo de soja, formando o anel 
oxirânico e regenerando o ácido fórmico (LA SCALA; WOOL, 2002), como exemplificado com um dos triglicerídeos presentes no óleo de soja na Figura 2.2.

É importante observar que o óleo de soja possui diferentes triglicerídeos, com diferentes ácidos graxos compondo o éster. A Tabela 2.1 mostra a composição média de óleo de soja no Brasil.

Tabela 2.1 - Composição de óleo de soja no Brasil

\begin{tabular}{lccc}
\hline Componente (ácido graxo) & Fórmula & $\begin{array}{c}\text { Massa } \\
\text { Molecular }\end{array}$ & $\begin{array}{c}\text { Concentração } \\
\text { (\% ma ssa) }\end{array}$ \\
\hline PALMÍTICO & $\mathrm{C}_{16} \mathrm{H}_{32} \mathrm{O}_{2}$ & 236,42 & 16,4 \\
\hline ESTEÁRICO & $\mathrm{C}_{18} \mathrm{H}_{36} \mathrm{O}_{2}$ & 284,47 & 4,1 \\
\hline OLEICO & $\mathrm{C}_{18} \mathrm{H}_{34} \mathrm{O}_{2}$ & 282,46 & 18,4 \\
\hline LINOLEICO & $\mathrm{C}_{18} \mathrm{H}_{32} \mathrm{O}_{2}$ & 280,44 & 52,8 \\
\hline LINOLÊNICO & $\mathrm{C}_{18} \mathrm{H}_{30} \mathrm{O}_{2}$ & 278,42 & 4,3 \\
\hline ARAQUIDÔNICO & $\mathrm{C}_{20} \mathrm{H}_{32} \mathrm{O}_{2}$ & 304,50 & 0,3 \\
\hline OUTROS (SATURADOS) & - & - & 3,7 \\
\hline
\end{tabular}

Fonte: Lima, Vasconcelos e Silva (2008)

Figura 2.2 - Esquema da reação de epoxidação do óleo de soja

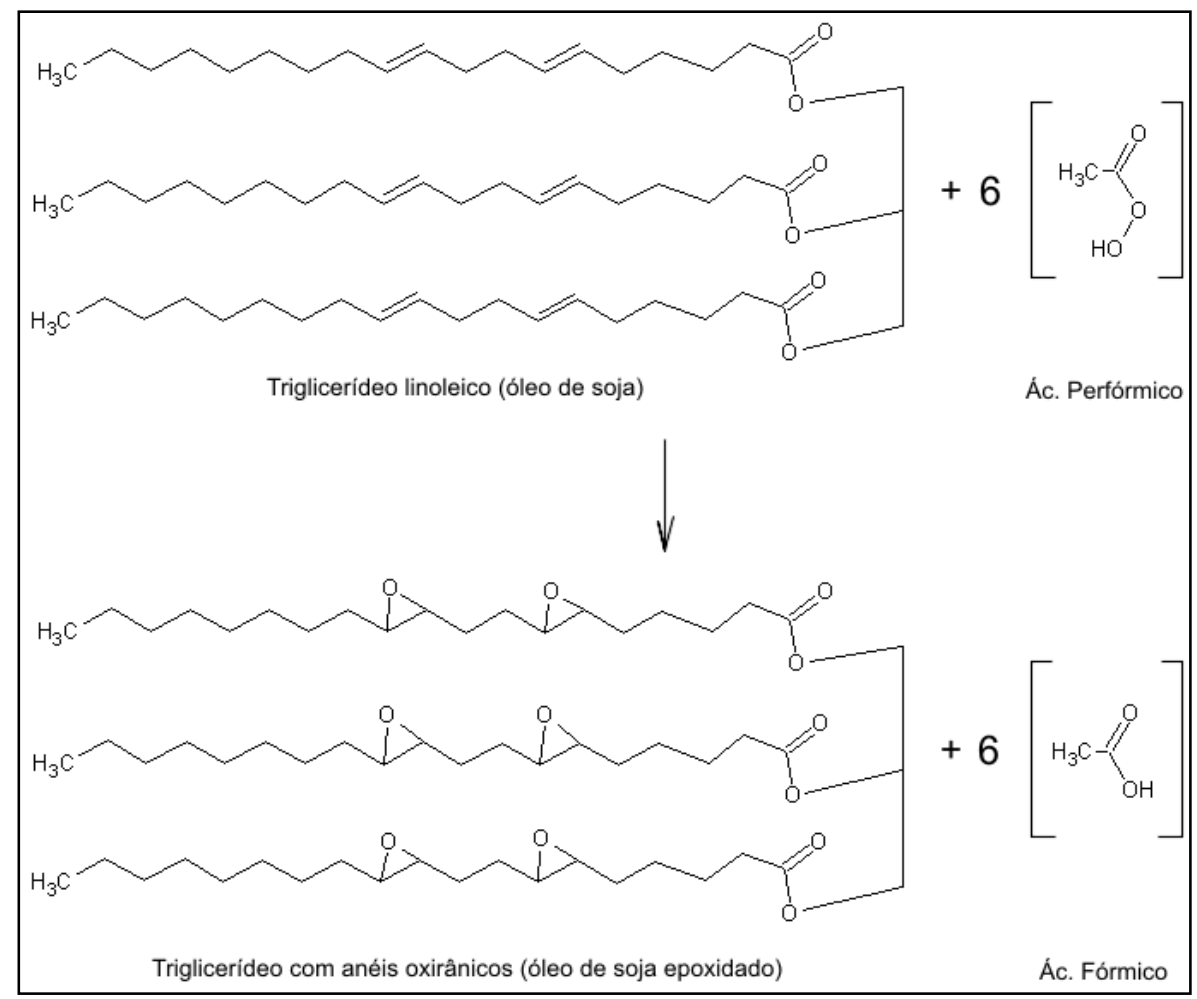

Fonte: La Scala e Wool (2002) 
Santacesaria et al. (2010) estudaram as cinéticas das reações de epoxidação com óleo de soja e formação de ácido perfórmico "in situ". Os autores propuseram uma simplificação do modelo reacional, considerando-o como apenas uma fase. Nesse caso a reação foi considerada de primeira ordem para a concentração de duplas ligações do óleo de soja (insaturações) e de primeira ordem para a concentração de ácido perfórmico, que é formado pela reação entre ácido fórmico e peróxido de hidrogênio.

Pressupondo-se que o efeito das reações secundárias e transferência de massa é desprezível, a reação pode ser simplificada como de um passo apenas, na forma:

$$
\text { Óleo de soja + Peróxido } \stackrel{\text { Ácido Fórmico }}{\longrightarrow} \text { Óleo de soja epoxidado + Água }
$$

Os dados da cinética da reação, observados dessa forma, são mostrados na Tabela 2.2

Tabela 2.2 - Características cinéticas da reação de epoxidação simplificada

\begin{tabular}{|c|c|c|c|}
\hline Mecanismo da reação & $\begin{array}{l}\text { Taxa de Reação } \\
{\left[\mathrm{mol} \mathrm{m^{-1 }} \mathbf{L}^{-1}\right]}\end{array}$ & $\begin{array}{c}\text { Energia de Ativação } \\
{[\mathrm{kcal} / \mathrm{mol}]}\end{array}$ & 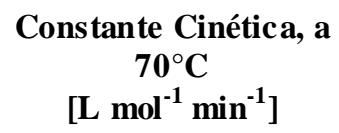 \\
\hline $\mathrm{H}_{2} \mathrm{O}_{2}+\mathrm{C}=\mathrm{C} \rightarrow$ Epóxido $+\mathrm{H}_{2} \mathrm{O}$ & $\mathrm{r}_{\mathrm{a}}=\mathrm{k}_{\mathrm{a}} \mathrm{C}_{\text {perox }} \mathrm{C}_{\text {insat }}$ & 18,30 & 0,017 \\
\hline
\end{tabular}

Fonte: Santaces aria et al. (2010)

Os autores também analisaram as reações secundárias e indesejáveis, de destruição do anel oxirânico e de degradação do peróxido. Citam também a importante observação de que a degradação de peróxido é catalisada por alguns tipos de metais e, para a construção de um reator adequado que minimize esse efeito, é necessário usar aço inoxidável 316L passivado. As reações indesejáveis apresentam constantes cinéticas significativamente menores que a reação de epoxidação. O estudo também conclui que acima de $80^{\circ} \mathrm{C}$ a reação de degradação de peróxido é extremamente exotérmica e se retroalimenta, de forma que o processo entra em colapso, com risco de explosão. 


\subsubsection{Descrição do sistema de duas fases}

Em estudo mais recente, Santacesaria et al. (2011a) descreveram a modelagem de um sistema em duas fases, onde são levadas em consideração as reações em cada fase, e as transferências de massa entre as fases. Os dados experimentais de uma reação com alimentação gradual de peróxido de hidrogênio foram comparados com os dados do modelo e observou-se um ajuste aceitável.

A

Figura 2.3 ilustra esse esquema da reação supondo a existência de duas fases líquidas e a transferência de massa (tanto de ácido fórmico como de ácido perfórmico) entre as fases. $O$ ácido fórmico adicionado reage com o peróxido na fase aquosa (aq) para formar o ácido perfórmico (APF), o qual se transfere para a fase orgânica (org), onde reage com as duplas ligações do óleo, formando ligações epóxido (Epox) e ácido fórmico (AF). Este se transfere para a fase aquosa onde reage com o peróxido novamente.

Figura 2.3 - Esquema das reações e da transferência de massa entre fases APF = ácido perfórmico; AF = ácido fórmico; Epox = ligações epóxido.

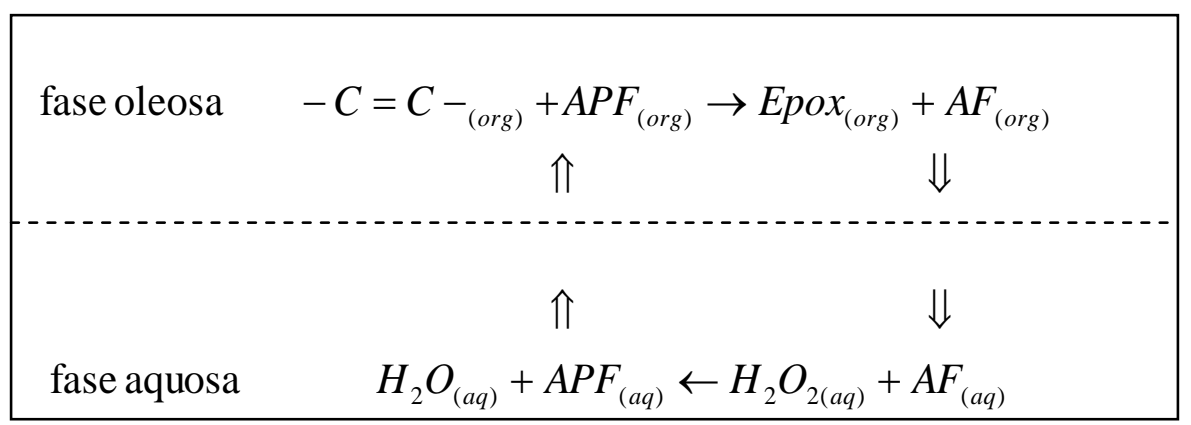

Fonte: Santacesaria et al. (2011a)

No estudo de cinética da epoxidação do éster metílico de soja feito por Campanella, Fontanini e Baltanás (2008), foram consideradas as duas fases (uma aquosa e uma oleosa), sendo as reações químicas e eventos de transferência de massa descritos conforme abaixo:

(a) Formação de ácido perfórmico (APF) a partir da reação de peróxido de hidrogênio com ácido fórmico (AF), na fase aquosa (aq):

$$
\mathrm{H}_{2} \mathrm{O}_{2}(a q)+\mathrm{AF}(a q) \underset{k_{2}}{\stackrel{k_{1}}{\longrightarrow}} A P F(a q)+\mathrm{H}_{2} \mathrm{O}(a q)
$$




$$
\begin{aligned}
& k_{1}^{a q}=5,5 \times 10^{-4} L /(\text { mol } . \min ) \\
& k_{2}^{a q}=7,5 \times 10^{-4} L /(\text { mol. } \min )
\end{aligned}
$$

(b) Transferência de massa de ácido perfórmico da fase aquosa para a fase oleosa (org):

$$
A P F(a q) \underset{\rightarrow}{\leftarrow} A P F(\text { org })
$$

(c) Transferência de massa de ácido fórmico entre fase aquosa e fase oleosa:

$$
A F(\text { org }) \underset{\rightarrow}{\leftarrow} A F(a q)
$$

(d) Reação de epoxidação das duplas ligações, formando o anel oxirânico ou grupo epóxido (Epox):

$$
C=C(\text { org })+A P F(\operatorname{org}) \stackrel{k_{3}}{\longrightarrow} \operatorname{Epox}(\text { org })+A F(\text { org })
$$

No mesmo estudo foi determinado um valor médio para a cinética da reação de epoxidação:

$$
k_{3}^{\text {org }}=3,88 \times\left(10^{-2} L /(\text { mol. } \min )\right)
$$

\subsubsection{Descrição das reações secundárias}

Estudos da degradação de anel oxirânico e sua cinética também são fundamentais, uma vez que esse processo ocorre simultaneamente com a reação de epoxidação. São reações indesejáveis, principalmente para o mercado de PVC, uma vez que a quebra do anel oxirânico resulta na formação de hidroxilas, o que reduz a compatibilidade do óleo epoxidado com o polímero.

Um estudo específico sobre as reações de degradação com o uso de ácido fórmico (ZAHER;EL-SHAMI, 1990) contribui para o entendimento do que ocorre nos processos industriais atuais. Estudos mais genéricos sobre a perda de anéis oxirânicos, em ambiente ácido (CAMPANELLA;BALTANÁS, 2005) ou em condições onde as concentrações de ácido são conhecidas e controladas (ZAHER, ELMALLAH; EL-HEFNAWY, 1989) são úteis para estimar as perdas também para processos diferentes dos atualmente usados industrialmente. 
No caso de destruição dos anéis oxirânicos na presença de ácido fórmico, a reação é considerada de segunda ordem para a concentração de peróxido, como indicado por Zaher e El-Shami (1990) e por Campanella e Baltanás (2005). É importante notar que a degradação na presença de ácidos é mais rápida quando há também a presença de peróxido de hidrogênio, de acordo com Campanella e Baltanás (2005), conforme mostram as Figura 2.4 Figura 2.5.

Figura 2.4 - Reação de degradação do OSE (sem peróxido)

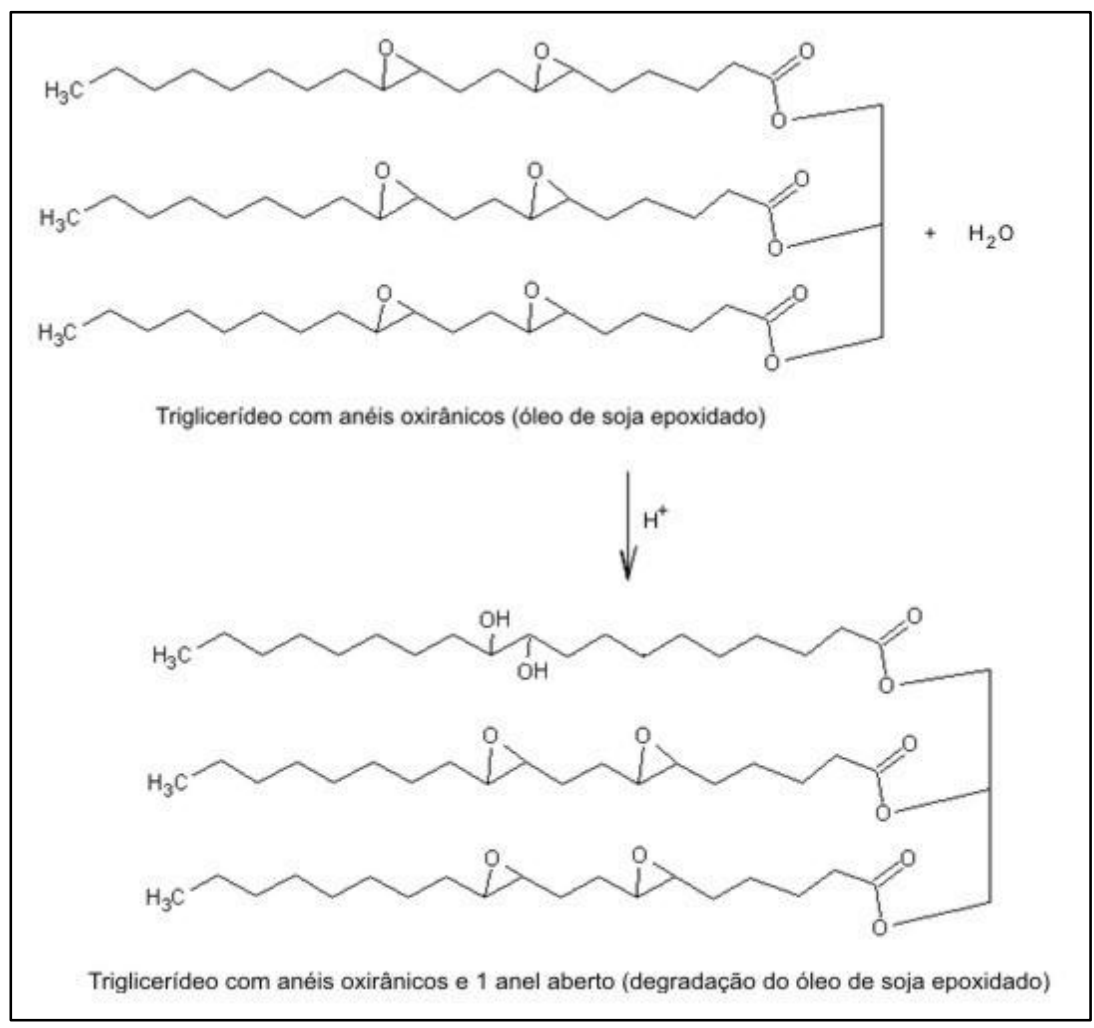


Figura 2.5 - Reação de degradação do OSE (com peróxido)

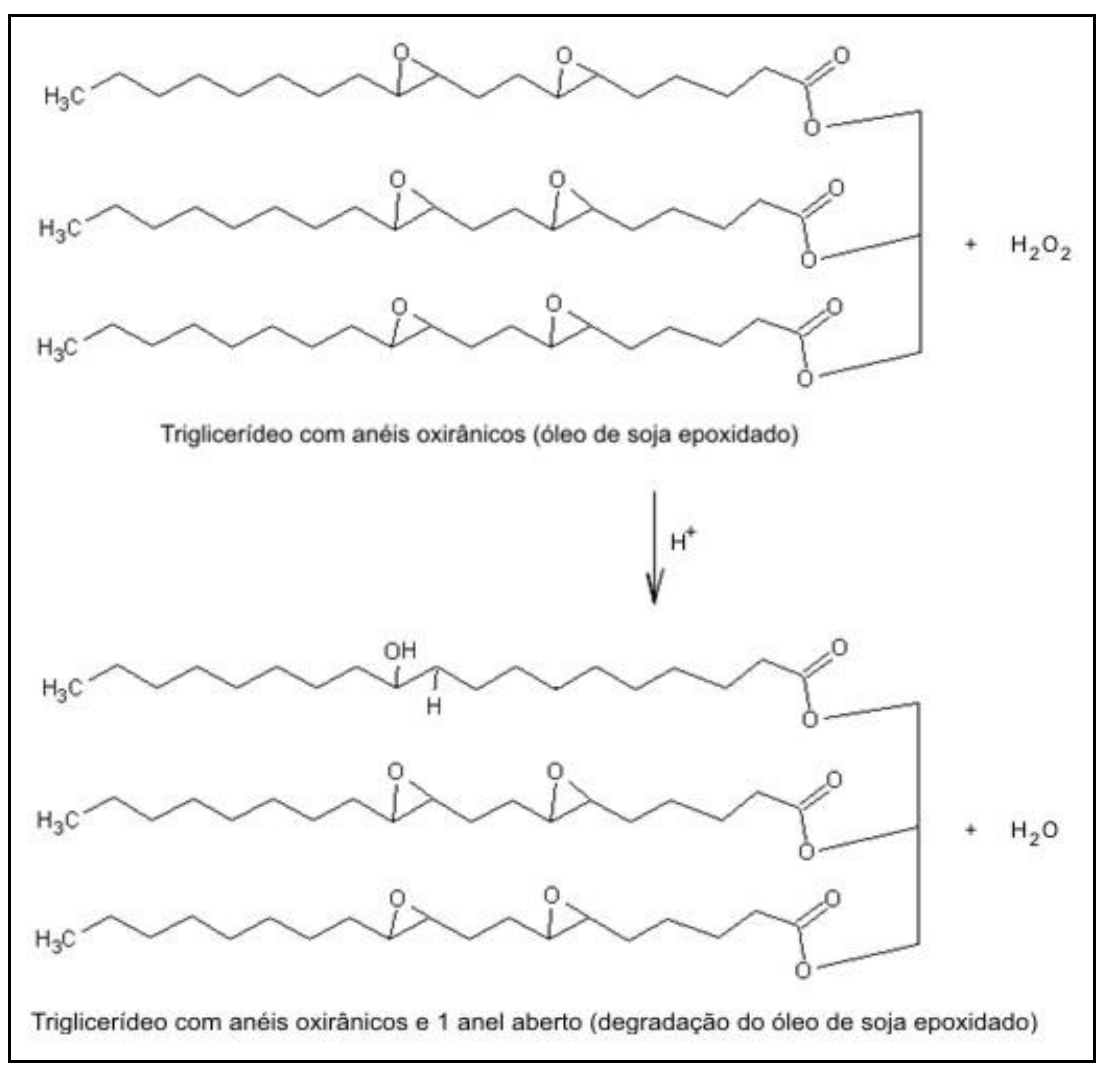

No mesmo estudo, Campanella e Baltanás (2005) mostram que quanto menor o pH aparente da mistura, mais rápida é a degradação. Todo o processo de epoxidação ocorre na presença de ácido e peróxido e, como as reações de degradação são mais lentas que as reações de epoxidação, quanto mais rápida a reação de epoxidação atingir seu máximo, menor será a degradação dos anéis oxirânicos.

Outro estudo feito por Campanella, Fontanini e Baltanás (2008) sobre epoxidação de ésteres metílicos de soja elucida os detalhes dos processos, onde as cinéticas das diversas reações são determinadas. Os parâmetros cinéticos foram determinados por ajuste aos dados experimentais calculados. Nesse mesmo estudo, o éster metílico já depois de epoxidado foi submetido à presença de ácido fórmico e perfórmico, além do peróxido de hidrogênio, para estudar a reação de degradação do anel oxirânico em várias temperaturas e concentrações de ácidos e de peróxido. Foram avaliadas as cinéticas das reações secundárias, de degradação dos anéis oxirânicos (Deg), descritas na forma:

$$
\begin{gathered}
E p(\text { org })+F A(\text { org }) \stackrel{k_{4}}{\rightarrow} D e g_{1} \\
E p(\text { org })+P F A(\text { org }) \stackrel{k_{5}}{\rightarrow} D e g_{2}
\end{gathered}
$$


Os valores de $k_{4}$ e $k_{5}$ foram obtidos para uma proporção molar de 1 de éster metílico de soja epoxidado para 2 de peróxido de hidrogênio para 0,3 de ácido fórmico (ou ácido perfórmico). Apesar de se tratar de éster metílico de soja epoxidado e não do triglicerídeo (óleo de soja epoxidado), esses valores indicam uma cinética bastante mais lenta, em uma ou mais ordens de grandeza, dessas reações de degradação quando comparadas com a cinética da reação de epoxidação.

$$
\begin{aligned}
& k_{4}^{\text {org }}=(6,5 \pm 0,10) \times 10^{-5} L^{2} /\left(\mathrm{mol}^{2} \min \right) \\
& k_{5}^{\text {org }}=(4,4 \pm 0,77) \times 10^{-3} L^{2} /\left(\mathrm{mol}^{2} \min \right)
\end{aligned}
$$

\subsubsection{Outros sistemas reacionais e informações adicionais}

A cinética da reação foi também estudada por Chuanshang et al. (2007), em condições controladas de laboratório, indicando os parâmetros encontrados e as velocidades de reação esperadas, utilizando ácido sulfúrico como catalisador.

A avaliação da reação de epoxidação realizada por Petrovic et al. (2002) foi feita comparando as cinéticas com ácido fórmico e ácido acético; o resultado mostrou maior conversão em menor tempo da reação realizada com ácido acético para temperaturas mais altas; esse trabalho, no entanto, empregou tolueno como diluente. Por outro lado, um estudo de epoxidação de óleo de canola (MILCHERT; SMAGOWICZ, 2008) conclui o que vem sendo mais comumente aceito pela indústria: reações com ácido fórmico promovem resultados melhores do que com ácido acético.

Um estudo realizado com materiais de composição conhecida e controlada (LA SCALA; WOOL, 2002) permitiu a avaliação da reatividade da formação de anéis oxirânicos para diversos tipos de triglicerídeos e ésteres metílicos de ácidos graxos (FAME, da sigla em inglês para Fatty Acid Methyl Esters). Nesse estudo ficou evidenciada a maior reatividade de uma das duplas ligações existentes em ácidos graxos com 3 duplas ligações (trienos) quando comparada à reatividade das demais duplas ligações existentes em ácidos graxos com 1 ou 2 insaturações. A diferença é significativa: ácido oleico e ácido linoleico (1 e 2 duplas ligações respectivamente) apresentam constante de velocidade de reação $(k)$ de 0,0145 [L/(mol.min)] enquanto 
o ácido linolênico (3 duplas ligações) tem $k$ de 0,0254 [L/(mol.min)]. Esse efeito faz com que seja necessário considerar duas cinéticas separadas para modelar adequadamente processos onde misturas desses ácidos são encontradas. O estudo mostra que esses sítios mais reativos têm velocidade de epoxidação maior, porém também apresentam maior velocidade de reação de degradação do anel.

Dinda et al. (2008) apresentaram uma avaliação da epoxidação de óleo de algodão e, dentre outros parâmetros analisados, mostraram que há diferenças significativas na conversão quando é modificada a agitação do sistema. Isso seria esperado, indicando a existência de efeitos de transporte de massa sobre a cinética aparente da reação; os experimentos também sugerem que a partir de um determinado nível de agitação, não há mais diferenças de cinética aparente. Essa informação, obtida para os sistemas reacionais propostos neste trabalho, tem grande validade para dimensionar adequadamente um potencial equipamento de processo contínuo.

\subsection{Epoxidação: processos reacionais e entalpia da reação}

\subsubsection{Processos de obtenção}

Os processos de obtenção de óleos vegetais epoxidados são conhecidos há muitos anos. Na patente de Swern e Findley (1945), o reagente principal é o ácido peracético, formado pela reação prévia de ácido acético e peróxido de hidrogênio. Esse método não seria viável em escala industrial, pois apresenta grande risco de segurança devido à instabilidade do perácido.

Em uma das primeiras patentes referentes ao tema de epoxidação de óleos vegetais com viabilidade industrial (NIEDERHAUSER; KOROLY, 1948), a reação foi realizada com ácido perfórmico formado "in-situ" através da adição de ácido fórmico ao óleo e posterior adição gradativa de peróxido de hidrogênio. Esse processo se mostrou adequado para controlar a reação em condições de processo industriais. A patente detalha o processo de epoxidação de óleo de soja com a formação de ácido perfórmico "in-situ" através da adição de peróxido de hidrogênio concentrado (70 \%) a uma temperatura controlada e já apresenta referências às características principais da reação e suas conversões. No principal exemplo citado, $200 \mathrm{~g}$ óleo de soja previamente misturado com $16,9 \mathrm{~g}$ de ácido fórmico a $90 \%$ é epoxidado com adição lenta de $74,8 \mathrm{~g}$ de peróxido de hidrogênio a $50 \%$. A mistura reacional foi agitada 
por 24 horas, mantendo a temperatura abaixo de $42{ }^{\circ} \mathrm{C}$ com um banho refrigerante. O produto final apresentou índice oxirânico (percentual de anéis oxirânicos) de $6,0 \%$, após lavagem e separação da água residual. Esse processo é o mais usado atualmente na indústria. Os processos comerciais usados hoje não evoluíram significativamente nos últimos 60 anos, com poucas modificações ou inovações (SAURABH et al., 2011). Nessa mesma patente, há uma menção indicando que o uso excessivo de ácido fórmico é indesejável, pois a reação de quebra do anel oxirânico é acelerada e o produto final apresenta índice oxirânico de apenas 1,9\%, o que seria inaceitável para aplicações como plastificante de PVC.

A proporção de $60 \mathrm{~g}$ de ácido fórmico para $1000 \mathrm{~g}$ de óleo aparece em várias avaliações como um ponto ótimo para a cinética da reação de epoxidação sem perda significativa de anéis oxirânicos pela reação de quebra dos anéis. Na presente tese essa questão é revisitada para avaliar se essa concentração de fórmico é ideal em um sistema com remoção máxima de calor e adição de todos os reagentes de forma única.

\subsubsection{Entalpia de reação}

As reações envolvidas no processo de epoxidação são extremamente exotérmicas e esse calor tem que ser rapidamente removido para evitar que a temperatura aumente muito e comece a comprometer tanto a estabilidade do anel oxirânico, quanto a estabilidade do peróxido e da própria reação. O valor de entalpia aparente calculado na literatura apresenta variações significativas: de $-230 \mathrm{~kJ} / \mathrm{mol}$ (SANTACESAREA et al., 2010), a $-116 \mathrm{~kJ} / \mathrm{mol}$ (LEVENEUR et al., 2014), a $-41 \mathrm{~kJ} / \mathrm{mol}$ (CHUANSHANG et al., 2007). Essas diferenças promoveram a necessidade de realizar, dentro do escopo da presente tese, um experimento para determinar a entalpia das reações nas condições e reagentes que serviram de base para esta tese.

O controle de temperatura é fundamental para a segurança do processo, pois em condições de pressão atmosférica, como usado na indústria, em altas temperaturas o peróxido de hidrogênio poderá se degradar rapidamente formando uma espuma rica em oxigênio que cria uma condição extremamente insegura, com risco de explosão. Como regra prática, a massa de reação tem que ser mantida abaixo de $80^{\circ} \mathrm{C}$, e idealmente não ultrapassar $75^{\circ} \mathrm{C}$ (SANTACESARIA et al., 2010). A 
temperatura foge de controle por dois efeitos: primeiro, acima de determinada temperatura a própria cinética das reações de epoxidação e consequente geração de calor pode ultrapassar a capacidade máxima de refrigeração do sistema; segundo, a reação de degradação do peróxido, que tem entalpia de $-98,2 \mathrm{~kJ} / \mathrm{mol}$ (MARZZACCO, 1999), também é acelerada, contribuindo para ainda maior geração de calor.

A entalpia da reação de quebra de anéis oxirânicos foi estudada por Leveneur et al. (2014), e o valor obtido foi de $-50 \mathrm{~kJ} / \mathrm{mol}$.

\subsection{Intensificação dos processos reacionais}

Vários estudos foram realizados para melhor entender alternativas para intensificar as reações, buscando melhorar a cinética e a seletividade.

Essa intensificação, visando maiores conversões e menor tempo total para atingir a conversão desejada, foi estudada em diversos trabalhos que focaram a catálise. Vários autores (TURCO et al., 2013; JIANG et al., 2012; HE et al., 2012; CHAVAN; PATWARDHAN; GOGATE, 2012; CHENG et al., 2015; DI SERIO et al., 2012) fizeram avaliações do uso de catalisadores tradicionais ou alternativos, catalisadores de transferência de fase e até nanotecnologia para diminuir o tempo dos processos reacionais e aumentar a conversão. Esses trabalhos apresentam opções de intensificação, com catalisadores heterogêneos, com ácido sulfúrico, com resinas de troca iônica e com catalisadores enzimáticos, mas em todos os casos não se observou um ganho significativo após avaliação de cinética da reação em diversas condições.

Avaliação do uso de agentes complexantes (JOURDAN-LAFORTE, 1980) demonstra que a reação pode ser otimizada, mas não considera os fatores de troca de calor para que uma reação mais rápida seja viável.

Outro ponto fundamental para o aumento da velocidade dos processos reacionais é o aumento da interface água/óleo, uma vez que a transferência de massa entre fases é um dos fatores limitantes das reações. A indústria, no seu modelo atual de processo em batelada, usa normalmente um sistema de mistura por agitação mecânica simples, o que é aceitável, pois a própria limitação da capacidade de remoção de calor é compatível com esse processo de mistura pouco eficiente. Há estudos (HAN et al, 2010a; RETHWISCH et al., 2005) demonstrando que a melhoria 
do processo de agitação, ou de redução do tamanho das gotículas com consequente aumento da área de interface entre fases, melhora significativamente a velocidade efetiva da reação.

\subsection{Estado da arte}

Dentre os diversos estudos previamente descritos, o principal objetivo era a melhoria da cinética e a seletividade da reação em si. Em sua maioria, porém, estudos experimentais não levaram em consideração nem os limitantes práticos de troca de calor para acelerar os processos industriais nem a possibilidade de adição única de todos os reagentes.

Mesmo os estudos que buscaram intensificação do processo de transferência de massa entre as fases não discutiram com profundidade que essas soluções teriam que ser aplicadas em combinação com a intensificação da remoção de calor.

Rangarajan et al. (1995) apresentaram uma análise detalhada e demonstraram que a velocidade de reação pode ser significativamente aumentada se as questões de transferência de massa (agitação extrema) e remoção de calor (resfriamento máximo) forem resolvidas. Com isso, fica evidenciada a possibilidade de melhoria dos processos atuais. Esse artigo, contudo, não avalia a viabilidade de um sistema industrial com remoção de calor máxima e adição única de reagentes, que é o objeto do presente trabalho.

Um estudo recente (HAN et al., 2010a) mostra o efeito de melhoria da velocidade aparente da reação através de intensificação de mistura por ultrassom. A conversão (análise de oxigênio oxirânico) foi $17 \%$ mais alta que a da reação sem ultrassom, e a promoção do aumento da área de transferência entre as fases reduziu o tempo de reação à praticamente a metade. Em estudo semelhante (HAN et al., 2010b), com o uso de ácido acético no lugar do ácido fórmico e ácido sulfúrico como catalisador, a melhoria chegou a mais que 29 \% na conversão e a redução do tempo da reação em mais que $50 \%$, quando comparados aos processos de agitação mecânica. O estudo, porém, se vale da adição gradativa de peróxido devido à limitação da troca de calor, o que faz com que os tempos totais de reação sejam longos.

Rethwisch et al. (2005) avaliaram a reação de epoxidação com o uso de surfactantes que promovem um ambiente de micro emulsão, otimizando a transferência de massa. Micro emulsão é uma forma estável de emulsão, onde as partículas são tão 
reduzidas que não são visíveis a olho nu e a suspensão se apresenta como uma única fase, límpida. Esses pesquisadores avaliaram esse efeito na presença de uma variedade de surfactantes observando a conversão final da reação de epoxidação. A dificuldade de separação adequada dos emulsificantes após a reação, no entanto, pode comprometer a viabilidade comercial desse processo.

A patente americana de Dieckelmann et al. (1986) de um processo contínuo de produção de óleo epoxidado de soja propõe um processo com vários reatores menores em sequência, principalmente desenvolvido para promover separação em cada estágio, reduzindo a degradação esperada dos anéis oxirânicos, porém sem resolver a questão da velocidade da reação, uma vez que a proposta é o uso de vários reatores (multi-estágio) agitados mecanicamente e não é explorada a possibilidade de remoção de calor com alta eficiência. Esse processo contínuo proposto não chegou a ser adotado industrialmente.

Outro estudo, realizado por Hang e Yang (1999), apresenta a modelagem matemática para um processo de epoxidação contínuo em cascata, usando vários reatores agitados mecanicamente, porém sem realizar separação em cada estágio. Apesar de se tratar de uma modelagem usando óleo da pupa de bicho-da-seda, os conceitos são aplicáveis para a epoxidação de óleo de soja. O modelo matemático sugere que o processo contínuo é possível e viável em escala industrial, mas não aprofunda a questão para calcular velocidades de reação em situação de remoção de calor extrema. Os autores também não avaliam o efeito potencial do aumento do número de reatores de 3 ou 4 para muitos, o que simularia uma aproximação de reação contínua em reator tubular.

No experimento descrito por Santacesaria et al. (2010), os autores apresentam a possibilidade teórica de intensificar a reação, aumentando sua velocidade através do uso de microreatores. A proposta é obter grande intensidade de troca térmica, para evitar que a temperatura suba excessivamente e provoque a degradação do peróxido.

Em estudo mais recente (MONONO; HAAGENSON; WIESENBORN, 2015), a epoxidação do óleo de canola é realizada em condição de remoção de calor intensa, porém a adição de peróxido é feita de forma contínua numa taxa máxima de $4,6 \mathrm{~g} / \mathrm{min}$, o que ainda não caracteriza a adição única de todos os componentes.

O estudo de He et al. (2013) trata da reação em micro-reatores, catalisada por ácido sulfúrico e sal dissódico de ácido etileno diamina tetraacético (EDTA 2Na - do inglês 
Ethylenediaminetetraacetic Acid Disodium Salt - $\left.\mathrm{C}_{10} \mathrm{H}_{14} \mathrm{~N}_{2} \mathrm{Na}_{2} \mathrm{O}_{8}\right)$. Nessa condição de micro-fluxo a reação apresentou excelente conversão (índice oxirânico de 7,3 \%) em tempo extremamente reduzido $(6,7 \mathrm{~min})$. A proporção molar de fórmico era 1:1 em relação ao peróxido e a proporção molar de peróxido era 8:1 em relação às duplas ligações do óleo de soja. As condições do experimento, entretanto, não seriam replicáveis em maior escala e ainda haveria questão de custo devido à proporção alta de ácido fórmico no sistema. Porém, o estudo mostra que a reação pode ser extremamente rápida, indicando que a direção de intensificação que os trabalhos mais recentes têm abordado pode ser viável.

O estudo de Kralisch et al. (2012) propõe uma metodologia para avaliar a viabilidade de intensificação da reação de epoxidação do óleo de soja e sugere que um dos principais fatores limitantes é a remoção de calor. Além disso, Santacesaria et al. (2011b) usaram um modelo matemático para mostrar que é possível realizar a reação em reator contínuo, onde os reagentes seriam adicionados integralmente e a remoção de calor seria maximizada.

Não foram, porém, encontrados estudos ou publicações que demonstrassem experimentalmente a possibilidade de reduzir significativamente as limitações da remoção de calor e permitir a adição única de todos os reagentes, analisando nessas condições a velocidade e a viabilidade prática desse tipo de processo. 


\section{MATERIAIS E METODOLOGIA}

Este capítulo é apresentado em duas partes: 1) metodologia e materiais usados nos ensaios práticos realizados e; 2) metodologia para a modelagem do processo.

\subsection{Metodologia e materiais dos ensaios experimentais}

\subsubsection{Comentários iniciais}

As observações sobre cinéticas diferentes para os diversos tipos de insaturações dos ácidos existentes no óleo de soja (LA SCALA; WOOL, 2002) puderam ser desconsideradas para efeito do trabalho desta tese, uma vez que o óleo de soja usado tinha composição constante e dessa forma permitia considerar a cinética média das reações das diferentes insaturações com o perácido. Isso foi assegurado pela aquisição de quantidade de óleo de soja refinado de um mesmo lote, suficiente para todo o estudo. Foram adquiridos 200 litros (1 tambor) de óleo de soja refinado, cortesia da empresa Nexoleum Bioderivados Ltda.

Todos os ensaios foram realizados com reagentes e equipamento de laboratório devidamente aferidos, conforme normas ABNT.

\subsubsection{Reagentes e Materiais}

Os reagentes usados nas reações de epoxidação foram óleo de soja (Nexoleum Bioderivados Ltda.), ácido fórmico $85 \%$ (Coremal, grau industrial), e peróxido de hidrogênio (água oxigenada $60 \%$, Coremal, grau industrial). Observação sobre segurança: na armazenagem deve-se garantir a segregação física entre o ácido fórmico e $\circ \mathrm{H}_{2} \mathrm{O}_{2}$, pois o perácido formado é extremamente instável e pode ser explosivo.

Os reagentes usados para a medição de índice oxirânico e índice de iodo foram adquiridos e/ou preparados a partir de reagentes grau analítico (Vetec), de acordo com as metodologias da American Oil Chemists' Society (AOCS).

Todos os ensaios foram realizados com equipamentos de laboratório devidamente aferidos, conforme normas ABNT. 
Os ensaios experimentais foram realizados em um reator de vidro de volume $500 \mathrm{~mL}$, com tampa de plástico com furações para (1) agitador mecânico, (2) medidor de temperatura da massa reacional, (3) pipeta para amostragem do meio reacional e para alimentação de peróxido.

O agitador mecânico (lka Labortechnik, RW20DZM) permite o controle da velocidade de rotação e o impelidor era do tipo hélice com pás de $6 \mathrm{~cm}$ de diâmetro.

O reator é mergulhado em um banho termostático (Quimis, Q218) de volume $30 \mathrm{~L}$, contendo água como fluido termostático, cuja temperatura era controlada com precisão de $\pm 1^{\circ} \mathrm{C}$.

Termopares do tipo $\mathrm{J}$ foram usados para medir a temperatura dentro do reator e do banho termostático, e as temperaturas eram registradas em computador usando um sistema de captura de dados (Incoterm).

Um dispositivo especialmente desenhado para a avaliação das variações de viscosidade do meio reacional foi também utilizado. Este dispositivo é descrito no item 3.1.4.4.

Outros equipamentos usados foram:

- Balança analítica, para medição das quantidades de reagentes

- Cronômetro com alarme

- Chapa quente para evaporação de água e ácido fórmico

- Vidraria de laboratório para titulações, medição de densidade, pesagens, etc.

- Viscosímetro Brookfield, para a caracterização reológica do produto final

- Equipamento de proteção individual

- Luvas de látex

- Jaleco

- Óculos de segurança

A Figura 3.1 apresenta um esquema do reator utilizado. As Figuras 3.2 e 3.3 apresentam fotografias dos equipamentos utilizados. 
Figura 3.1 - Esquema do equipamento (reator e periféricos)

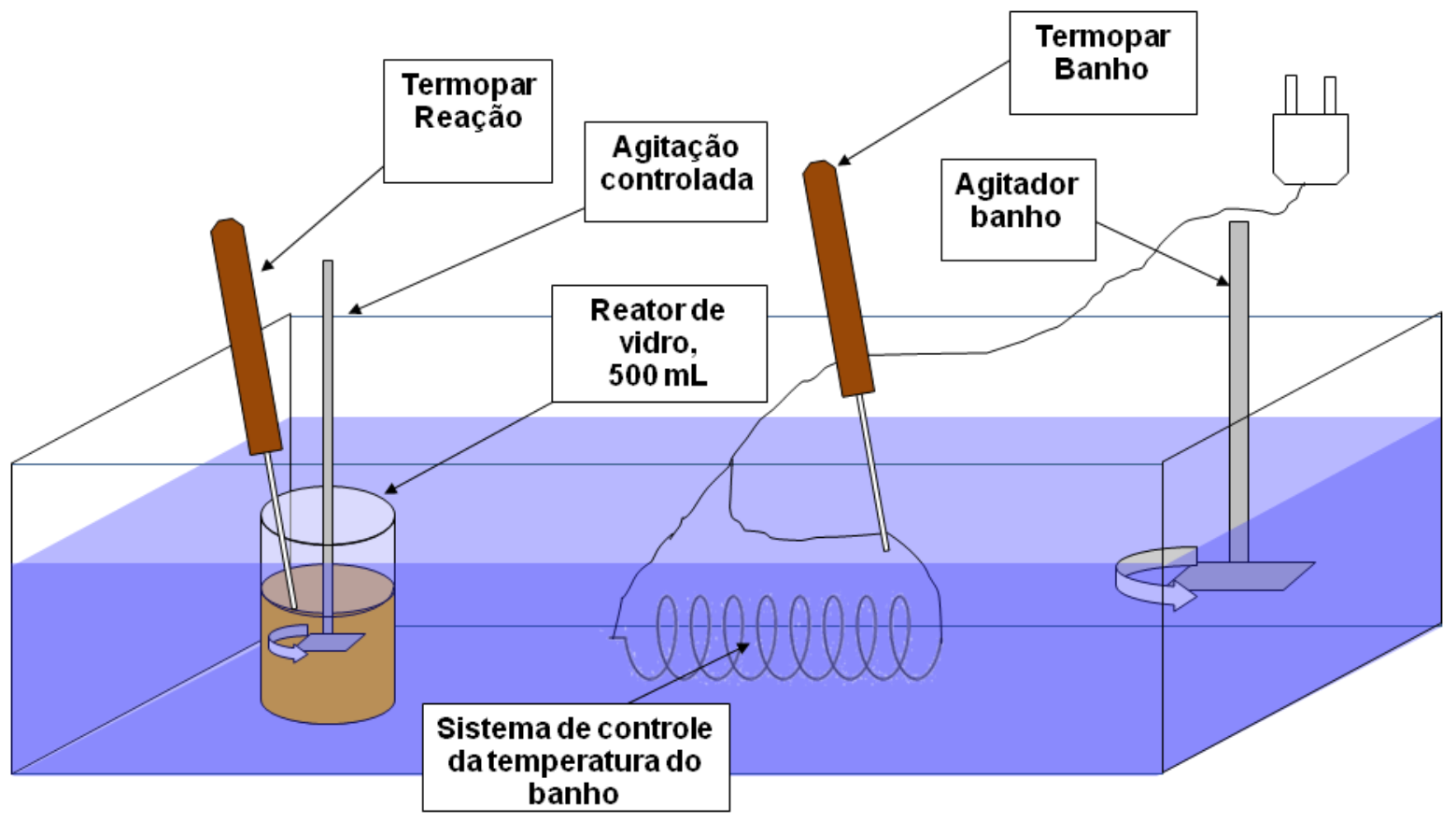

Figura 3.2 - Fotografia do Variac e do reator

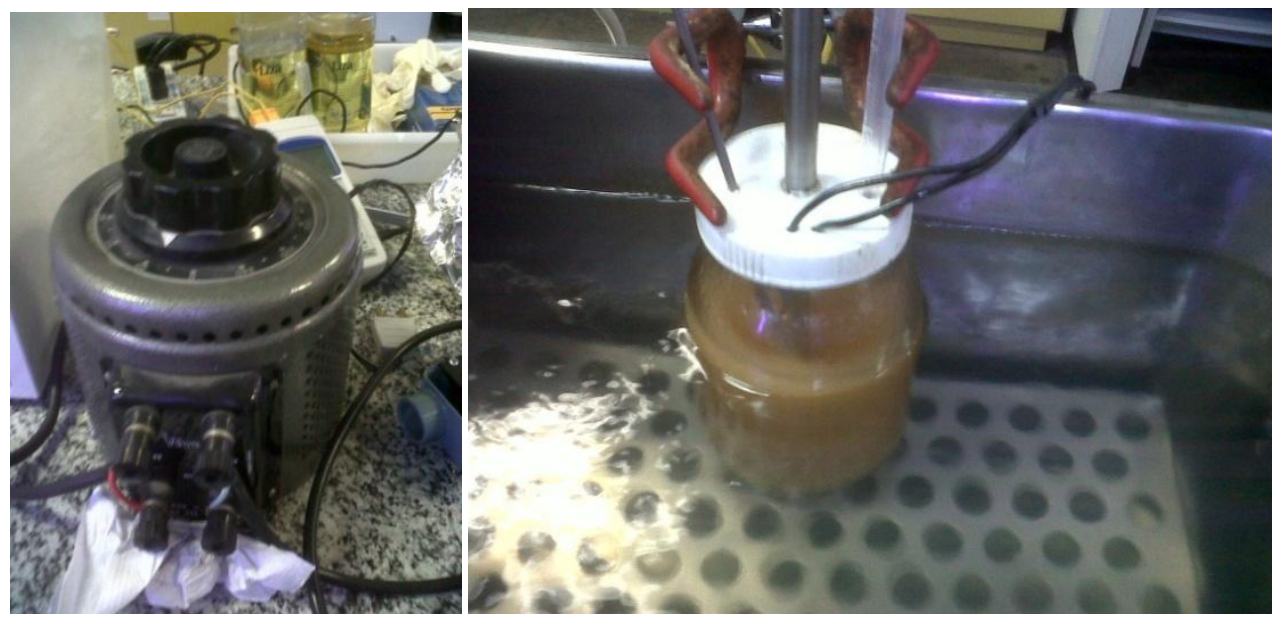

Figura 3.3 - Fotografias do controlador de rotação do agitador, do termômetro com termopares e do sistema de aquisição de dados
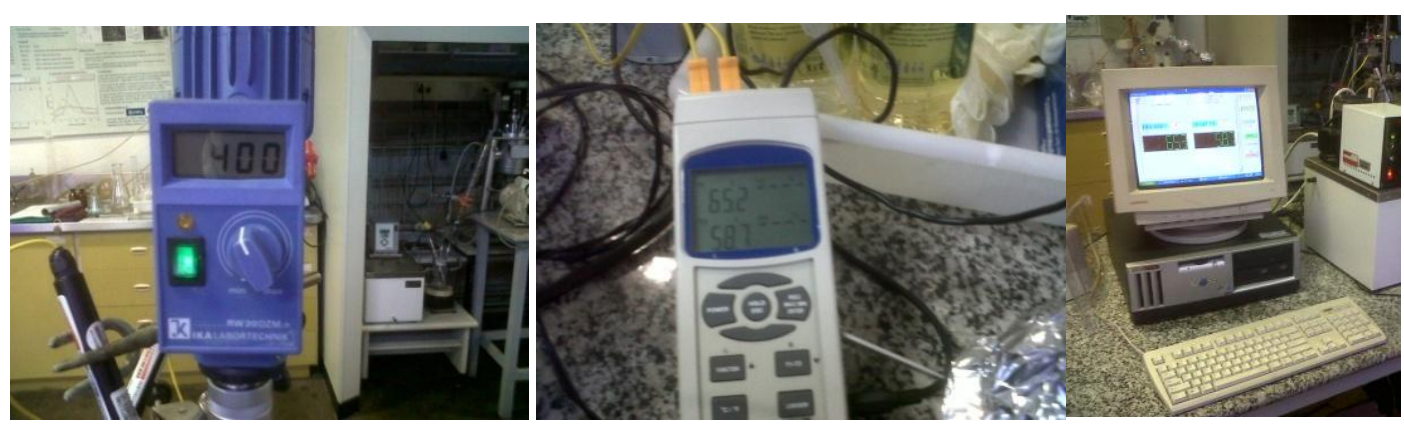


\subsubsection{Experimentos}

Os experimentos foram realizados de acordo com as seguintes etapas:

- Ensaios preliminares para teste da metodologia, avaliação de risco e limites do experimento

- Planejamento de experimentos para avaliação dos parâmetros necessários

- Ensaios de epoxidação conforme desenho de experimentos para obtenção de dados experimentais para serem usados na estimação de parâmetros do modelo do processo e para avaliação da dinâmica de processo.

- Foram realizados ensaios específicos para a determinação experimental de:

- Entalpia da reação

- Coeficientes de troca térmica do sistema

- Viscosidade do sistema durante o processo reacional

Os experimentos de epoxidação, viscosidade e coeficiente de troca térmica foram conduzidos em reator de vidro, de volume relativamente pequeno $\left(500 \mathrm{~cm}^{3}\right)$ em relação à área de troca térmica $\left(201 \mathrm{~cm}^{2}\right)$. O banho térmico é agitado, com temperatura controlada e com grande quantidade de água (30 litros).

O aparato para ensaios de epoxidação e para determinação de coeficiente de troca térmica e viscosidade possui um sistema de aquisição de dados conectado a um termômetro digital equipado com termopares, que permite a leitura de dados ao longo da reação, com intervalo de 5 segundos entre cada medida. Dessa forma a temperatura interna do reator e a temperatura do banho são registradas ao longo do tempo do experimento.

As variáveis controladas incluem a rotação do agitador, a temperatura do banho, as concentrações de reagentes e a velocidade de adição do peróxido.

A conversão da reação pode ser estimada pela combinação dos resultados de índice de iodo (correspondente à concentração de insaturações) - método AOCS Cd 1-25 - e do Índice Oxirânico (percentual em massa de oxigênio oxirânico na molécula) método AOCS Cd 9-57, ambos da American Oil Chemists' Society (AOCS), apresentadas no Anexo II. O índice oxirânico máximo teórico é função das insaturações do óleo de soja refinado usado como matéria prima. No caso do óleo de soja refinado usado para os ensaios desta tese, com índice de lodo 126, o cálculo resultou num índice oxirânico máximo teórico de 7,35\%. 
A entalpia foi determinada com um aparato específico, de maior porte, conforme descrito no item 3.1.4.3.

O aparato para os ensaios de viscosidade inclui também um tubo especialmente escolhido para realizar os testes de escoamento, como descrito no item 3.1.4.4.

\subsubsection{Procedimentos}

\subsubsection{Ensaios de epoxidação}

Os ensaios de epoxidação consistiram em realizar a reação de epoxidação em banho de temperatura controlada, de acordo com a programação de ensaios. 0 reator de vidro foi colocado no banho de forma que o nível de água estivesse na linha máxima de volume interno após adição de todos os reagentes. A tampa do reator possui uma furação central para o agitador, uma descentralizada para o termopar e outra descentralizada e com rolha para a adição de peróxido, que foi feita através de uma pipeta descartável.

A adição das quantidades programadas de óleo de soja e ácido fórmico foi feita com o sistema ainda desligado.

A temperatura do banho foi especificada no sistema de controle e aguardou-se que atingisse o valor programado.

A agitação foi iniciada conforme a programação do experimento e aguardou-se que a temperatura interna do reator entrasse em equilíbrio com a temperatura do banho. Ligou-se o sistema de aquisição de dados. Nomeou-se o arquivo que foi registrado no livro de anotações.

Iniciou-se a captura de dados e em seguida foi feita a adição programada de $\mathrm{H}_{2} \mathrm{O}_{2}$. No caso de mais que uma adição, foram repetidas as adições até o término do volume programado de $\mathrm{H}_{2} \mathrm{O}_{2}$.

Aguardou-se 6 horas até o final da reação, quando o sistema de captura de dados foi interrompido e o arquivo de dados salvo. Desligaram-se então todos os equipamentos.

Foi importante observar, por questão de segurança, que a temperatura não ultrapassasse $85^{\circ} \mathrm{C}$. Nesse caso, seria necessário jogar água fria diretamente dentro do reator para interromper a reação, além de descartar o conteúdo do reator e desconsiderar o experimento. 
Depois de encerrada a reação, transferiu-se a mistura para um balão de decantação. Depois de 24 horas de decantação, descartou-se a fase aquosa e separou-se a fase oleosa que foi submetida a uma secagem, em béquer de $500 \mathrm{~mL}$, mantendo a temperatura a $120^{\circ} \mathrm{C}$ em chapa de temperatura controlada, até que o material estivesse completamente cristalino e livre de odor de ácido. Recolheu-se o produto final em frasco fechado com batoque, que foi etiquetado adequadamente para os ensaios de conversão.

\subsubsection{Ensaios para determinação do coeficiente de troca térmica (U)}

Os ensaios de determinação do coeficiente de troca térmica $U$ consistiram em montar o mesmo aparato usado na epoxidação e aquecer a mistura de componentes com filamento elétrico (resistor elétrico inserido dentro do reator, mergulhado na mistura), depois desligar e deixar a temperatura baixar conforme programação de experimentos. O resistor consistiu de um filamento de níquel-cromo de $30 \mathrm{~cm}$. $O$ resistor elétrico estava ligado a uma fonte de corrente contínua (12 V) e a um Variac (variador da voltagem aplicada ao circuito). A curva de variação da temperatura com o tempo obtida é usada para o cálculo final do $U$ em cada condição testada.

O material programado para cada teste foi adicionado ao reator. Acionou-se o banho térmico na temperatura programada para o ensaio e aguardou-se que atingisse 0 valor desejado. Acionou-se a agitação, conforme o valor programado e deixou-se a massa de reação equilibrar com a temperatura do banho.

Iniciava-se então o software de aquisição de dados, nomeando o arquivo e registrando no livro de anotações.

O filamento elétrico foi acionado até que a temperatura interna do reator aumentasse em pelo menos $10^{\circ} \mathrm{C}$. Nesse momento desligava-se o filamento e aguardava-se que a temperatura voltasse ao nível inicial. Registraram-se quaisquer observações relevantes no livro de anotações. A curva de temperaturas versus tempo foi preparada e apresentada de forma gráfica.

O valor do coeficiente de transferência de calor $U$ é obtido a partir destes dados de variação de temperatura com o tempo durante o resfriamento, como explicado a seguir. Considera-se que o $c_{p}$ da mistura é constante, por se tratar de uma faixa estreita de temperaturas e não há variação da composição. Para a parte inicial da curva, correspondente ao aquecimento com uma resistência elétrica, o balanço de energia fica: 


$$
\left(m c_{p}\right) \frac{d T}{d t}=Q-U A\left(T-T_{\text {banho }}\right)
$$

Para a parte final da curva, quando o aquecimento elétrico é desligado, ocorrendo apenas o resfriamento do conteúdo do reator por troca de calor com o banho externo, o balanço de energia é simplificado:

$$
\left(m c_{p}\right) \frac{d T}{d t}=-U A\left(T-T_{\text {banho }}\right)
$$

A equação (2) pode ser integrada analiticamente, obtendo-se:

$$
\ln \left(T(t)-T_{\text {banho }}\right)=\ln \left(T\left(t_{0}\right)-T_{\text {banho }}\right)-\frac{U A}{m c_{p}}\left(t-t_{0}\right)
$$

Portanto, o gráfico de $\ln \left(T(t)-T_{\text {banho }}\right)$ versus $t$ traçado com os dados da parte da curva correspondente ao resfriamento deve ser uma reta com inclinação (coeficiente angular) igual $\mathrm{a}-\frac{U A}{m c_{p}}$. Conhecidos os valores da área de troca de calor $A$ e da massa $m$ e calor específico $c_{p}$ da mistura contida no reator, estima-se o valor do coeficiente $\mathrm{U}$

\subsubsection{Ensaio para verificação da entalpia da reação}

O ensaio para determinação da entalpia da reação foi um experimento em que a reação foi realizada em um reator ilustrado na Figura 3.4. O reator, de $50 \mathrm{~L}$, possui parede dupla, de espaço interno aproximado de $3 \mathrm{~cm}$, recheada com poliuretano expandido. Devido a esse isolamento o experimento é considerado adiabático. $O$ agitador usado era de tipo hélice (com pás agitadoras de $20 \mathrm{~cm}$ de diâmetro). Uma bomba centrífuga em aço inox (Bombinox $1 / 2 \mathrm{HP}$ ) fazia o líquido dentro do reator recircular entre o reator e um aquecedor elétrico externo (potência de $5 \mathrm{~kW}$ ).

O experimento é realizado com uma quantidade significativamente maior que os ensaios de epoxidação para melhorar a precisão da medida de calor gerado.

O experimento foi realizado da seguinte forma. O óleo de soja e o ácido fórmico foram adicionados ao reator, com recirculação de 20 litros/min (fundo para topo), 
agitação mecânica intensa (1000 rpm). Dois termopares (um posicionado no topo e outro no fundo do reator) permitiam a medida da temperatura do meio reagente. $A$ temperatura é previamente elevada até o ponto desejado para o experimento através de um aquecedor elétrico externo por onde recircula o meio reacional. Os dois termopares devem marcar a mesma temperatura, com discrepância máxima de $1^{\circ} \mathrm{C}$, aguardando a estabilização por 2 minutos. Uma vez atingida a temperatura desejada, a quantidade de peróxido de hidrogênio programada deveria ser adicionada. A temperatura foi monitorada até atingir seu máximo e o valor foi anotado. Se houvesse diferença de mais que $1^{\circ} \mathrm{C}$ entre os termômetros ao atingir essa temperatura máxima, o experimento seria descartado e deveria ser repetido.

Figura 3.4 - Esquema do reator piloto, de 50 litros, termicamente isolado, usado na determinação da entalpia de reação.

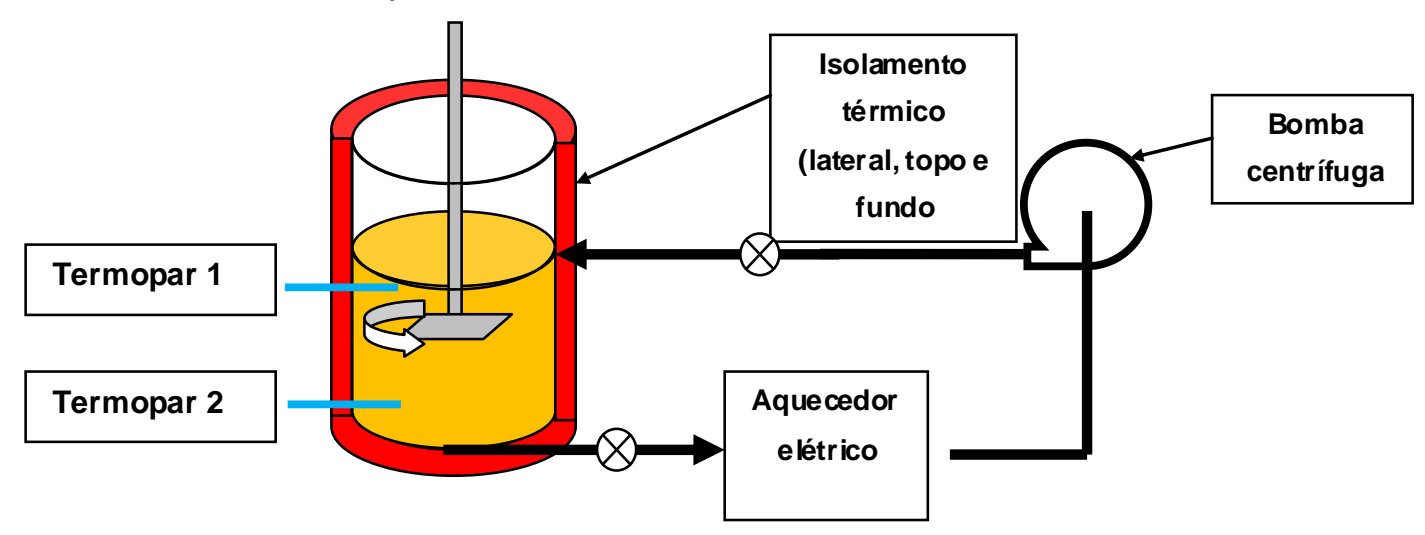

O cálculo para obter a entalpia da reação é feito conforme a equação (4):

$$
\Delta H=-\frac{m \cdot c_{p} \cdot\left(T_{\max }-T_{0}\right)}{\left(N_{i}-N_{f}\right)}
$$

onde $m$ é a massa da mistura reacional, $c_{p}$ é o calor específico médio da mistura reacional, $T_{0}$ é a temperatura inicial do conteúdo do reator (após regulagem da potência do aquecedor elétrico para compensar as perdas de calor), $T_{\max }$ é a máxima temperatura alcançada pela mistura reacional após a adição do peróxido, $N_{i}$ é o número de mols de peróxido adicionado, $N_{f}$ é o número de mols final de peróxido (admitido ser igual a zero). 
Esse cálculo pressupõe que o reator seja considerado adiabático e que o $c_{p}$ da mistura reacional é constante. O experimento foi realizado com termopares calibrados e medidas precisas das massas adicionadas.

\subsubsection{Ensaios para determinação da viscosidade}

O meio reacional é afetado por diversos fatores que influenciam a viscosidade aparente do sistema: temperatura, composição do sistema, tamanho de gotículas da fase dispersa.

Ao longo da reação, a temperatura varia, subindo até um patamar máximo e depois voltando à temperatura do banho, quando a reação está chegando ao seu término.

Uma vez que o processo reacional começa, ocorre a epoxidação do óleo de soja. A fase oleosa tem a formação gradativa de OSE, que é bem mais viscoso que o óleo de soja refinado. Além disso, a fase aquosa inicial contém concentração bem mais elevada do peróxido de hidrogênio, que vai sendo consumido ao longo da reação.

O tamanho de gotícula é função da agitação e das características físicas das duas fases. Mesmo com a agitação mantida constante, o tamanho de gotículas varia, uma vez que tanto a tensão interfacial como a viscosidade das duas fases variam com os componentes e também com a temperatura.

Devido à dificuldade e complexidade de realizar estimativas teóricas, foram realizados ensaios para determinar a viscosidade aparente do meio reacional durante a reação. Estas medições foram necessárias para ajudar a interpretar e explicar as variações do coeficiente de transferência de calor ao longo do tempo de reação.

A medida experimental da viscosidade também apresentava complexidades, pois a medida deveria ser feita durante a reação, de forma rápida (menos que 30 segundos), por haver necessidade de observar a variação da viscosidade em um intervalo relativamente curto de tempo (30 minutos), onde ocorrem as principais variações de temperatura do experimento. Além disso, havia a necessidade de realizar cada teste sem remover material do reator, para manter as características de tamanho de gotículas e temperatura do instante desejado, que poderiam sofrer alterações significativas na amostra retirada do reator, caso se adotasse a amostragem.

Para solucionar essas questões, foi desenvolvido especialmente para esta necessidade um dispositivo para permitir uma avaliação, ainda que simplificada, das 
variações de viscosidade aparente do meio reacional. O dispositivo consta de um tubo de vidro que fica fixo em uma posição dentro do reator, com uma das extremidades inserida na mistura reacional em agitação e a outra para fora. Esse tubo possui uma redução de diâmetro interno na sua extremidade inferior, semelhante aos equipamentos adotados para medidas de viscosidade cinemática (baseados em escoamento de um líquido por um tubo capilar), conforme apresentado no esquema da Figura 3.5. Foram testados vários tubos com diâmetros internos diferentes para chegar a uma configuração que permitisse medição dentro do intervalo desejado (a cada 2 minutos durante a reação), mantendo um tempo razoável para que a medida fosse feita com precisão. O tubo encontrado tem $3 \mathrm{~mm}$ de diâmetro interno e $1,5 \mathrm{~mm}$ no ponto onde o diâmetro é reduzido. O intervalo ideal de escoamento foi de aproximadamente 1 segundo para os líquidos menos viscosos do ensaio e de 16 segundos para os líquidos mais viscosos.

O procedimento consiste de preencher o tubo com o líquido da mistura reacional, usando-se uma pera de laboratório para succionar o fluido. A pera é removida e anota-se o tempo que leva para o fluido escorrer entre duas marcas (distanciadas entre si em $10 \mathrm{~cm}$ ). A posição do tubo é mantida inalterada em todos os experimentos, para garantir a repetibilidade. O procedimento contempla succionar e deixar escorrer o fluido por 3 vezes antes de anotar o tempo, para melhor equalizar a temperatura interna do tubo com a temperatura do reator.

O tempo registrado para o escoamento entre as duas marcas é diretamente proporcional à viscosidade cinemática do fluido em análise (de modo análogo a viscosímetros capilares tipo Ubbelohde, Cannon-Fenske, Micro-Ostwald, etc.). Materiais com viscosidade conhecida em diversas temperaturas foram analisados com o mesmo aparato para verificar a coerência de funcionamento e para estabelecer a constante de correção necessária para converter o valor de tempo de escoamento no correspondente valor de viscosidade. 
Figura 3.5 - Aparato para medida de viscosidade cinemática

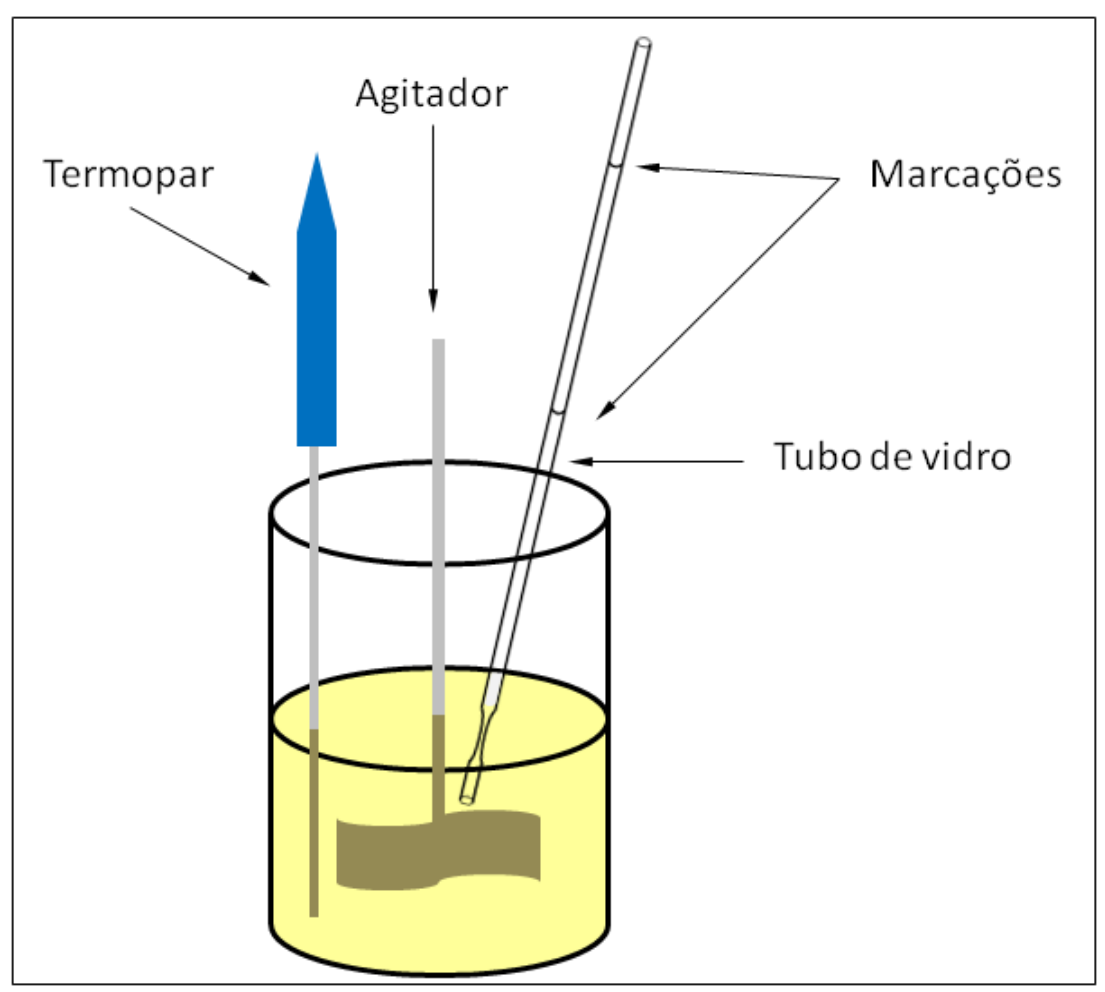

\subsection{Metodologia para cálculo da modelagem}

O modelo do processo de reação de epoxidação do óleo de soja considera a simplificação da reação adotando-se uma abordagem pseudo-homogênea, ou seja, considerando todo o conteúdo do reator como uma única fase. Como a principal questão para o a intensificação do processo industrial é o controle da temperatura, o principal objetivo da modelagem é simular a liberação de energia pela reação exotérmica e a transferência de calor, de modo a permitir futuras avaliações da viabilidade de sistemas reacionais alternativos.

Foram usadas informações da literatura onde é considerada a simplificação da reação como pseudo-homogênea, sendo de primeira ordem em relação à concentração de duplas ligações disponíveis (não reagidas) e de primeira ordem em relação à concentração de ácido perfórmico (SANTACESAREA et al., 2010). Essa simplificação parte da premissa de que a transferência de massa entre as fases aquosa e oleosa são instantâneas. Isso foi aproximado pelos níveis altos de agitação escolhidos para os experimentos.

O modelo consiste das seguintes equações: 
Balanço de massa de duplas ligações

$$
\frac{d C_{2}}{d t}=-r
$$

Balanço de energia do reator

$$
\sum_{i} m_{i} c_{p i} \frac{d T}{d t}=(-\Delta H) r V-U A\left(T-T_{o}\right) \quad T(t=0)=T_{o}
$$

Cinética efetiva pseudo-homogênea da reação

$$
r=k_{0} \exp \left(-\frac{E}{R T}\right) C_{2} C_{1}
$$

onde: $\quad \mathrm{C}_{2}=$ concentração de duplas ligações; e

$$
\mathrm{C}_{1}=\text { concentração de ácido perfórmico. }
$$

O ácido perfórmico (APF) é formado da reação entre o peróxido de hidrogênio e o ácido fórmico $(\mathrm{AF})$, neste modelo admitida como instantânea. Inicialmente, com o excesso de peróxido em relação ao $\mathrm{AF}$, a concentração de $\operatorname{APF}\left(C_{1}\right)$ será igual à do reagente limitante, o AF. Isso é válido quando admite-se que a transferência de AF para a fase aquosa, a reação entre AF e peróxido de hidrogênio na fase aquosa e a transferência de massa do APF da fase aquosa para a fase orgânica sejam muito rápidas, comparadas com a reação na fase orgânica. Quando a quantidade residual de APF calculada pela estequiometria da reação for menor que a concentração inicial de AF, então a concentração de APF será esta concentração residual calculada pela estequiometria da reação:

$$
C_{1}=\min \left\{C_{10}-\left(C_{20}-C_{2}\right) ; C_{A F, 0}\right\}
$$

As equações (5) e (6) foram resolvidas numericamente usando o método de Euler explícito (programado em planilha Excel), usando um passo de integração suficientemente pequeno para este parâmetro não afetar os resultados obtidos. A convergência foi verificada repetindo-se as simulações com diferentes valores de passo de integração, e só usando os resultados quando os resultados da integração obtidos com dois diferentes valores de passo coincidiram, dentro de uma dada precisão. 


\section{RESULTADOS E DISCUSSÃo}

Neste capítulo descrevem-se e discutem-se os resultados dos experimentos realizados de epoxidação de óleo de soja, com o sistema reacional em reator de batelada, com peróxido de hidrogênio e ácido fórmico, sem adição de catalisadores, agentes complexantes ou solventes, que é o sistema mais comumente usado na indústria. Um estudo recente (LEHNEN et al., 2014) reforça a praticidade desse tipo de sistema, mostrando que a seletividade e a conversão desejadas podem ser atingidas com um balanço adequado das proporções dos reagentes. O mesmo estudo sugere que quanto menor o tempo de reação, maior o índice oxirânico e menor a perda por quebra de anéis, o que é concordante com a proposta dessa tese de focar na intensificação da troca de calor e adição de todos os reagentes de forma única, reduzindo o tempo total de reação.

A modelagem do experimento foi feita em seguida, considerando uma simplificação do sistema reacional como sendo de fase única.

\subsection{Detalhamento dos resultados dos experimentos realizados}

\subsubsection{Determinação da entalpia da reação}

Um ensaio de avaliação da entalpia da reação foi realizado para determinar esse valor, conforme metodologia descrita no item 3.1.4.3.

Ao reator, considerado adiabático, $27 \mathrm{~kg}$ de óleo de soja e 1,62 kg de ácido fórmico $85 \%$ foram adicionados (proporção de 1000:60). A massa de reação foi préaquecida a $50^{\circ} \mathrm{C}$ e depois a massa de peróxido foi adicionada rapidamente. Considerou-se que todo o peróxido reage, por ser quantidade pequena em relação à proporção estequiométrica. Dessa forma a concentração final $\left(C_{f}\right)$ de peróxido é considerada zero. Considera-se também um valor médio de calor específico $c_{p}$ da mistura reacional ponderado pelas massas de óleo de soja, ácido fórmico e peróxido de hidrogênio adicionados (fonte: TURCO, R., 2011). A entalpia da reação $(\Delta H)$ foi estimada conforme os cálculos mostrados na Tabela 4.1. 
Tabela 4.1 - Dados medidos e cálculos preliminares para determinação da ental pia

Massas:

$\begin{array}{rrr}\text { Óleo de soja refinado } & 27 & \mathrm{~kg} \\ \text { Acido fórmico } & 1,62 & \mathrm{~kg}\end{array}$

Peróxido adicionado (60 \%)

Massa total reação $(m)$

$39,42 \mathrm{~kg}$

Massa peróxido (60 \%) adicionado

$504 \mathrm{~g}$

Massa peróxido adicionado (puro)

$302 \mathrm{~g}$

Massa molecular peróxido

$34 \mathrm{~mol} / \mathrm{g}$

Peróxido puro adicionado $\left(N_{i}\right)$

$8,89 \mathrm{~mol}$

$T_{0}$

$50,4{ }^{\circ} \mathrm{C}$

$T_{\max }$

$74,6 \quad{ }^{\circ} \mathrm{C}$

Calor específico (óleo de soja)

$0,425 \mathrm{cal} / \mathrm{g} .{ }^{\circ} \mathrm{C}$

Calor específico (Acido Fórmico)

$0,643 \mathrm{cal} / \mathrm{g} \cdot{ }^{\circ} \mathrm{C}$

Calor específico $\left(\mathrm{H}_{2} \mathrm{O}_{2}\right)$

$0,629 \mathrm{cal} / \mathrm{g} .{ }^{\circ} \mathrm{C}$

Calor específico massa reação $\left(c_{p}\right)$

$\mathbf{0 , 4 4} \mathrm{cal} / \mathrm{g} .{ }^{\circ} \mathrm{C}$

De acordo com a equação (4), obtém-se a entalpia:

$$
\Delta H=-\frac{39,42 * 0,44 *(74,6-50,4)}{(8,89-0)}=-47 \mathrm{kcal} / \mathrm{mol}
$$

O valor de entalpia da reação de epoxidação do óleo de soja foi estimado ser -47 $\mathrm{kcal} / \mathrm{mol}$ de peróxido $=-196 \mathrm{~kJ} / \mathrm{mol}$. Esse valor encontra-se entre os valores $-230 \mathrm{~kJ} / \mathrm{mol}$ reportado por Santacesaria et al. (2010) e $-116 \mathrm{~kJ} / \mathrm{mol}$ reportado por Leveneur et al. (2007), diferindo substancialmente do valor $-41 \mathrm{~kJ} / \mathrm{mol}$ reportado por Chanshang et al. (2007). 


\subsubsection{Determinação de coeficiente de troca térmica (U)}

O coeficiente de troca térmica é um parâmetro fundamental para o entendimento e para a modelagem da variação da temperatura do sistema reacional nas condições dos ensaios. O objetivo destes ensaios foi buscar uma forma de estimar, de forma experimental, os valores de $U$ para as diversas condições do experimento, inclusive ao longo do processo reacional.

Foram realizados ensaios para avaliar o coeficiente de troca térmica $U$ entre o conteúdo do reator e o banho termostático. Para isso uma fonte de aquecimento com potência conhecida foi usada para aquecer o conteúdo do reator até uma dada temperatura e então foi desligado. Devido à troca de calor com meio exterior ao reator (banho termostático), a temperatura do conteúdo do reator diminui até voltar ao equilibrio com a temperatura do banho. A partir das medidas de temperatura ao longo do tempo é possível estimar o valor do U. Estes ensaios são realizados com o cuidado de preparar misturas não reativas, de modo que não exista geração de calor no processo.

Para este experimento foi usado um filamento de níquel-cromo, de $30 \mathrm{~cm}$, com resistividade medida de 7,1 $\Omega$. A ele foi aplicada uma voltagem de $12,1 \mathrm{~V}$ através de um Variac. A energia foi fornecida à mistura selecionada para o experimento até que a temperatura subisse $10^{\circ} \mathrm{C}$ em relação ao nível inicial. A agitação do reator foi regulada conforme o planejado para cada experimento.

\subsubsection{Ensaio preliminar (sem reação)}

Um ensaio inicial para verificação de viabilidade e precisão do cálculo e para determinar um valor base de $U$ experimental foi realizado com agitador em rotação de 400 rpm, utilizando uma mistura de óleo de soja (250 g) e ácido fórmico (15 g), com a temperatura do banho termostático controlada a $60^{\circ} \mathrm{C}$.A Figura 4.1 mostra o resultado de dois experimentos replicados, com a curva de temperaturas e de $\ln (\Delta T)$ por tempo (min). 
Figura 4.1 - Resultados do cálculo do U para dois experimentos replicados
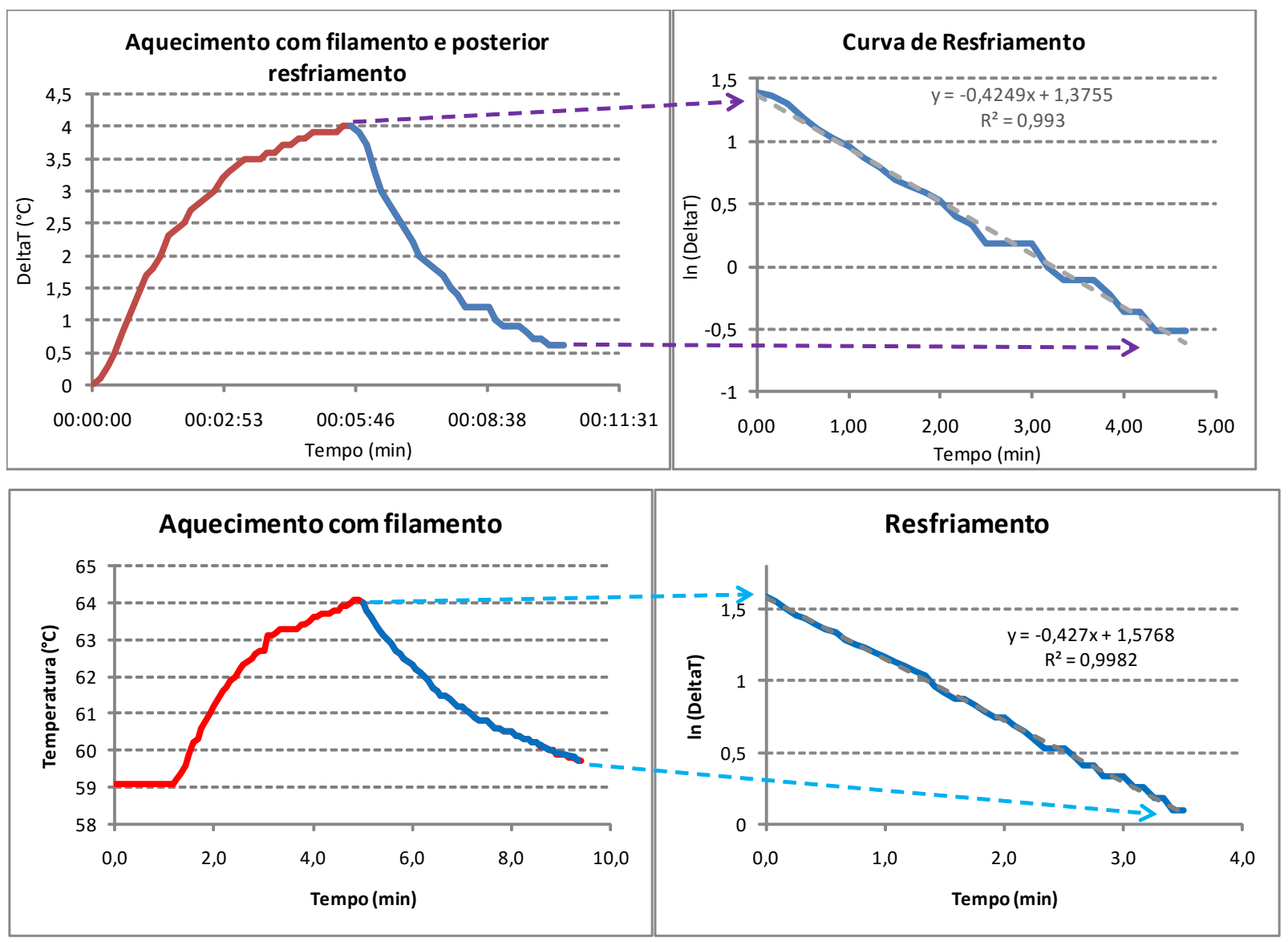

Com esses dados do gráfico de $\ln \left(T(t)-T_{\text {banho }}\right)$ versus $t$, calcula-se $o U$ do fluxo de calor pela parede do reator, conforme a metodologia descrita no item 3.1.4.2. Pelo gráfico mostrado na Figura 4.1, tem-se que a inclinação da curva é 0,427 $\min ^{-1}$. A massa da mistura é $265 \mathrm{~g}$ e o $\mathrm{c}_{\mathrm{p}}$, calculado pela média de óleo de soja e ácido fórmico, é $0,47 \mathrm{kcal} / \mathrm{kg} .{ }^{\circ} \mathrm{C}$ ou $1,98 \mathrm{~kJ} / \mathrm{kg} . \mathrm{K}$. Como o reator fica encostado no fundo do banho, a área de troca térmica é igual à área do cilindro, com altura igual à coluna de líquido, com o sistema em agitação: $A=2 \pi r h$, onde $r=0,04 \mathrm{~m} \mathrm{e} h=0,08 \mathrm{~m}$. Com isso $A=0,020106 \mathrm{~m}^{2}$

$$
-0,427 \mathrm{~min}^{-1}=-\frac{U \cdot 0,020106 \mathrm{~m}^{2}}{0,265 \mathrm{~kg} \cdot 1,98 \mathrm{~kJ} \cdot \mathrm{kg}^{-1} \cdot \mathrm{K}^{-1}}
$$

o que resulta em uma estimativa de do $\mathrm{U}$ :

$$
U=11,16 \frac{\mathrm{kJ}}{\mathrm{m}^{2} \cdot K \cdot \min }=186 \frac{\mathrm{W}}{\mathrm{m}^{2} \cdot K}
$$


Resultados muito semelhantes foram encontrados nas duas repetições mostradas na Figura 4.1, indicando que o procedimento é adequado para avaliar experimentalmente o $\mathrm{U}$, com boa reprodutibilidade de resultados.

\subsubsection{Avaliação de $U$ em diversas condições}

Para a modelagem do processo, seria necessário definir como o coeficiente de transferência de calor varia ao longo da reação. Além disso, o coeficiente $U$ teria que ser estimado em diversas condições de agitação e temperatura.

Para uma dada agitação, as principais variações ao longo da reação seriam consequência das diferentes viscosidades entre reagentes e produtos formados, com a alteração potencial do tamanho das gotículas presentes no sistema de duas fases líquidas. A viscosidade do óleo de soja (reagente) é significativamente mais baixa que a do OSE (produto).

Uma análise do efeito da variação de viscosidade sobre o coeficiente de troca térmica foi realizado com base nas informações teóricas e empíricas disponíveis na literatura. $O$ coeficiente $U$ é um coeficiente global de transferência de calor entre 0 conteúdo do reator e o fluido do banho termostático (água), e pode ser descrito por uma combinação de resistências térmicas do lado interno do reator, da parede e do lado externo do reator:

$$
\frac{1}{U}=\frac{1}{h_{\text {int }}}+\frac{d}{k_{w}}+\frac{1}{h_{\text {ext }}}=\frac{1}{h_{\text {int }}}+C
$$

onde $h_{\text {int }}$ é o coeficiente interno de transferência de calor (entre o líquido no reator e a parede interna do reator), $h_{\text {ext }}$ é o coeficiente externo de transferência de calor (entre a parede externa do reator e a água do banho termostático), $d$ é a espessura da parede do reator e $k_{w}$ é a condutividade térmica da parede do reator. Considerando que a parede do reator e as condições de agitação da água no banho termostático não se alteram, o termo $\frac{d}{r_{w}}+\frac{1}{h_{\text {ext }}}$ é constante (C).

O coeficiente interno $h_{\text {int }}$ é usualmente correlacionado empiricamente com as condições de agitação e as propriedades físicas do líquido na forma (ENGESKAUG et al., 2005):

$$
N u=a \cdot \operatorname{Re}^{b} \cdot \operatorname{Pr}^{c} \cdot\left(\frac{\mu}{\mu_{w}}\right)^{d}
$$


Ou seja:

$$
\left(\frac{h_{i n t} T}{k_{t}}\right)=a \cdot\left(\frac{D^{2} N \rho}{\mu}\right)^{b} \cdot\left(\frac{c_{p} \mu}{k_{t}}\right)^{c} \cdot\left(\frac{\mu}{\mu_{w}}\right)^{d}
$$

onde T é o diâmetro das pás do agitador, $k_{t}$ é a condutividade térmica do fluido dentro do reator, $D$ é o diâmetro do reator, $N$ é a velocidade de rotação do agitador, $\rho$ é a densidade do fluido, $\mu$ é a viscosidade do fluido dentro do reator, $\mu_{w}$ é a viscosidade do fluido à temperatura da parede.

Considerando que os reagentes e produtos da reação são fluidos Newtonianos, de acordo com Akse et al. (1967), pode-se considerar os seguintes valores para os expoentes desta correlação empírica: $b \cong \frac{2}{3}, c \cong \frac{1}{3}, d \cong \frac{1}{5}$

Com isso, como a geometria do tanque e do agitador se mantêm constantes, e considerando $\left(\mu / \mu_{w}\right) \cong$ constante a equação (11) se reduz:

$$
h_{i n t}=a^{\prime} k_{t}^{2 / 3} c_{p}^{1 / 3} \rho^{2 / 3} \mu^{-1 / 3} N^{2 / 3}
$$

Substituindo este resultado na equação (9), resulta:

$$
\frac{1}{U}=\frac{\mu^{1 / 3}}{a^{\prime} N^{2 / 3} k_{t}^{2 / 3} c_{p}^{1 / 3} \rho^{2 / 3}}+C
$$

ou

$$
U=\frac{1}{b^{\prime} \cdot \frac{\mu^{1 / 3}}{N^{2 / 3} k_{t}^{2 / 3} c_{p}^{1 / 3} \rho^{2 / 3}}+C}
$$

que mostra que o valor de U sofreria uma variação em relação à viscosidade do meio reacional. Um aumento da viscosidade provoca uma diminuição do coeficiente U. A equação (14) também mostra que um aumento na velocidade de rotação do agitador promove um aumento do coeficiente $U$.

Por outro lado, existe a possibilidade de que os tamanhos de gota tenham influência não só sobre viscosidade aparente do sistema, mas também sobre o próprio 
coeficiente de transferência de calor. Isso gera uma complexidade adicional ao cálculo teórico, uma vez que o tamanho de partículas pode variar significativamente e não foi possível estabelecer um critério adequado para realizar estimativas.

Devido a essas incertezas, foram definidos ensaios para obter experimentalmente os coeficientes de transferência de calor em diversas condições. O objetivo foi definir pontos experimentais com o valor do coeficiente de transferência de calor para serem usados na modelagem do processo.

Esses ensaios foram planejados com base nos parâmetros usados para realizar os ensaios de epoxidação. Os resultados estão listados na Tabela4.2. As misturas de óleo de soja/ácido fórmico, e de OSE/água representam respectivamente o início e o fim da reação, sendo que em ambas misturas os componentes reativos foram retirados para evitar a liberação de calor devido à reação exotérmica. A substituição por água é uma aproximação razoável, pois a viscosidade é semelhante aos componentes substituídos. Os cálculos de $U$ foram realizados da mesma forma que apresentados anteriormente, a partir dos dados experimentais e da inclinação da reta traçada pelos pontos de $\ln \left(T(t)-T_{\text {banho }}\right)$ versus t na condição de resfriamento sem reação.

Tabela4.2 - Resultados dos ensaios planejados para determinação do U

\begin{tabular}{ccccc}
\hline Ensaio & Mistura & $\begin{array}{c}\text { Temperatura } \\
\text { Banho }\left({ }^{\circ} \mathbf{C}\right)\end{array}$ & $\begin{array}{c}\text { Rotação } \\
\text { Agitador }(\mathbf{r p m})\end{array}$ & $\left(\frac{\boldsymbol{k J}^{\mathbf{J}}}{\boldsymbol{m}^{\mathbf{2}} \cdot \boldsymbol{K} \cdot \boldsymbol{m i n}}\right)$ \\
\hline U1 & Óleo soja/Ácido fórmico & 40 & 500 & 12,3 \\
\hline U2 & Óleo soja/Ácido fórmico & 40 & 1000 & 15,3 \\
\hline U3 & Óleo soja/Ácido fórmico & 60 & 500 & 13,2 \\
\hline U4 & Óleo soja/Ácido fórmico & 60 & 1000 & 16,1 \\
\hline U5 & OSE/Água & 40 & 500 & 8,5 \\
\hline U6 & OSE/Água & 40 & 1000 & 7,9 \\
\hline U7 & OSE/Água & 60 & 500 & 10,7 \\
\hline
\end{tabular}


Pelos resultados experimentais encontrados, pode-se concluir que o coeficiente de transferência de calor no início da reação (mistura óleo de soja/ácido fórmico) tem pouca influência da temperatura, e maior influência da velocidade de agitação. Porém, para a mistura encontrada no final da reação (OSE/Água) há influência mais significativa tanto da agitação quanto da temperatura. É notável também a diminuição do $U$ no fim da reação quando comparado ao início, coerente com o aumento da viscosidade durante a reação.

Admitindo que as demais propriedades físicas na equação (14) não variem significativamente (ou melhor, que a variação destas outras propriedades, densidade, calor específico e condutividade térmica, seja comparativamente muito menor que a variação da viscosidade aparente da mistura reacional), a variação de U pode ser simplificadamente descrita por,:

$$
U=\frac{1}{d^{\prime} \cdot \frac{\mu^{1 / 3}}{N^{2 / 3}}+C}
$$

O valor de viscosidade da mistura reacional inicial a $60^{\circ} \mathrm{C}$ pode ser estimado como de aproximadamente $10 \mathrm{~mm}^{2} / \mathrm{s}$ e da mistura reacional final a $60{ }^{\circ} \mathrm{C}$ de $100 \mathrm{~mm}^{2} / \mathrm{s}$ (estes valores foram medidos e serão apresentados posteriormente na Figura 4.4). Usando estes valores de viscosidade e os valores de $U$ e de velocidade de rotação para os resultados obtidos a $60^{\circ} \mathrm{C}$, apresentados na Tabela 4.2 (experimentos U3, U4, U7 e U8), é possível testar a equação (15). Se a equação (15) representar corretamente os efeitos da viscosidade e da velocidade de rotação sobre o coeficiente $U$, o gráfico de $(1 / U)$ versus $\left(\mu^{0,33} / N^{0,67}\right)$ deve ser uma reta, $A$ viscosidade medida a $60^{\circ} \mathrm{C}$ apresentou os seguintes resultados: $13 \mathrm{~mm}^{2} / \mathrm{s}$ para o início da reação (antes da adição do peróxido, em ambas rotações - 500 e 1000 rpm), $97 \mathrm{~mm}^{2} / \mathrm{s}$ para o fim da reação a $500 \mathrm{rpm}$, e $107 \mathrm{~mm}^{2} / \mathrm{s}$ para o fim da reação a 1000 rpm. A Figura 4.2 apresenta o gráfico com estes pontos, mostrando um compostamento linear, e permite estimar os valores das constantes d' e C, que correspondem respectivamente aos valores da inclinação da reta obtida (coeficiente angular) e do ponto de interseção com o eixo vertical do gráfico (coeficiente linear); os valores obtidos foram d' $=1,387$ e $C=0,029$. 
Figura 4.2 - Efeito da viscosidade e velocidade de rotação sobre o coeficiente de trans ferência de calor. Verificação da equação (15).

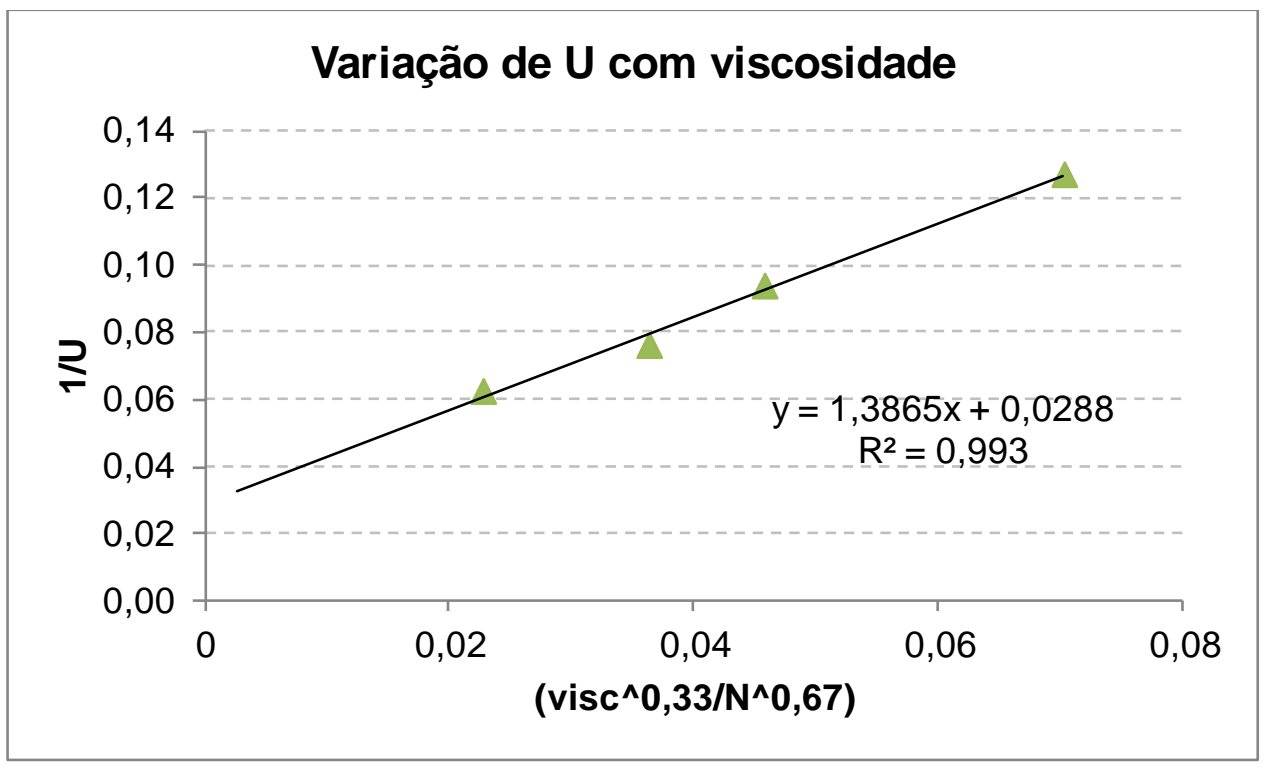

\subsubsection{Ensaios de medição da viscosidade}

Como existe uma correlação entre o U e a viscosidade aparente do sistema, foram realizados ensaios para buscar uma estimativa das viscosidades do sistema ao longo da reação de epoxidação. Essas estimativas têm utilidade para a modelagem do sistema, buscando estimar de forma mais adequada os valores de $U$ ao longo da reação. $O$ efeito da tensão superficial não foi considerado para avaliar sua influência sobre tamanho de gotícula e sua potencial influência sobre o $U$.

As viscosidades do óleo de soja puro são reportadas na literatura, e apresentados na Tabela 4.3.

Tabela 4.3 - Viscosidades do óleo de soja

\begin{tabular}{cc}
\hline Temperatura $\left({ }^{\circ} \mathrm{C}\right)$ & Viscosidade cinemática $\left(\mathrm{mm}^{2} / \mathrm{s}\right)$ \\
\hline 50 & 23.00 \\
\hline 60 & 17.47 \\
\hline 70 & 13.67 \\
\hline
\end{tabular}

Fonte: Esteban et al. (2012)

Para as viscosidades do OSE, foram obtidos resultados experimentais obtidos no presente trabalho, a partir de medições realizadas com viscosímetro de torque tipo Brookfield. Os valores obtidos são apresentados na Tabela 4.4. 
Tabela 4.4 - Viscosidades do OSE

\begin{tabular}{cc}
\hline Temperatura $\left({ }^{\circ} \mathrm{C}\right)$ & Viscosidade cinemática $\left(\mathrm{mm}^{2} / \mathbf{s}\right)$ \\
\hline 23 & 361 \\
\hline 38 & 210 \\
\hline 57 & 113 \\
\hline
\end{tabular}

A medição de viscosidade utilizando-se o dispositivo descrito no item 3.1.4.4 resultou nos valores para o OSE puro e para o óleo de soja puro, conforme mostrado nas Tabela 4.5 e 4.6. Na Figura 4.3 os mesmos dados experimentais são analisados e podem ser correlacionados pela equação empírica mostrada neste gráfico, com fórmula exponencial e boa aproximação estatística $\left(R^{2}=0,986\right)$.

A curva tem utilidade na modelagem, para estimar a viscosidade em diversas condições de temperatura ao longo das reações realizadas conforme 0 planejamento de ensaios.

Tabela 4.5 - Viscosidades de OSE puro, medidas experimentais

\begin{tabular}{c|ccc|c}
\hline & \multicolumn{4}{|c|}{ Valores medidos (tempo, s) } \\
\hline $\mathbf{T}\left({ }^{\circ} \mathbf{C}\right)$ & $\mathbf{1}$ & $\mathbf{2}$ & $\mathbf{3}$ & Tempo médio (s) \\
\hline 43,7 & 13,13 & 13,05 & 13,28 & 13,15 \\
\hline 39,0 & 13,58 & 14,17 & 14,05 & 13,93 \\
\hline 37,4 & 14,57 & 14,53 & 14,83 & 14,64 \\
\hline 35,0 & 15,41 & 15,69 & 15,87 & 15,66 \\
\hline 31,0 & 18,43 & 18,46 & 18,58 & 18,49 \\
\hline 29,0 & 20,36 & 20,74 & 20,67 & 20,59 \\
\hline 20,8 & 28,47 & 28,4 & 28,3 & 28,39 \\
\hline 60,0 & 7,29 & 7,36 & 7,16 & 7,27 \\
\hline
\end{tabular}

Tabela 4.6 - Viscosidades de óleo de soja puro, medidas experimentais

\begin{tabular}{c|ccc|c}
\hline & \multicolumn{4}{|c|}{ Valores medidos (tempo, s) } \\
\hline $\mathbf{T}\left({ }^{\circ} \mathbf{C}\right)$ & $\mathbf{1}$ & $\mathbf{2}$ & $\mathbf{3}$ & Tempo médio (s) \\
\hline 50,0 & 1,43 & 1,75 & 1,67 & 1,62 \\
\hline 60,0 & 1,23 & 1,29 & 1,34 & 1,29 \\
\hline 70,0 & 0,97 & 0,89 & 1,01 & 0,96 \\
\hline
\end{tabular}


Figura 4.3 - Viscosidades de OSE puro, e curva de tendência

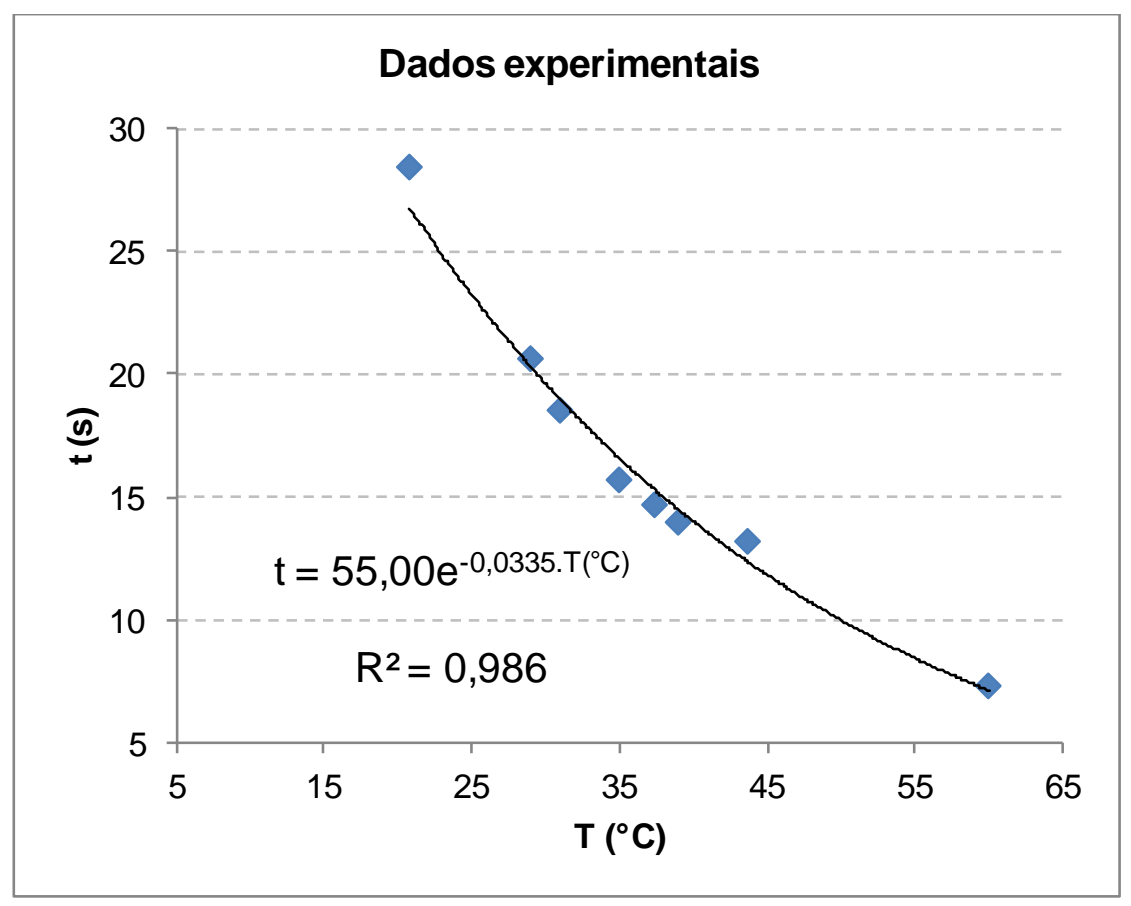

Para estabelecer o fator de correlação entre a medida do tempo de escoamento no capilar e a viscosidade em $\mathrm{mm}^{2} / \mathrm{s}$ medida no viscosímetro Brookfield, os resultados obtidos para o OSE são mostrados na Tabela 4.7. Os dados da viscosidade de óleo de soja foram também incluídos para o cálculo do fator, usando-se os dados da literatura para o comparativo.

Tabela 4.7 - Dados comparativos e fator multiplicador

\begin{tabular}{ccccc}
\hline Material & $\begin{array}{c}\text { Temperatura } \\
\mathbf{T}\left({ }^{\circ} \mathbf{C}\right)\end{array}$ & $\begin{array}{c}\text { Tempo } \\
\text { médio } \\
\mathbf{t}(\mathbf{s})\end{array}$ & $\begin{array}{c}\text { Viscosidade medida } \\
\text { ou da literatura } \\
\boldsymbol{\mu}\left(\mathbf{m m}^{\mathbf{2}} / \mathbf{s}\right)\end{array}$ & $\begin{array}{c}\text { Fator } \\
\text { Multiplicador }\end{array}$ \\
\hline OSE & 23 & 25,0 & 361 & 14,4 \\
\hline OSE & 38 & 15,1 & 210 & 13,9 \\
\hline OSE & 57 & 8,0 & 113 & 14,1 \\
\hline Óleo de Soja & 50 & 1,62 & 23,00 & 14,2 \\
\hline Óleo de Soja & 60 & 1,24 & 17,47 & 13,6 \\
\hline Óleo de Soja & 70 & 0,96 & 13,67 & 14,3 \\
\hline
\end{tabular}

Com isso, adota-se o fator multiplicador $\left(F_{\text {mult }}\right)$ a partir da média dos fatores obtidos:

$$
F_{\text {mult }}=\frac{14,4+13,9+14,1+14,2+13,6+14,3}{6}=14,2 \mathrm{~mm}^{2} \mathrm{~s}^{-2}
$$

A viscosidade em $\mathrm{mm}^{2} / \mathrm{s}$ deve então ser estimada pelo valor do tempo medido (s) no dispositivo de escoamento capilar multiplicado por $F_{\text {mult. }}$ 
A Figura 4.4 mostra a evolução da viscosidade, medida com esse aparato ao longo de duas reações com temperatura do banho $60^{\circ} \mathrm{C}$, com $250 \mathrm{~g}$ de óleo de soja, $100 \mathrm{~g}$ de peróxido de hidrogênio e $15 \mathrm{~g}$ de ácido fórmico e com agitação em dois níveis, a 500 e a 1000 rpm.

Figura 4.4 - Evolução da viscosidade aparente (medida com o dispositivo capilar) e da temperatura durante ensaios de reação de epoxidação.

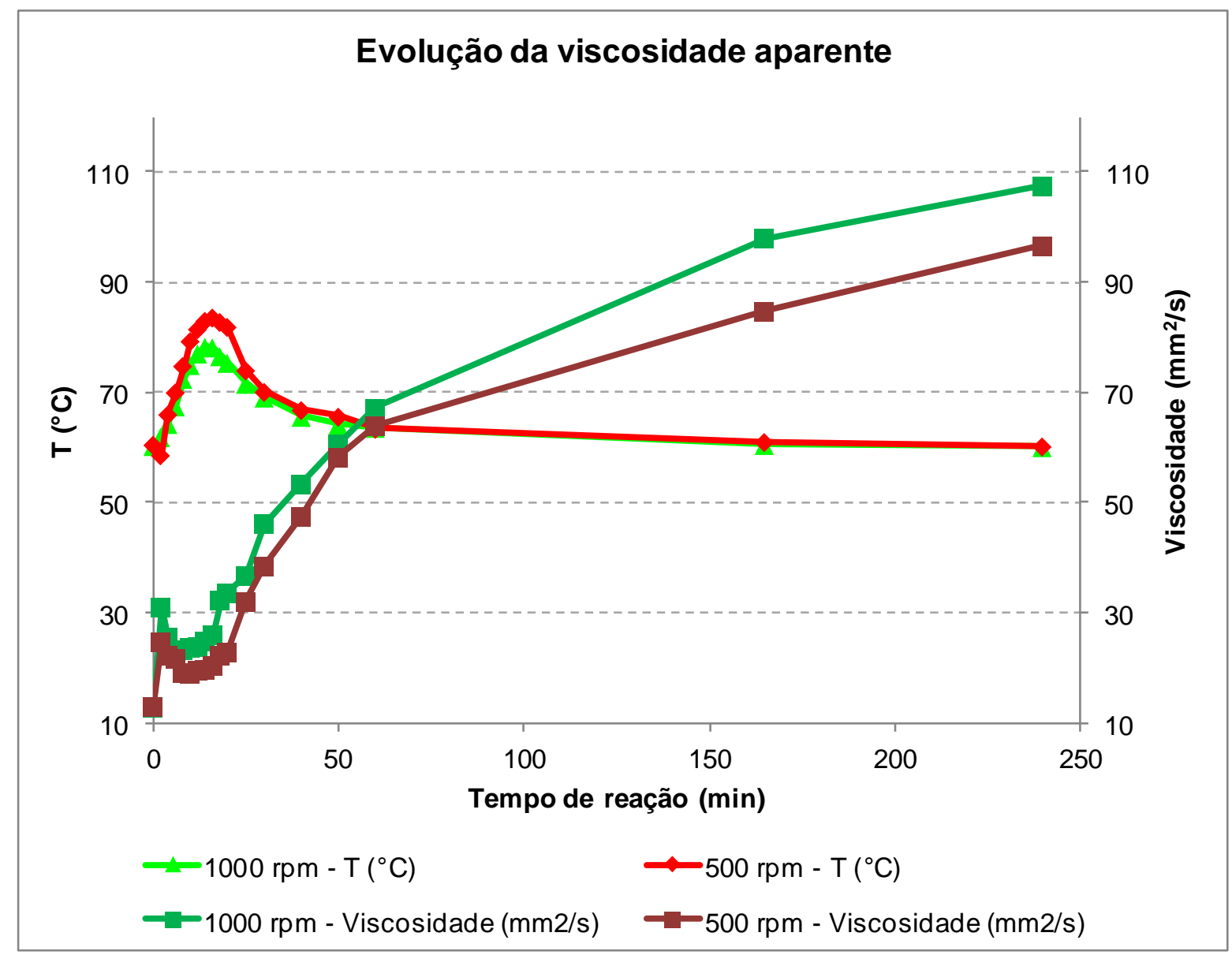

Pode-se notar que a temperatura sobe mais no caso da rotação mais baixa, como observado anteriormente. A viscosidade em rotações mais baixas é menor que em rotações mais altas. Esse efeito, no intervalo em que as temperaturas são diferentes (até aproximadamente 50 minutos) poderia ser explicado pela diferença de temperatura. No intervalo seguinte, porém, não há diferença notável de temperaturas. Nesse caso a diferença de viscosidade poderia ser explicada por dois efeitos: 1) a menor taxa de conversão observada nos sistemas com menor agitação e; 2) a alteração da viscosidade de um sistema com componentes iguais devido ao impacto do tamanho de gotícula. Quanto maior a gotícula (menor agitação), menor a viscosidade. Esse efeito é coerente com informações obtidas na literatura (WOODS; 
KRIEGER; 1970). A medição do tamanho de gotícula no sistema durante a reação não foi realizada.

\subsubsection{Experimentos da reação de epoxidação}

\subsubsection{Análise da viabilidade de adição única de todos os componentes}

Devido à preocupação existente com o aumento de temperatura no início da reação e a potencial perda de controle do sistema, os experimentos foram feitos com aumento progressivo da quantidade de peróxido por adição, iniciando em 1/20 (20 adições de $5 \mathrm{~g}$ cada, das $100 \mathrm{~g}$ totais programadas) até 1/1 (100 g em uma única adição). Todos os experimentos dessa avaliação preliminar de viabilidade foram realizados sob agitação de 400 rpm.

A

Figura 4.5 ilustra os resultados das curvas de temperatura versus tempo para duas adições de $5 \mathrm{~g}$ de peróxido. É possível observar que a temperatura ficou bem abaixo do limite de $75^{\circ} \mathrm{C}$, mantendo-se o banho a $60^{\circ} \mathrm{C}$. Foi sempre observada a temperatura máxima para decidir sobre o próximo passo de adição de quantidades maiores.

Figura 4.5 - Curvas experimentais de temperatura vs. tempo
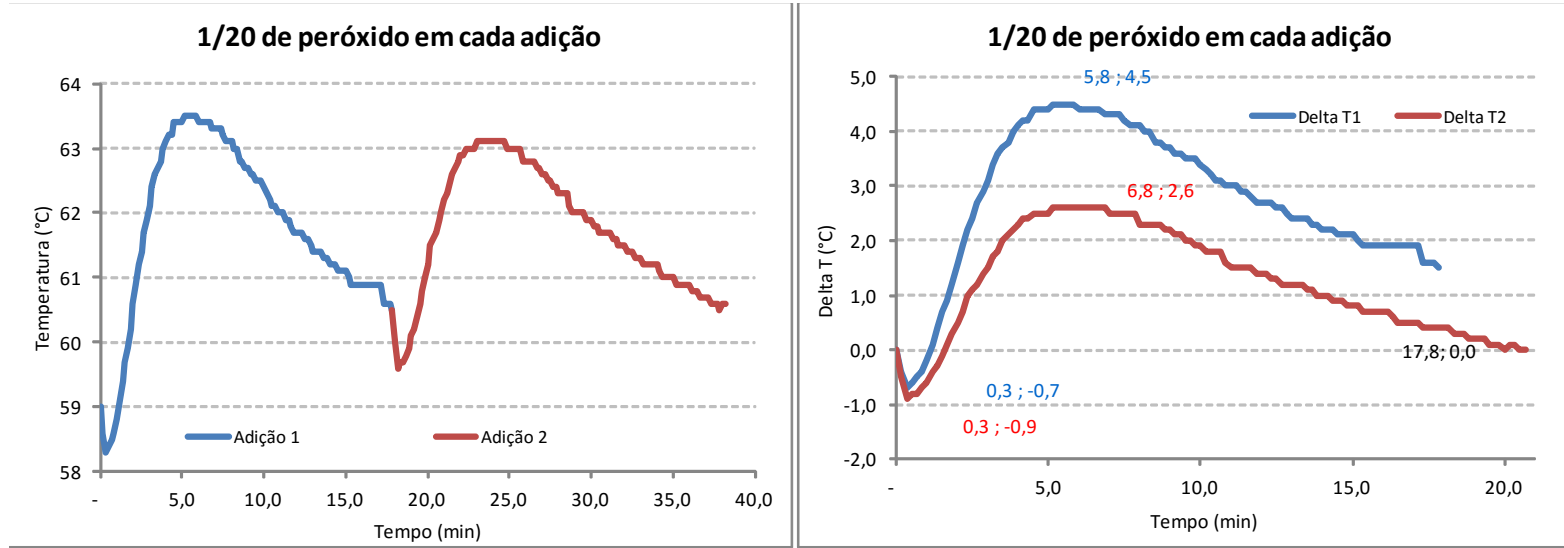

Por esses primeiros ensaios é possível notar também que o tempo para atingir o pico de temperatura para ambas as adições foi muito semelhante - cerca de 6 minutos. A elevação de temperatura é menor na segunda adição, pois um dos reagentes (as duplas ligações) já foi parcialmente consumido durante a primeira adição de peróxido. 
No ensaio comparativo com adições de 1/20 e 1/10 do peróxido (Figura 4.6), podese notar que há pouca diferença entre estes dois ensaios quanto ao tempo para atingir a temperatura máxima. A temperatura máxima é naturalmente diferente, uma vez que se trata de quantidades de energia gerada diferentes.

Figura 4.6 - Comparação: adições de 1/20 e 1/10 de peróxido

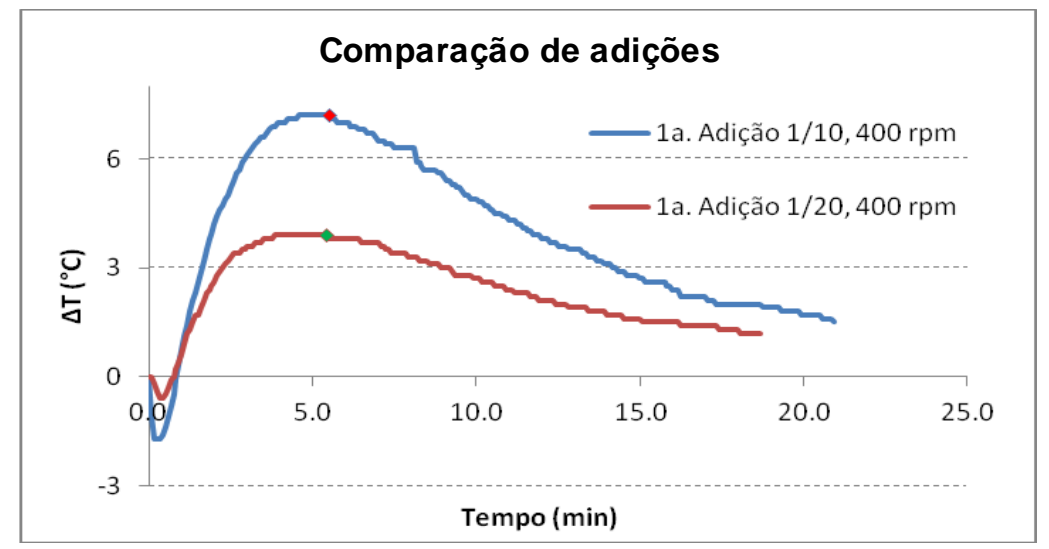

Foram feitas também avaliações comparativas para diferentes níveis de agitação do reator, medido em rotações por minuto, cujos resultados estão apresentados na Figura 4.7. Fica claro que o nível mais alto de agitação promove maior troca térmica e com isso a temperatura máxima é menor quando se utiliza maior velocidade de agitação. É possível também notar que o tempo para atingir a temperatura máxima é aproximadamente o mesmo, cerca de 6 minutos.

Figura 4.7 - Comparação da elevação da temperatura

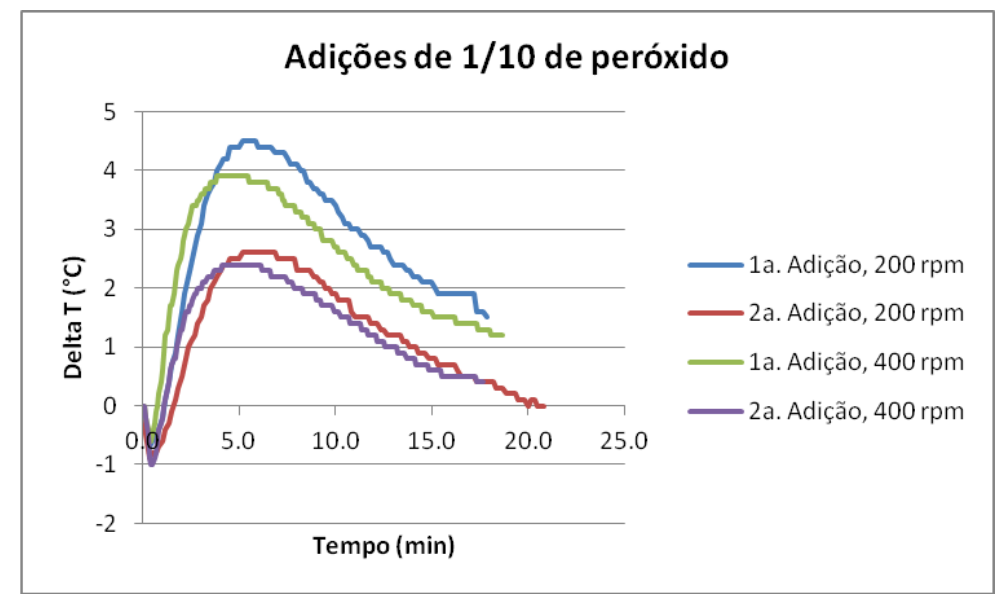

A Com as curvas sobrepostas - Figura 4.9 - é possível notar que as temperaturas máximas, indicadas pelo ponto em destaque na curva, vão gradativamente diminuindo. Isto é coerente com o consumo das insaturações que já reagiram nas 
adições anteriores, fazendo com que cada "pico" subsequente de temperatura seja menor que o anterior, devido à menor concentração de reagente no sistema e consequente menor quantidade de calor gerada.

Figura 4.8 mostra as curvas das 5 adições de 1/5 de peróxido (20 g) a cada adição. Todas realizadas a $400 \mathrm{rpm}$ e temperatura do banho em $60{ }^{\circ} \mathrm{C}$.

Com as curvas sobrepostas - Figura 4.9 - é possível notar que as temperaturas máximas, indicadas pelo ponto em destaque na curva, vão gradativamente diminuindo. Isto é coerente com o consumo das insaturações que já reagiram nas adições anteriores, fazendo com que cada "pico" subsequente de temperatura seja menor que o anterior, devido à menor concentração de reagente no sistema e consequente menor quantidade de calor gerada.

Figura 4.8 - Variação da temperatura para 5 adições sequenciais de peróxido

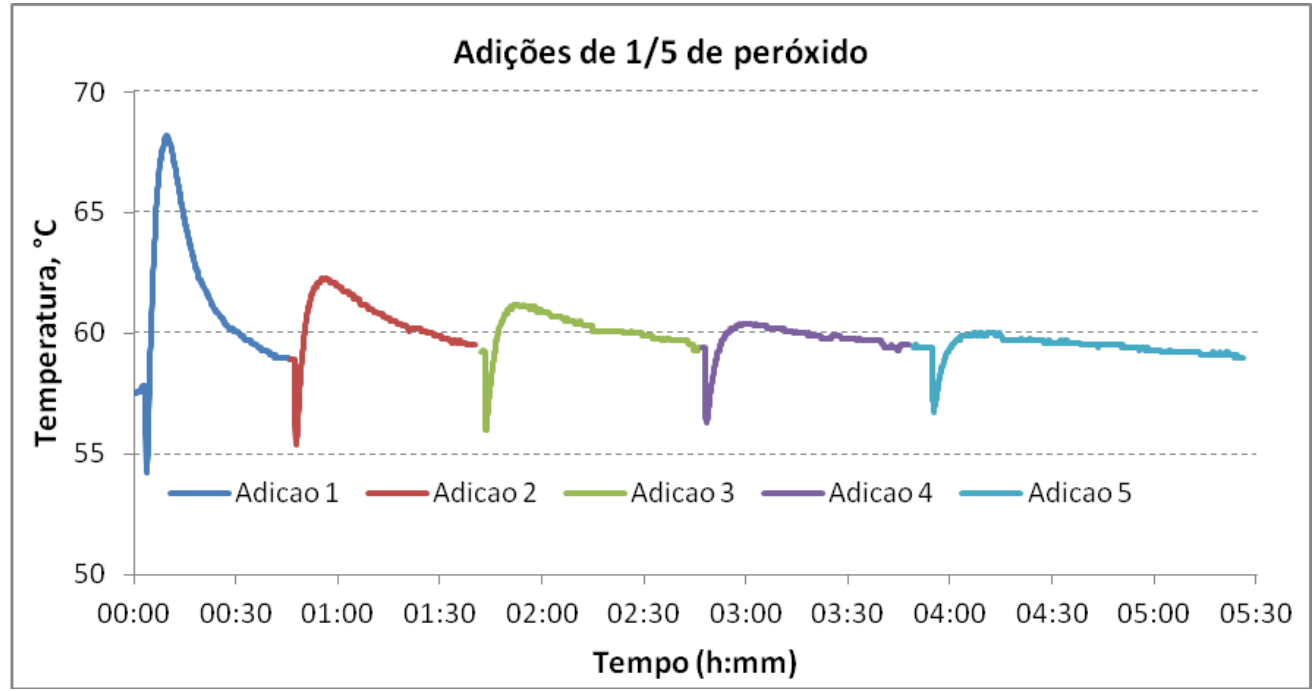

Figura 4.9 - Comparação da elevação de temperatura

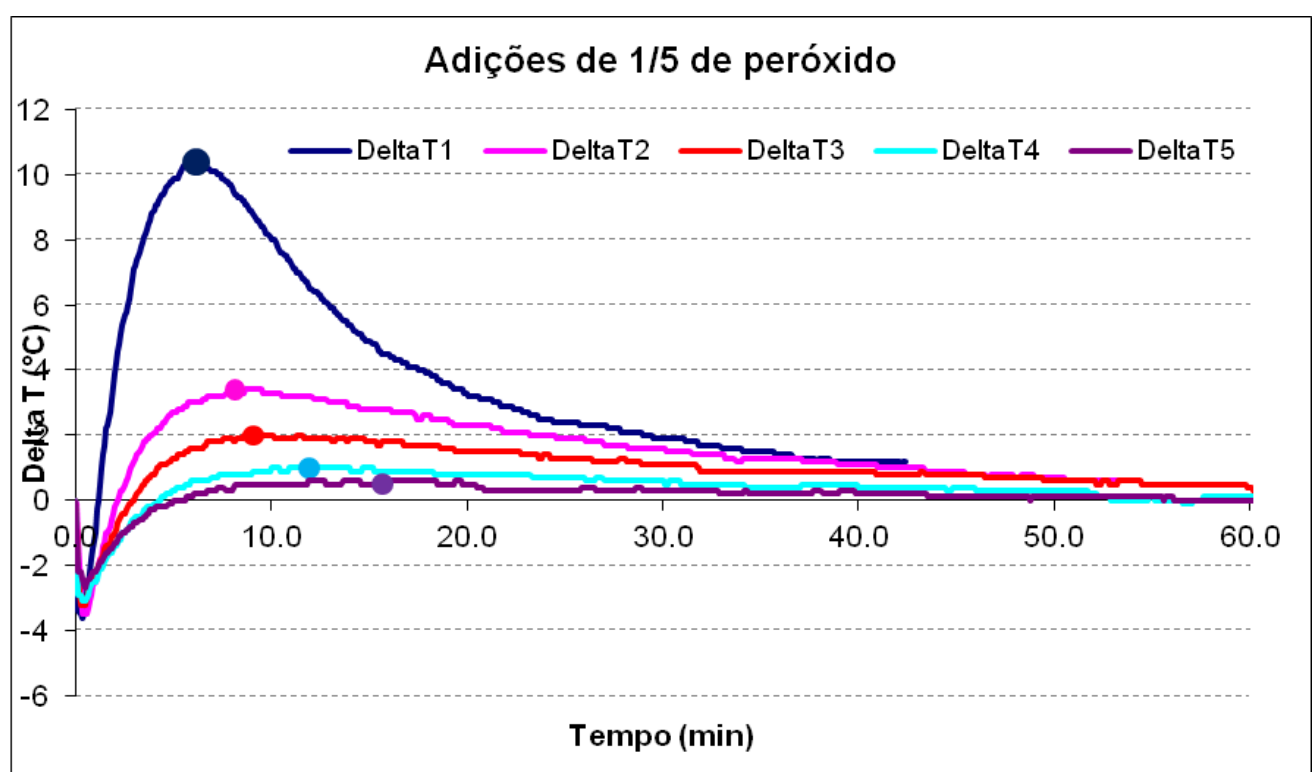


Todas os experimentos a partir desse ponto foram realizados com $400 \mathrm{rpm}$ de rotação do agitador e $60^{\circ} \mathrm{C}$ para a temperatura do banho.

Ao realizar o passo seguinte, referente a 3 adições de (1/3) do total de peróxido cada, pode-se notar que a temperatura subiu, mas ainda ficou sob controle, como mostra a Figura 4.10. O mesmo ocorre com 2 adições de 50 \% do total de peróxido, como na Figura 4.11.

Figura 4.10 - Curvas de temperatura para três adições de peróxido

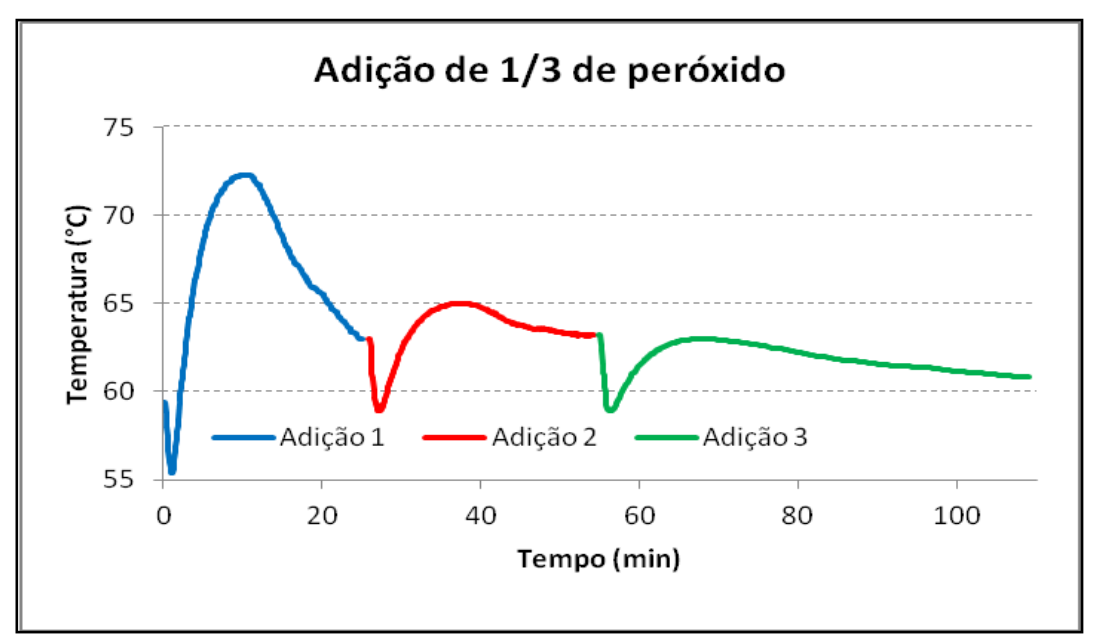

Figura 4.11 - Curvas de temperatura para duas adições de peróxido

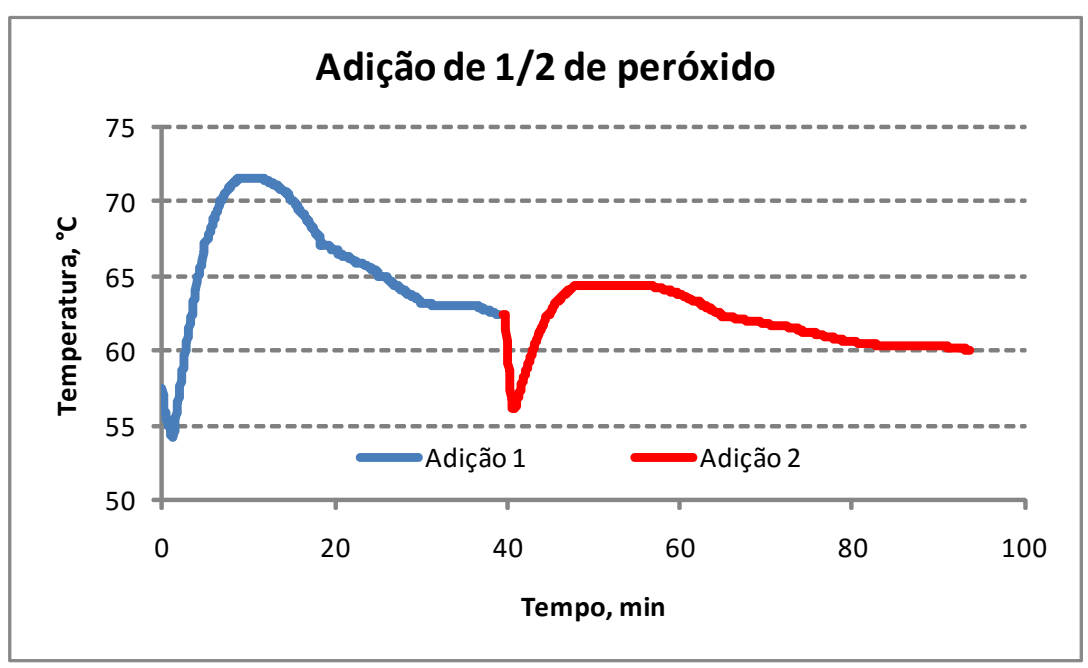


Figura 4.12 - Curva de temperatura para adição única de peróxido

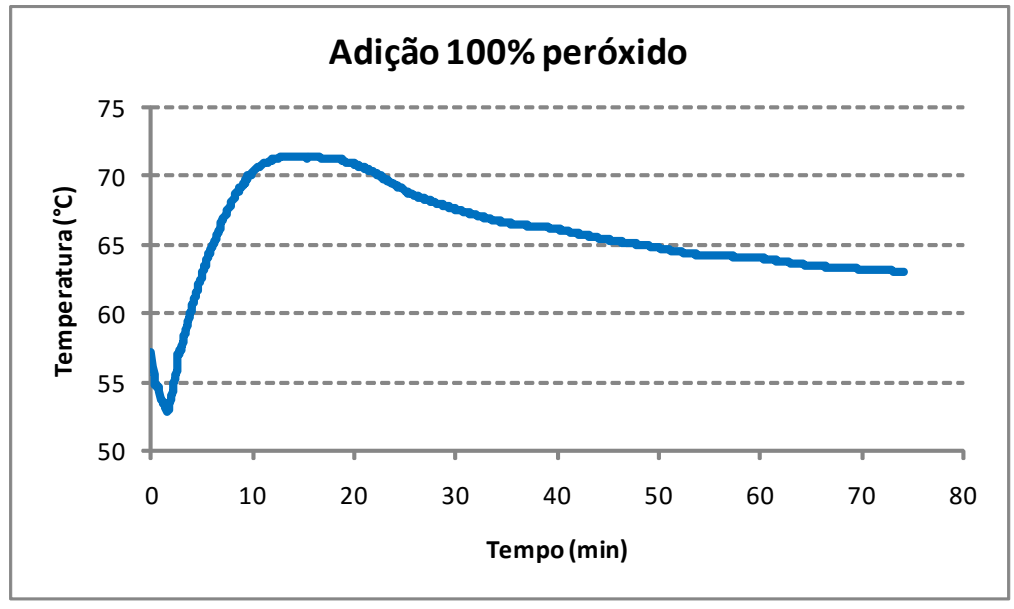

Em todos os experimentos a temperatura do banho não sofreu variação significativa, mantendo-se em $60,2 \pm 0,4^{\circ} \mathrm{C}$. Essa variação foi igual àquela do banho mantido sem a realização de qualquer reação, portanto corresponde à variação do controlador. A observação mais importante foi a constatação de que a temperatura manteve-se sob controle mesmo com a adição do total de peróxido de uma só vez como mostra a Figura 4.12. Observa-se que, como esperado, as primeiras adições apresentam maiores elevações de temperatura. Porém, mesmo com a adição de todo o peróxido de uma única vez, a elevação de temperatura não ultrapassou $85^{\circ} \mathrm{C}$ (chegou a um máximo de $73^{\circ} \mathrm{C}$ ), mostrando que a troca de calor com o banho térmico foi eficiente para não permitir descontrole da temperatura, indicando que nestas condições o sistema está operando em região segura (no que se refere ao controle da temperatura). Na Figura 4.13 - Primeira adição de $33 \%$, $50 \%$ e $100 \%$ do peróxidoas curvas superimpostas permitem observar como a temperatura se comportou conforme a primeira quantidade de peróxido adicionada. Nota-se que a temperatura sobe mais rápido com adições menores, o que pode ser explicado pela maior massa a ser aquecida e a mesma geração de energia, por haver limitação da quantidade de ácido fórmico disponível. Observa-se também que a temperatura cai mais lentamente com adições maiores, o que se explica pela maior disponibilidade de peróxido, aumentando o calor gerado, por ter-se ultrapassado o limitante de ácido fórmico e a quantidade de peróxido disponível ser o limitante da reação. 
Figura 4.13 - Primeira adição de $33 \%, 50 \%$ e $100 \%$ do peróxido

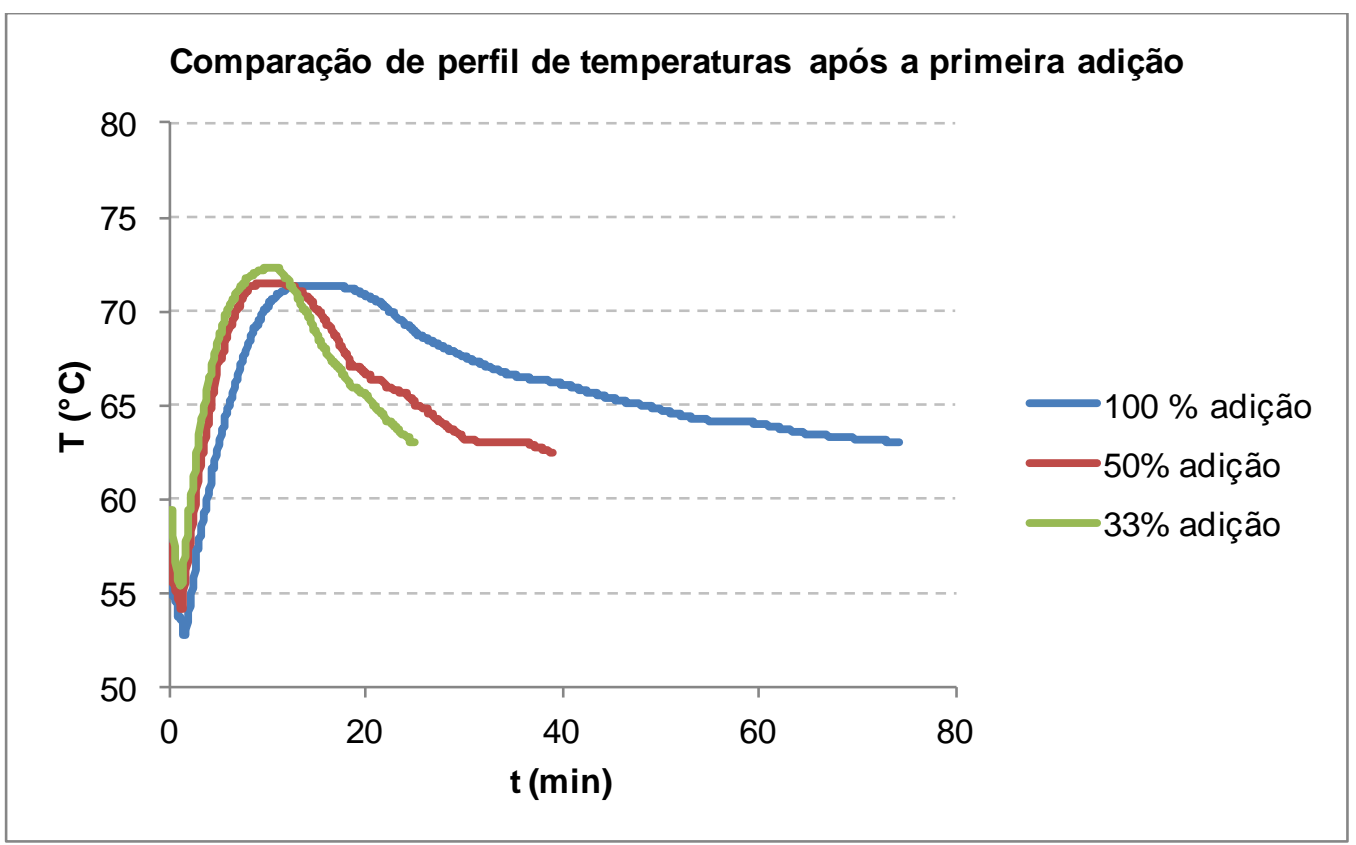

Em todas as reações, após as adições, o sistema foi mantido sob agitação de 400 rpm e com temperatura controlada por 6 horas. As medições de índice oxirânico e índice de iodo indicam que a conversão foi comparável ou até melhor que a dos produtos comerciais e houve pouca degradação dos anéis oxirânicos, como mostra a Tabela 4.8.

Tabela 4.8 - Índice oxirânico e índice de iodo do produto final. Comparação com o produto comercial.

\begin{tabular}{lccc}
\hline Ensaios de conversão & $\begin{array}{c}\text { Tempo total de } \\
\text { reação }\end{array}$ & $\begin{array}{c}\text { Índice } \\
\text { oxirânico }\end{array}$ & $\begin{array}{c}\text { Índice de } \\
\text { lodo }\end{array}$ \\
\hline 2 adições de $1 / 2$ quantidade de peróxido $60 \%$ & 6 horas & 6,88 & 1,92 \\
\hline 1 adição de total de peróxido $60 \%$ & 6 horas & 7,08 & 1,34 \\
\hline Produto comercial $^{*}$ & 8 horas & 6,62 & 1,97 \\
\hline
\end{tabular}

${ }^{*}$ amostra de produt o comercial obtido por cortesia da empresa BBC Ind. e Com. Ltda. A repetibilidade do teste é de $\pm 0,05$ para ambos ensaios (Oxirânico e lodo)

\subsubsection{Ensaio comparativo de adição única com processo industrial}

O sistema com adição única teria, em teoria, maior velocidade total de reação, uma vez que todos os reagentes entram em ação imediatamente. Foram realizados três experimentos para comprovar essa possibilidade. O índice de lodo inicial do óleo utilizado para esses ensaios é de 126. O índice oxirânico máximo teórico nesse caso seria de 7,35\%. 
Inicialmente o processo industrial atual foi simulado. Esse ensaio foi realizado com a pesagem dos reagentes óleo de soja refinado $(250 \mathrm{~g})$ e ácido fórmico $85 \%$ (15 g) e adição ao reator com agitação de 400 rpm. Após o equilíbrio da temperatura, a $60{ }^{\circ} \mathrm{C}$, o peróxido $60 \%$ (100 g) foi adicionado gradativamente com o uso de uma bureta de titulação ao longo de 120 minutos, conforme as velocidades de adição mostradas na Tabela 4.9.

Tabela 4.9 - Adições de peróxido

\begin{tabular}{ccc}
\hline $\begin{array}{c}\text { Quantidade adicionada de } \\
\text { peróxido } \mathbf{6 0} \% \mathbf{( g )}\end{array}$ & $\begin{array}{c}\text { Tempo de } \\
\text { adição }(\mathbf{m i n})\end{array}$ & $\begin{array}{c}\text { Vazão mássica adicionada } \\
(\mathbf{g} / \mathbf{m i n})\end{array}$ \\
\hline 15 & 40 & 0,375 \\
\hline 15 & 30 & 0,500 \\
\hline 20 & 20 & 1,000 \\
\hline 20 & 15 & 1,333 \\
\hline 30 & 15 & 2,000 \\
\hline
\end{tabular}

A temperatura do banho foi mantida a $60^{\circ} \mathrm{C}$, com agitação, por $8 \mathrm{~h}$. Foram retiradas amostras de $20 \mathrm{~mL}$ de produto a cada $60 \mathrm{~min}$, adicionando-se $40 \mathrm{~mL}$ de água fria imediatamente para interromper a reação. As amostras foram então deixadas em decantadores. A fase aquosa foi descartada e a fase oleosa foi submetida a secagem, com temperatura mantida abaixo de $120^{\circ} \mathrm{C}$. Depois desse procedimento, foram determinados os parâmetros de conversão, através das titulações para obter o Índice Oxirânico e o Índice de lodo de cada amostra.

O mesmo procedimento foi realizado para a reação com adição única de peróxido, com $250 \mathrm{~g}$ de óleo de soja, $15 \mathrm{~g}$ de ácido fórmico $85 \%$ e $100 \mathrm{~g}$ de peróxido de hidrogênio $60 \%$.

Além disso, foram retiradas amostras a cada hora em um processo industrial existente, realizado em reator industrial de $3000 \mathrm{~kg}$, onde $2000 \mathrm{~kg}$ de óleo de soja refinado e $120 \mathrm{~kg}$ de ácido fórmico 85 \% são agitados vigorosamente com rotor mecânico e $800 \mathrm{~kg}$ de peróxido 60 \% são adicionados ao longo de 120 minutos.

Os resultados da conversão são apresentados nas Figuras 4.14 e 4.15. É importante notar que a conversão máxima é superior para o sistema de adição única e o valor de especificação é atingido em tempo significativamente menor que o processo industrial (simulado ou real). A conversão máxima em adição única é atingida em 
180 min (3 horas), o que é significativamente menor que o tempo de reação em sistemas de porte industrial (8 horas).

Figura 4.14 - Comparação da evolução de conversão - índice oxirânico

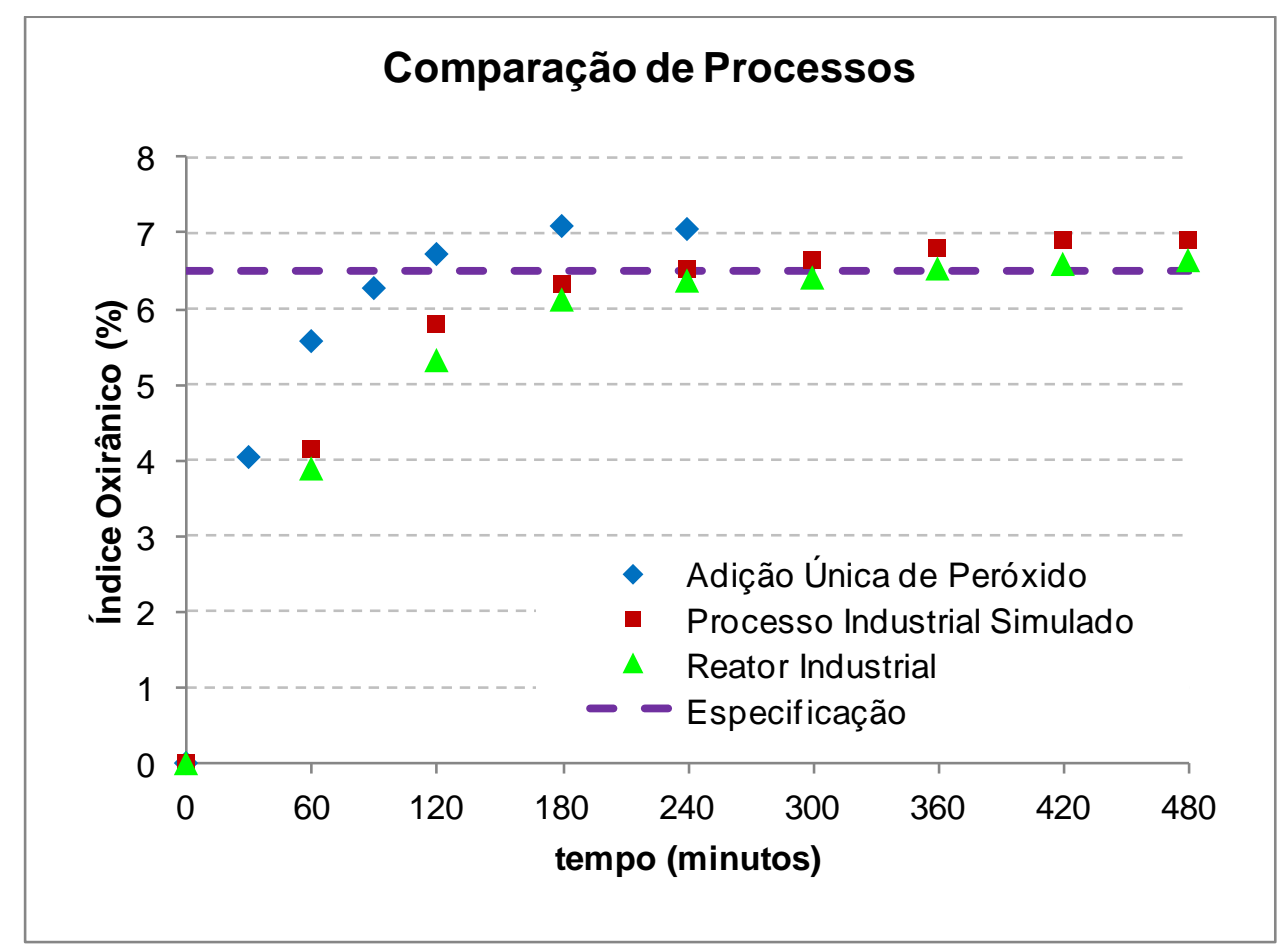

Figura 4.15 - Comparação da evolução de conversão - índice de lodo

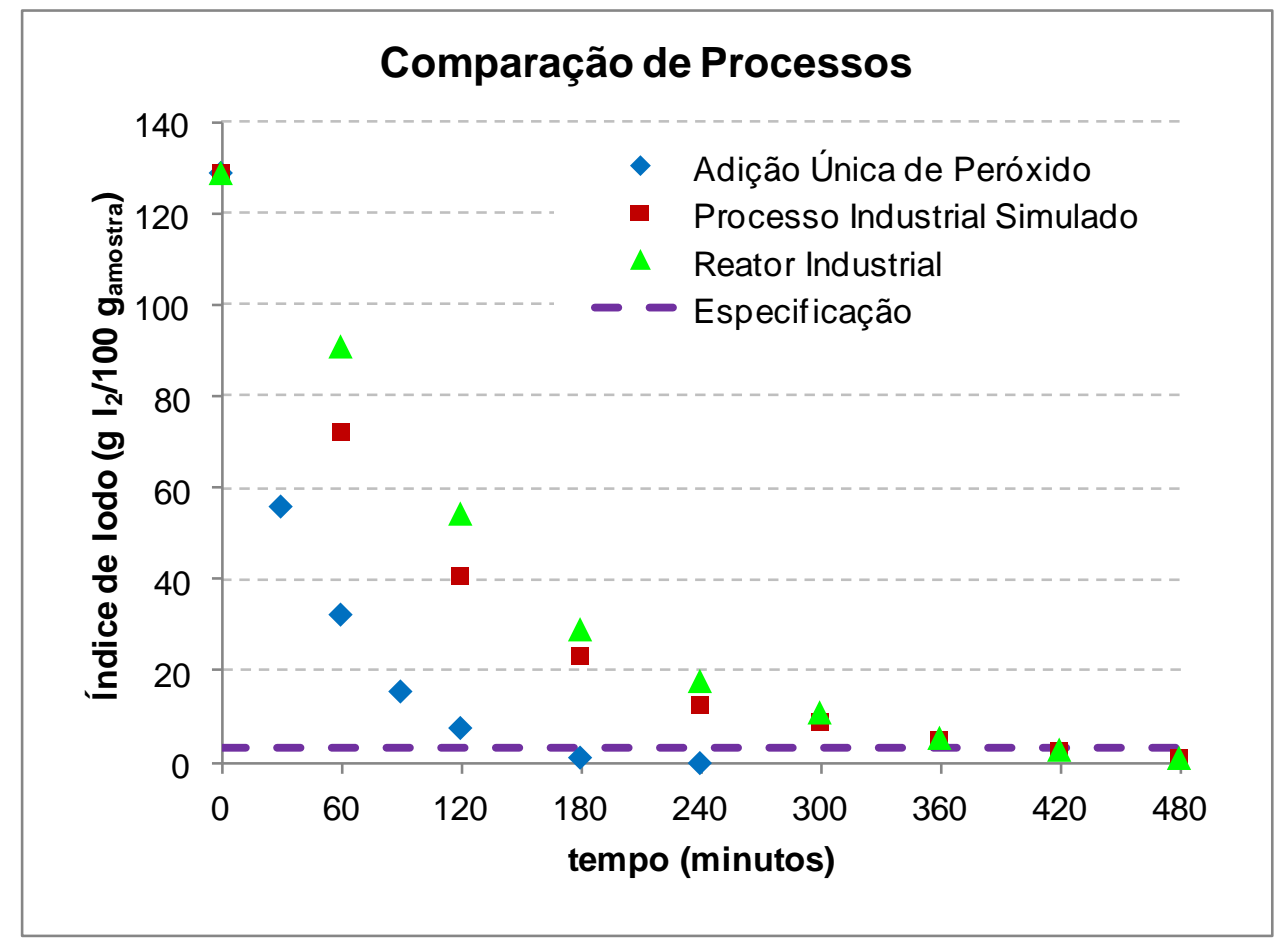




\subsubsection{Planejamento de experimentos}

Uma vez que foi possível verificar que não há risco da adição única de peróxido, foi realizado um conjunto de experimentos para avaliar o efeito da velocidade de agitação, das quantidades de ácido fórmico e de peróxido, e da temperatura de operação do reator. Neste estudo foi preparado um planejamento de experimentos, de forma a minimizar o número de ensaios necessários.

Para determinar os parâmetros, os ensaios anteriormente realizados ajudaram a definir pontos de amostragem e forma de coleta de dados para cada ensaio. O tempo de adição do peróxido foi de 30 segundos. O procedimento adotado está descrito no item 3.1.4.1, com duas alterações: (1) o reator foi mantido em capela com proteção de barreira física para garantir a segurança e evitar a necessidade de interromper a reação com água fria ao atingir $85^{\circ} \mathrm{C}$ como previsto no procedimento dos ensaios anteriores (essa medida foi tomada para poder observar os limites reais do sistema reacional nas condições do experimento); (2) os ensaios de conversão foram realizados com 4 horas de tempo total de reação, de forma a melhor evidenciar as diferenças de conversão obtidas.

Os experimentos foram realizados conforme planejamento fatorial de ensaios $2^{k}$ mostrado na Tabela 4.10.

As agitações de 200 e $400 \mathrm{rpm}$ anteriormente utilizadas buscavam simular as agitações encontradas em aplicações industriais, mas se mostraram demasiadamente baixas para garantir o controle da reação em situação de adição única de reagentes, principalmente se usada maior concentração de ácido fórmico. Com isso foram escolhidas para o planejamento fatorial agitações mais elevadas, de 500 e $1000 \mathrm{rpm}$, com o intuito de promover um melhor controle para todos as condições planejadas.

As concentrações escolhidas para o ácido fórmico foram um pouco acima e um pouco abaixo daquela usada tradicionalmente na indústria, para avaliar o efeito dessas mudanças num caso de reação com adição única de todos os componentes. Para o peróxido de hidrogênio, foram escolhidas as massas de adição igual à do uso comercial e uma menor, para avaliar a potencial melhora do desempenho da reação e consequente potencial redução da exigência de excesso desse reagente.

O planejamento de experimentos também contemplou duas temperaturas $\left(40^{\circ} \mathrm{C} \mathrm{e}\right.$ $60^{\circ} \mathrm{C}$ ) para avaliar as eventuais diferenças de comportamento da reação e dos 
fenômenos de transporte nessas condições. A temperatura menor que o utilizado na prática industrial foi selecionada para verificar se a adição única teria algum efeito positivo para essa condição.

Tabela 4.10 - Planejamento de experimentos para os ensaios.

\begin{tabular}{|c|c|c|c|c|}
\hline+ & 1000 rpm & $20 \mathrm{~g}$ & $100 \mathrm{~g}$ & $60^{\circ} \mathrm{C}$ \\
\hline- & 500 rpm & $10 \mathrm{~g}$ & $80 \mathrm{~g}$ & $40^{\circ} \mathrm{C}$ \\
\hline Ensaio & Agitação & Ácido Fórmico & Peróxido & Temperatura \\
\hline PE 01 & + & + & + & + \\
\hline PE 02 & + & + & + & - \\
\hline PE 03 & + & + & - & + \\
\hline PE 04 & + & + & - & - \\
\hline PE 05 & + & - & + & + \\
\hline PE 06 & + & - & + & - \\
\hline PE 07 & + & - & - & + \\
\hline PE 08 & + & - & - & - \\
\hline PE 09 & - & + & + & + \\
\hline PE 10 & - & + & + & - \\
\hline PE 11 & - & + & - & + \\
\hline PE 12 & - & + & - & - \\
\hline PE 13 & - & - & + & + \\
\hline PE 14 & - & - & + & - \\
\hline PE 15 & - & - & - & + \\
\hline PE 16 & - & - & - & - \\
\hline
\end{tabular}

\subsubsection{Experimentos de epoxidação planejados}

Uma vez determinado o planejamento, os experimentos foram realizados. Os resultados para $60^{\circ} \mathrm{C}$ estão sumarizados na Figura 4.16 e na Tabela 4.11.

Tabela 4.11 - Sumário dos experimentos planejados $\left(60^{\circ} \mathrm{C}\right)$

\begin{tabular}{|c|c|c|c|c|c|c|c|c|}
\hline & PE 01 & PE 03 & PE 05 & PE 07 & PE 09 & PE 11 & PE 13 & PE 15 \\
\hline Agitação (rpm) & 1000 & 1000 & 1000 & 1000 & 500 & 500 & 500 & 500 \\
\hline Fórmico (g) & 20 & 20 & 10 & 10 & 20 & 20 & 10 & 10 \\
\hline Peróxido (g) & 100 & 80 & 100 & 80 & 100 & 80 & 100 & 80 \\
\hline Temperatura máxima $\left({ }^{\circ} \mathrm{C}\right)$ & 98,7 & 92,8 & 62,9 & 65,4 & 150,2 & 152,3 & 66,8 & 68,6 \\
\hline Índice oxirânico final (\%) & 6,29 & 6,17 & 5,85 & 5,56 & $\mathrm{n} / \mathrm{a}$ & $\mathrm{n} / \mathrm{a}$ & 5,30 & 5,23 \\
\hline Índice de lodo final ( $\left.\mathrm{g} \mathrm{I}_{2} / 100 \mathrm{~g}\right)$ & 0,34 & 0,21 & 9,76 & 10,50 & $\mathrm{n} / \mathrm{a}$ & $\mathrm{n} / \mathrm{a}$ & 10,31 & 11,34 \\
\hline
\end{tabular}


Figura 4.16 - Sumário dos experimentos planejados $\left(60^{\circ} \mathrm{C}\right)$

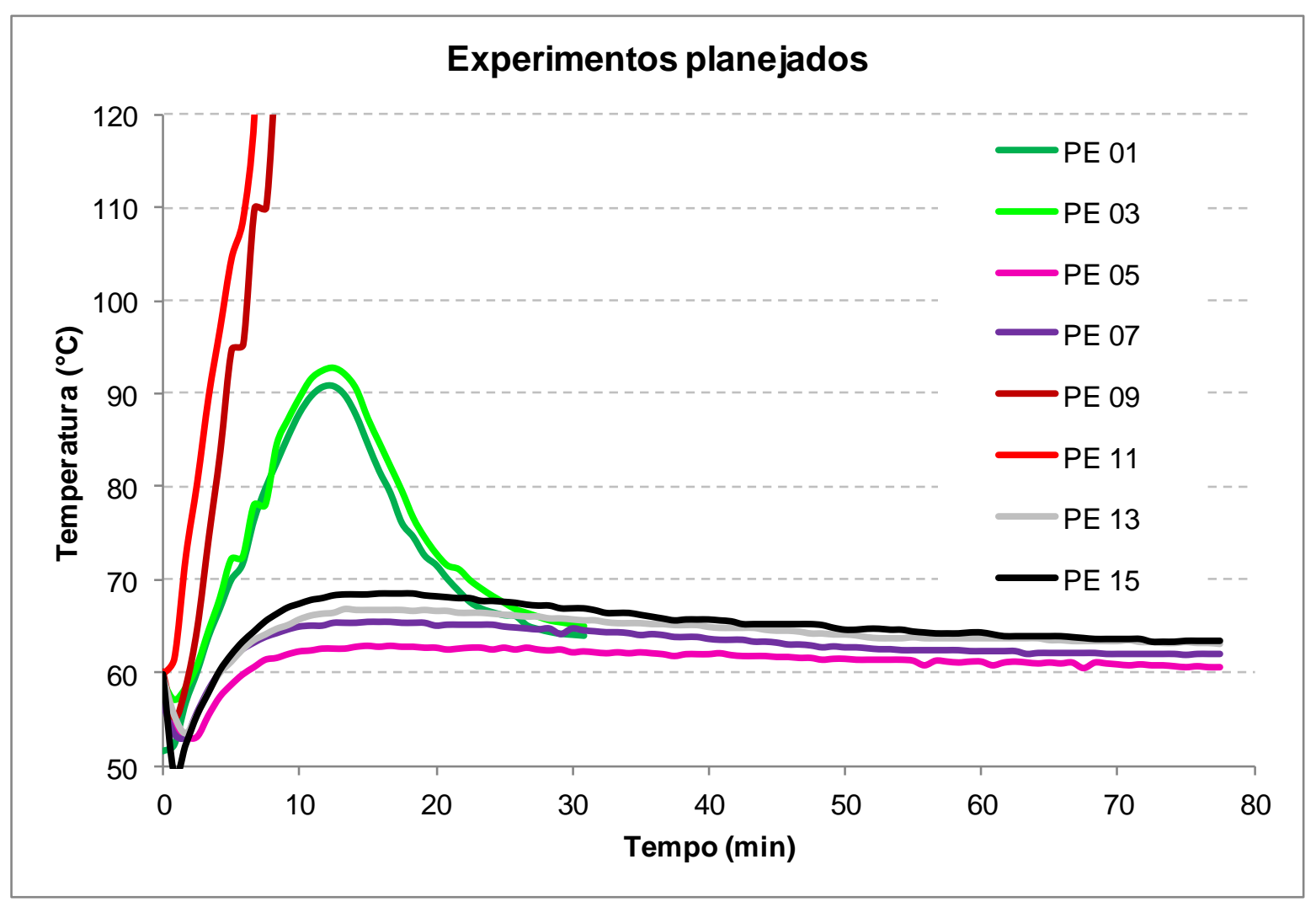

Nos experimentos 9 e 11 a reação saiu de controle. Nesses dois ensaios, a temperatura subiu rapidamente e a remoção de calor, ainda que elevada, não foi suficiente para controlar a reação de epoxidação e a degradação do peróxido. $O$ material foi ejetado pelas furações da tampa, com grande pressão e o experimento foi perdido. A temperatura máxima registrada foi de $150^{\circ} \mathrm{C}$.

Nos experimentos 1 e 3 a temperatura ultrapassou $85^{\circ} \mathrm{C}$, que é considerado o limite de segurança para o controle da reação. O sistema, porém, não chegou ao ponto de descontrole e a temperatura voltou ao nível inicial sem perda do experimento.

Pode-se notar que quanto maior a velocidade de rotação, menor a temperatura máxima atingida para uma mesma quantidade de reagentes. A comparação entre os experimentos 5 vs. 13 e entre 7 vs. 15 mostra esse efeito. Isso demonstra que a cinética de reação aumenta significativamente menos que o aumento da troca térmica com o aumento da agitação.

Os processos com maior quantidade de ácido fórmico provocaram um aumento mais rápido da temperatura e só puderam ser concluídos com 1000 rpm de rotação para o agitador, onde a troca térmica é maior. Houve também, maior quebra de anéis, 
indicados pelo nível baixo do índice de lodo associado a um nível não tão alto do índice oxirânico. Esse efeito era esperado, uma vez que o meio mais ácido favorece as reações secundárias de quebra dos anéis como discutido anteriormente.

Nos experimentos onde a quantidade de peróxido foi menor, o nível do índice de lodo ainda era alto ao atingir 4 horas, indicando que o excesso de peróxido contribui para a conversão mais rápida.

Nota-se também que os experimentos com menor nível de agitação apresentaram conversões menores em 4 horas, sugerindo que a transferência de massa foi um limitante significativo para a cinética aparente da reação.

Além disso, é interessante notar que menor quantidade de peróxido provocou um aumento maior de temperatura quando comparados experimentos com os demais parâmetros iguais em agitação maior. Esse efeito pode ser observado comparandose os experimentos 5 vs. 7 e 13 vs. 15 e 1 vs. 3 . Essas diferenças podem ter explicação na temperatura inicial menor ao adicionar mais peróxido (que entra a $25^{\circ} \mathrm{C}$ ), e também pelo efeito de viscosidade aumentada e, portanto, menor coeficiente de transferência de troca térmica do sistema.

Os experimentos realizados a $40^{\circ} \mathrm{C}$ estão sumarizados na Tabela 4.12 e na Figura 4.17 .

Tabela 4.12 - Sumário dos experimentos planejados $\left(40{ }^{\circ} \mathrm{C}\right)$

$\begin{array}{lcccccccc} & \text { PE 02 } & \text { PE 04 } & \text { PE 06 } & \text { PE 08 } & \text { PE 10 } & \text { PE 12 } & \text { PE 14 } & \text { PE 16 } \\ \text { Agitação }(\mathrm{rpm}) & 1000 & 1000 & 1000 & 1000 & 500 & 500 & 500 & 500 \\ \text { Fórmico }(\mathrm{g}) & 20 & 20 & 10 & 10 & 20 & 20 & 10 & 10 \\ \text { Peróxido }(\mathrm{g}) & 100 & 80 & 100 & 80 & 100 & 80 & 100 & 80 \\ \text { Temperatura máxima }\left({ }^{\circ} \mathrm{C}\right) & 46,0 & 47,8 & 41,0 & 41,4 & 49,3 & 49,7 & 42,9 & 43,2 \\ \text { Índice oxirânico }(\%) & 6,91 & 6,54 & 6,10 & 6,34 & 6,23 & 6,02 & 5,23 & 5,13 \\ \text { Índice de lodo } & 3,77 & 4,12 & 4,71 & 4,51 & 3,98 & 4,20 & 4,84 & 4,72\end{array}$

De forma semelhante ao que ocorreu nos experimentos realizados a $60^{\circ} \mathrm{C}$, as reações com maior quantidade de ácido fórmico apresentaram maiores temperaturas máximas (PE 02, PE04, PE10 e PE12). Nos experimentos a $40{ }^{\circ} \mathrm{C}$ foi também observado que os ensaios realizados com maior agitação produziram temperaturas máximas menores quando comparados aos ensaios com concentrações de componentes semelhantes. Também foi confirmado o efeito de maior temperatura máxima para os ensaios com menor quantidade de peróxido de hidrogênio comparados a ensaios com os demais parâmetros iguais. 
Figura 4.17 - Sumário dos experimentos planejados $\left(40^{\circ} \mathrm{C}\right)$

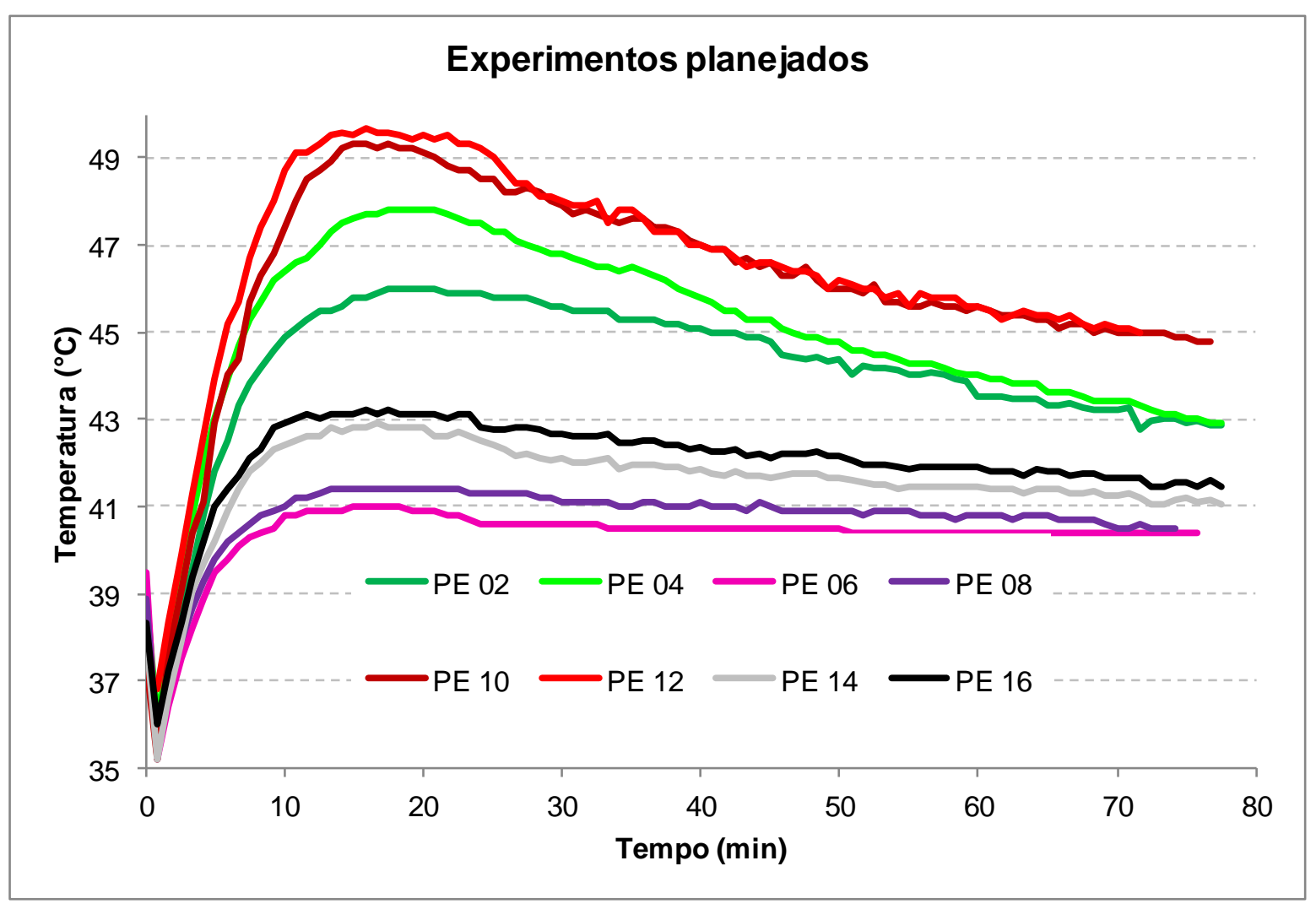

A diferença principal notada nos ensaios a $40^{\circ} \mathrm{C}$ quando comparado aos ensaios a $60^{\circ} \mathrm{C}$ foi a menor variação de temperatura em todos os casos. Isso seria esperado, pois o coeficiente de troca térmica é muito semelhante em ambas temperaturas, porém a cinética e consequente geração de calor da reação é significativamente reduzida. Justamente por essa redução da velocidade de reação, os resultados de conversão a $40^{\circ} \mathrm{C}$ são significativamente inferiores aos resultados obtidos a $60^{\circ} \mathrm{C}$. Ainda assim, a adição única permitiu atingir conversão melhor que os resultados obtidos em reatores industriais tradicionais trabalhando na temperatura de $60^{\circ} \mathrm{C}$. O experimento PE 02 mostra um resultado de Índice de lodo e Índice Oxirânico dentro das especificações do OSE com apenas 4 horas de reação. 


\subsection{Modelagem}

O modelo do processo foi preparado de acordo com as definições e metodologia descritos no item 3.2. Os parâmetros usados na simulação estão apresentados na Tabela4.13.

É importante notar que a modelagem deve considerar a variação do valor de coeficiente de troca térmica entre o meio reacional e o banho termo-controlado. $\mathrm{O}$ coeficiente $U$ vinha sendo considerado constante em modelagens anteriores encontradas na literatura. Essa variação do $U$ se mostrou bastante clara nos experimentos realizados. A viscosidade varia significativamente ao longo da reação, tanto pela variação de temperatura quanto pela mudança das concentrações dos componentes (que têm viscosidades bastante distintas) ao longo do processo. As medidas obtidas experimentalmente com misturas conhecidas indicam claramente que a composição da mistura reacional, a temperatura e a agitação têm influência significativa no coeficiente de troca térmica.

Não foi considerada a variação da tensão superficial dos componentes ao longo da reação. Mas foi possível considerar o ajuste do coeficiente de troca térmica no modelo ao longo do período da reação conforme a variação da viscosidade.

Foram usadas as curvas empíricas de viscosidade apresentadas na Figura 4.4, além dos dados de conversão obtidos para cada experimento apresentados nas Tabelas 4.11 e 4.12. Com esses dados, ajustando-se conforme os efeitos obtidos nos experimentos de viscosidade controlados (Tabela 4.7) e de variação de $U$ conforme os parâmetros do experimento e viscosidades observadas (Figura 4.2), prepararamse curvas de $U$ vs. tempo estimadas para cada reação. O cálculo consistiu em interpolar as viscosidades conforme os resultados experimentais apresentados na Figura 4.4, obtendo-se uma sequência de viscosidades estimadas para cada ponto de tempo do experimento de epoxidação. Com esses dados, foi usada a equação (15) para estimar o valor do coeficiente $U$ de em cada ponto de tempo, a partir do coeficiente $U_{0}$ obtido experimentalmente para cada caso conforme indicado na Tabela 4.2. Apenas para verificação, o valor de $U$ ao final da reação estimado com esses cálculos foi próximo dos valores do coeficiente $U$ obtidos para cada combinação de temperatura e agitação para a mistura de OSE e água (Tabela 4.2). Essa estimativa do coeficiente $U$ contempla o efeito combinado de tamanho de gotícula e viscosidade, uma vez que não foi realizado um estudo para observar 
esses efeitos de forma independente. Essa estimativa desconsidera o efeito das reações secundárias de quebra do anel, assumindo que os produtos dessas degradações são semelhantes ao óleo de soja epoxidado quanto ao seu efeito no coeficiente de troca térmica.

Tabela4.13 - Parâmetros e propriedades do modelo simplificado

\begin{tabular}{|c|c|c|c|c|}
\hline Parâmetro & Descrição & Valor & Unidade & Fonte \\
\hline$\% \mathrm{H}_{2} \mathrm{O}_{2}$ & fração mássica de $\mathrm{H}_{2} \mathrm{O}_{2}$ em água & $60 \%$ & $g / g$ & - \\
\hline $\mathrm{m} 2$ & massa de $\mathrm{H}_{2} \mathrm{O}_{2}$ adicionado & Variável & $g$ & Conforme experimento \\
\hline Cp2 & calor específico $\mathrm{H}_{2} \mathrm{O}_{2}$ & 0,628285 & $\mathrm{cal} / \mathrm{g} /{ }^{\circ} \mathrm{C}$ & TURCO, R., 2011 \\
\hline T10 & temperatura inicial do $\mathrm{H}_{2} \mathrm{O}_{2}$ & 25 & ${ }^{\circ} \mathrm{C}$ & - \\
\hline Mw2 & massa molar $\mathrm{H}_{2} \mathrm{O}_{2}$ & 34 & $\mathrm{~g} / \mathrm{mol}$ & - \\
\hline dens2 & densidade do $\mathrm{H}_{2} \mathrm{O}_{2}$ & 1,42 & $\mathrm{~g} / \mathrm{cm}^{3}$ & www.h2o2.com \\
\hline V2 & volume de $\mathrm{H}_{2} \mathrm{O}_{2}$ adicionado & Variável & $\mathrm{cm}^{3}$ & Calculado \\
\hline $\mathrm{N} 2$ & numero de mols de $\mathrm{H}_{2} \mathrm{O}_{2}$ & Variável & $\mathrm{mol} \mathrm{H}_{2} \mathrm{O}_{2}$ & Calc. conforme experim. \\
\hline $\mathrm{m} 1$ & massa de óleo de soja inicial & 250 & $\mathrm{G}$ & - \\
\hline Cp1 & calor específico do óleo de soja & 0,425227 & $\mathrm{cal} / \mathrm{g} /{ }^{\circ} \mathrm{C}$ & TURCO, R., 2011 \\
\hline T20 & temp. inicial do óleo de soja & 60 & ${ }^{\circ} \mathrm{C}$ & - \\
\hline Mw1 & massa molar óleo de soja & 864 & $\mathrm{~g} / \mathrm{mol}$ & www.biodiesel.org \\
\hline dens1 & densidade do óleo & 0,923 & $\mathrm{~g} / \mathrm{cm} 3$ & - \\
\hline R1 & $\mathrm{mol} \mathrm{C}=\mathrm{C} / \mathrm{mol}$ óleo & 4,8 & $\mathrm{~mol} / \mathrm{mol}$ & - \\
\hline V1 & volume de óleo & 270,8559 & $\mathrm{~cm}^{3}$ & - \\
\hline $\mathrm{N} 1$ & numero de mols de $\mathrm{C}=\mathrm{C}$ & 1,333333 & $\mathrm{~mol} \mathrm{C}=\mathrm{C}$ & - \\
\hline m3 & massa ac.fórmico & Variável & $g$ & Conforme experimento \\
\hline Cp3 & calor especifico ac. fórmico & 0,642618 & $\mathrm{cal} / \mathrm{g} /{ }^{\circ} \mathrm{C}$ & TURCO, R., 2011 \\
\hline Mw3 & massa molar do ac. fórmico & 46 & $\mathrm{~g} / \mathrm{mol}$ & - \\
\hline dens3 & densidade do ac. fórmico & 1,21 & $\mathrm{~g} / \mathrm{cm}^{3}$ & www.sciencelab.com \\
\hline V3 & volume de ac. Fórmico & Variável & $\mathrm{cm}^{3}$ & Calc. conforme experim. \\
\hline N3 & mols de ac. Fórmico & Variável & Mol & Calc. conforme experim. \\
\hline $\mathrm{V}$ & volume total no reat or & Variável & $\mathrm{L}$ & Calc. conforme experim. \\
\hline To & temperatura inicial após mistura & Variável & ${ }^{\circ} \mathrm{C}$ & Calc. conforme experim. \\
\hline $\mathrm{k}_{\mathrm{ap}, \mathrm{o}}$ & fator de freq aparente & $1,70 \mathrm{E}-02$ & $\mathrm{~L} / \mathrm{mol} / \mathrm{min}$ & $\begin{array}{l}\text { SANTACESARIA et al. } \\
2010\end{array}$ \\
\hline$E$ & energia de ativação ap & 18,3 & $\mathrm{Kcal} / \mathrm{mol}$ & $\begin{array}{l}\text { SANTACESARIA et al. } \\
2010\end{array}$ \\
\hline$\Delta \mathrm{H}$ & entalpia de reação & -47000 & $\mathrm{cal} / \mathrm{mol}$ & Experimental \\
\hline UA & coef. $\mathrm{TC}^{*}$ área $\mathrm{TC}$ & variável & $\mathrm{cal} / \mathrm{min} /{ }^{\circ} \mathrm{C}$ & $\begin{array}{l}\text { Experimental - baseado } \\
\text { na curva de estimativas } \\
\text { de cada experimento }\end{array}$ \\
\hline $\mathrm{C}_{20}$ & conc. inicial $\mathrm{C}=\mathrm{C}$ (após mix) & 3,63614 & $\mathrm{~mol} / \mathrm{L}$ & - \\
\hline $\mathrm{C}_{10}$ & conc. inicial $\mathrm{H}_{2} \mathrm{O}_{2}$ (após mix) & variável & $\mathrm{mol} / \mathrm{L}$ & Calc. conforme experim. \\
\hline $\mathrm{C}_{\text {formico }}$ & conc. Inicial ac. fórmico & variável & $\mathrm{mol} / \mathrm{L}$ & Calc. conforme experim. \\
\hline
\end{tabular}


Conforme discutido anteriormente, os parâmetros cinéticos da reação foram obtidos considerando-se que as reações na fase aquosa e as transferências de massa são muito rápidas e não foram explicitamente consideradas.

A Figura 4.18 mostra a comparação dos dados experimentais de temperatura medidos durante um experimento com os resultados do modelo em que 0 valor 0 coeficiente $U$ foi considerado constante e com os resultados do modelo quando se considera que o valor de $U$ varia, conforme descrito anteriormente. Foi usado 0 experimento com $250 \mathrm{~g}$ de óleo, $15 \mathrm{~g}$ de ácido fórmico, $100 \mathrm{~g}$ de peróxido, com agitação de $1000 \mathrm{rpm}$ e temperatura de $60^{\circ} \mathrm{C}$.

Figura 4.18 - Comparação de modelos - U variável e U constante

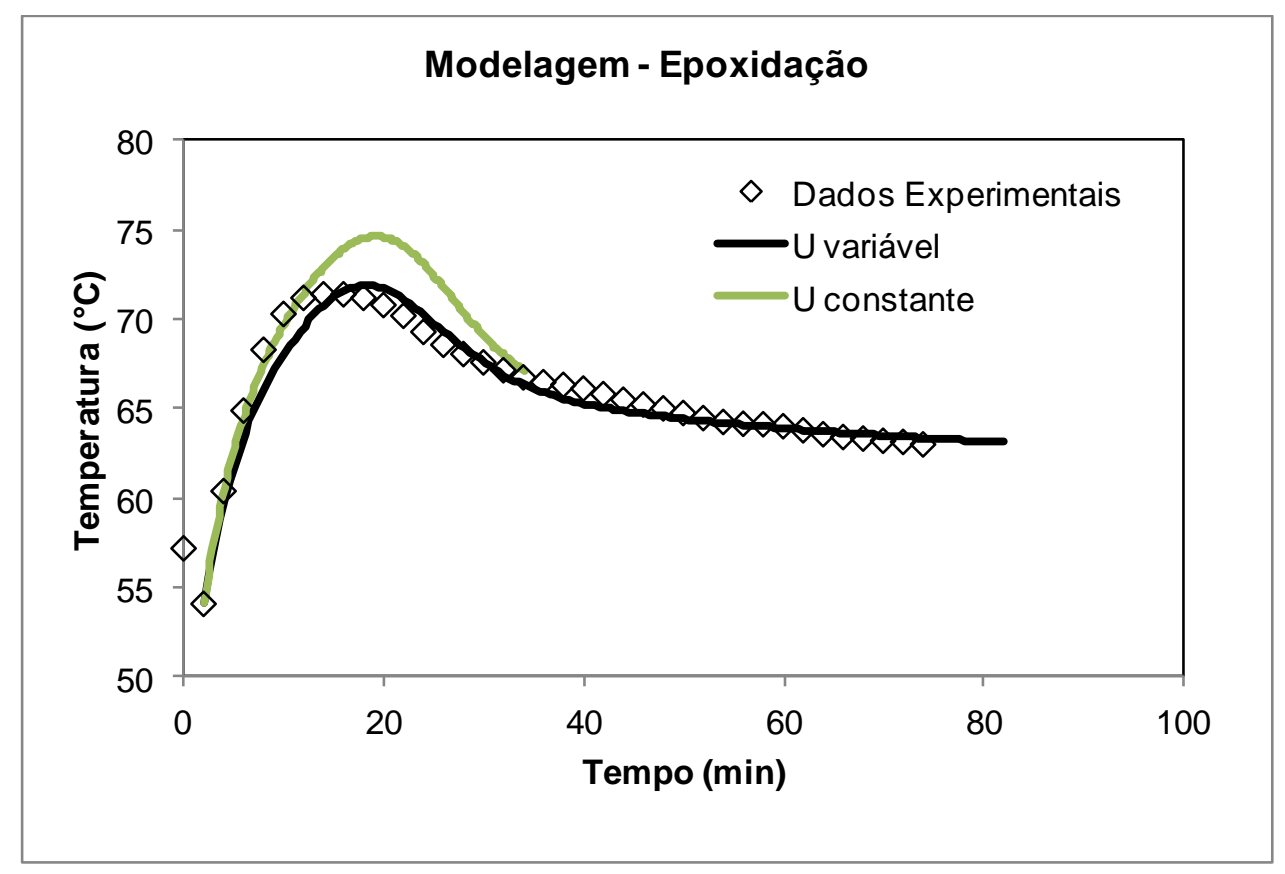

Apesar de pequenas diferenças, fica evidente que o modelo que contempla a variação do $U$ tem melhor ajuste à curva de dados experimentais.

Ainda não há um ajuste perfeito da curva do modelo aos dados experimentais, o que sugere que outros parâmetros devem ser estudados com maior profundidade, incluindo o modelo completo da reação, com as reações secundárias e os fluxos de transferência de massa.

Esse problema de ajuste fica mais evidente nas reações dos experimentos planejados, onde as condições de operação têm parâmetros mais extremos.

As figuras 4.19 e 4.20 mostram as discrepâncias para os dois extremos: onde o modelo prevê um descontrole da reação, que na prática não ocorre u - experimento 
PE01 - e outro onde o modelo mostra um perfil de temperaturas bem mais baixo que os dados práticos - experimento PE16.

Figura 4.19 - Comparação entre dados experimentais e modelo - PE01

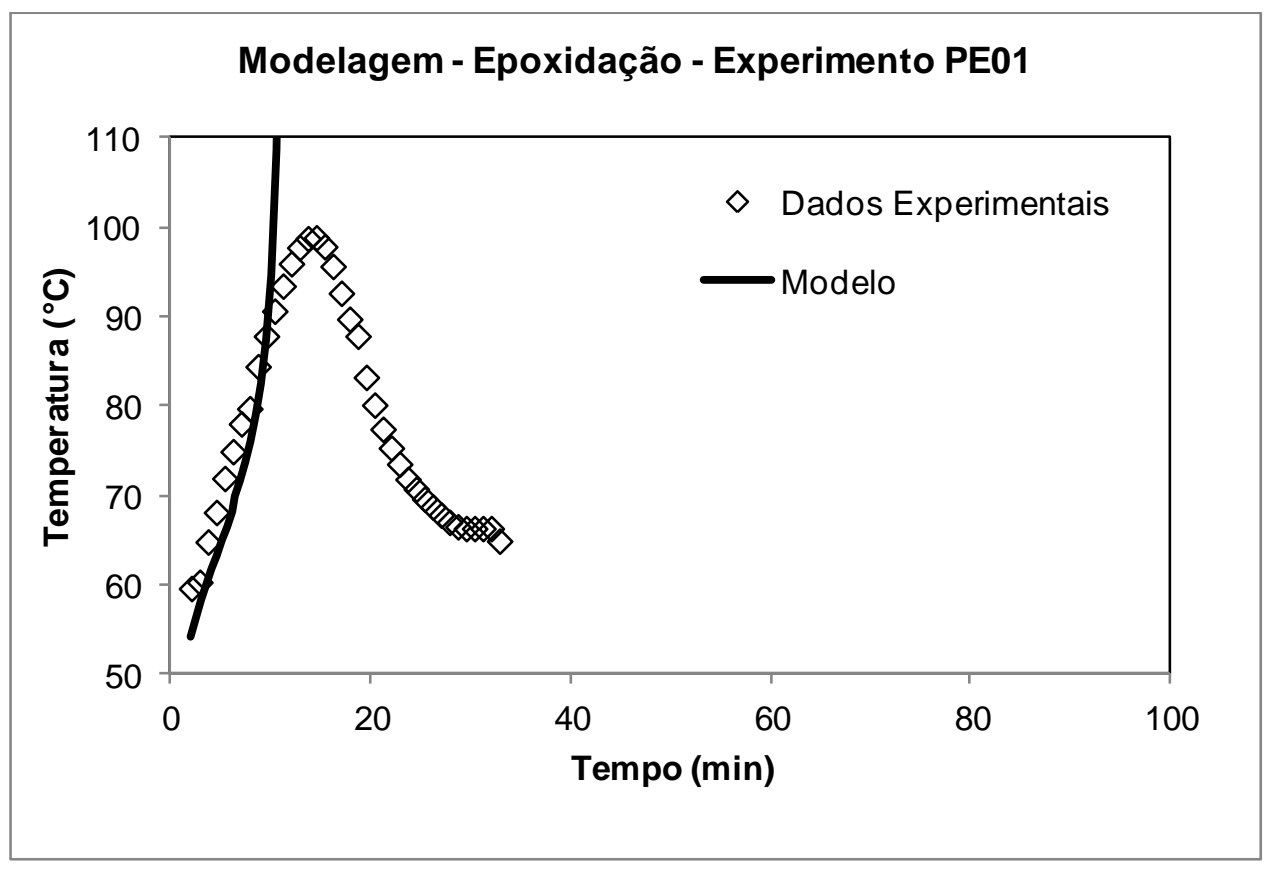

Figura 4.20 - Comparação entre dados experimentais e modelo - PE16

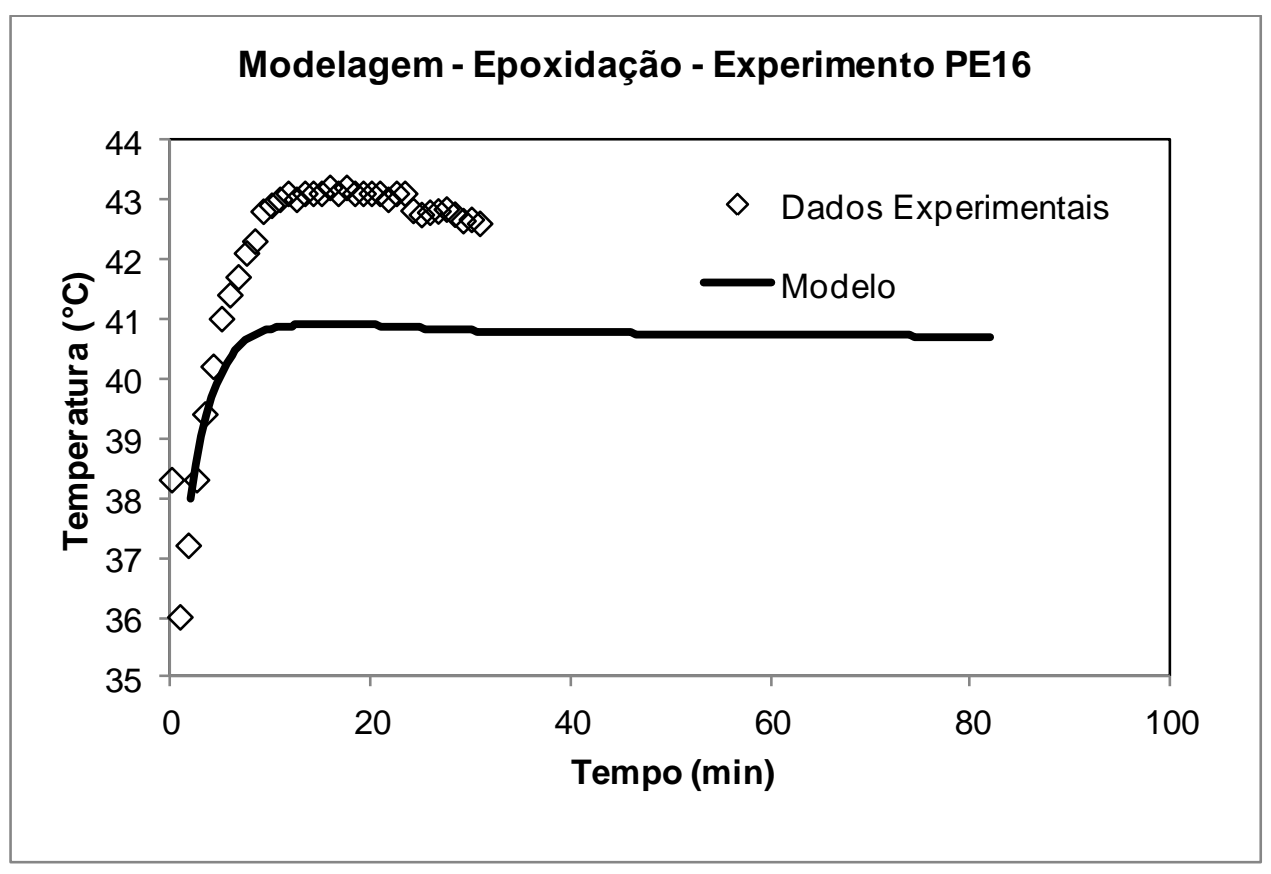


Para avaliar as diferenças entre o modelo e os resultados experimentais foram ajustadas as curvas através da alteração artificial da energia de ativação (E), como mostrado no exemplo da Figura 4.21. Os gráficos com todos os 14 modelos dos experimentos planejados ajustados encontram-se no Apêndice I. A energia de ativação foi escolhida para realizar os ajustes por ser uma forma simplificada de combinar os possíveis efeitos de divergência entre modelo e dados experimentais, como a transferência de massa e as reações secundárias em um só parâmetro (e por ser um dos parâmetros de maior sensibilidade sobre as respostas do modelo).

É importante notar que a variação de $U$ foi considerada para todas as simulações mostradas a seguir, de acordo com o perfil de temperaturas, a conversão ao longo do tempo e a agitação estabelecida.

Figura 4.21 - Comparação entre modelo e dados experimentais, com ajuste

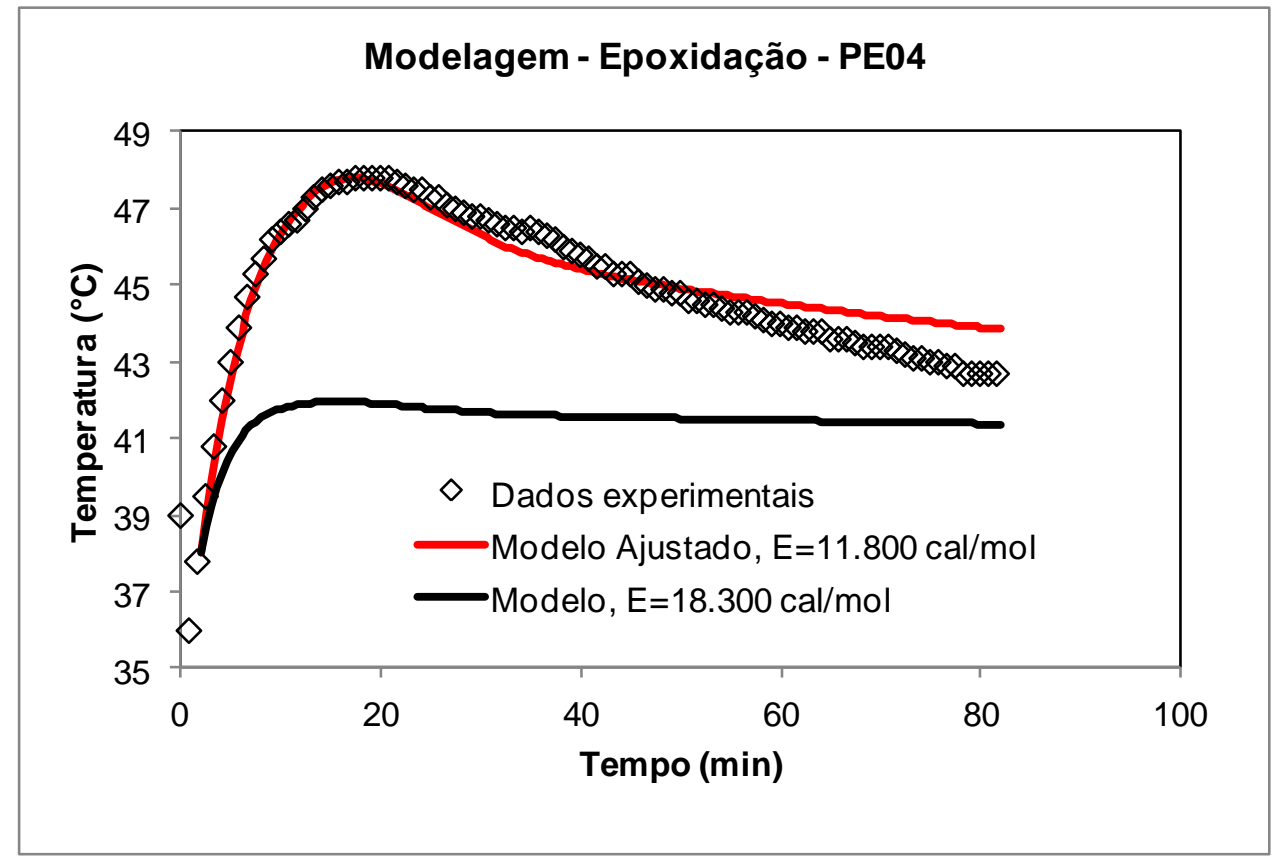

Nota-se que, mesmo com o ajuste, a curva do modelo ainda não apresenta um perfil totalmente compatível com os dados experimentais.

A Tabela 4.14 mostra os diversos valores de energia de ativação encontrados para o melhor ajuste da curva experimental ao modelo para todos os experimentos planejados. As curvas referentes ao ajuste de cada um dos ensaios estão apresentadas no Apêndice I. 
Tabela 4.14 - Comparação de ajustes dos modelos aos dados experimentais

\begin{tabular}{lccccc}
\hline & $\begin{array}{c}\text { Peróxido } \\
(\mathbf{g})\end{array}$ & $\begin{array}{c}\text { Fórmico } \\
(\mathbf{g})\end{array}$ & $\begin{array}{c}\text { Rotação } \\
(\mathbf{r p m})\end{array}$ & $\begin{array}{c}\text { Temperatura } \\
\left({ }^{\circ} \mathbf{C}\right)\end{array}$ & $\begin{array}{c}\text { E } \\
(\mathbf{c a l} / \mathbf{m o l})\end{array}$ \\
Simulação PE01 & 100 & 20 & 1000 & 60 & 10.350 \\
Simulação PE03 & 80 & 20 & 1000 & 60 & 8.700 \\
Simulação PE05 & 100 & 10 & 1000 & 60 & 40.000 \\
Simulação PE07 & 80 & 10 & 1000 & 60 & 30.000 \\
Simulação PE13 & 100 & 10 & 500 & 60 & 23.000 \\
Simulação PE15 & 80 & 10 & 500 & 60 & 20.500 \\
Simulação PE02 & 100 & 20 & 1000 & 40 & 13.000 \\
Simulação PE04 & 80 & 20 & 1000 & 40 & 11.800 \\
Simulação PE06 & 100 & 10 & 1000 & 40 & 21.000 \\
Simulação PE08 & 80 & 10 & 1000 & 40 & 17.000 \\
Simulação PE10 & 100 & 20 & 500 & 40 & 10.000 \\
Simulação PE12 & 80 & 20 & 500 & 40 & 10.200 \\
Simulação PE14 & 100 & 10 & 500 & 40 & 12.500 \\
Simulação PE16 & 80 & 10 & 500 & 40 & 12.000 \\
\hline
\end{tabular}

Os experimentos PE09 e PE11 não foram submetidos ao modelo devido à perda de controle da reação nos ensaios práticos.

Observa-se que na maioria dos casos a energia de ativação teve que ser corrigida para valores menores dos originais $18.300 \mathrm{cal} / \mathrm{mol}$ apresentados na literatura (SANTACESARIA et al., 2010). Há uma série de experimentos, 7 de 14, onde a correção fica na faixa de 10.000 a $13.000 \mathrm{cal} / \mathrm{mol}$. Apenas 1 experimento teve resultado abaixo de $10.000 \mathrm{cal} / \mathrm{mol}$.

A faixa ficou próxima do valor original, entre 17.000 e $23.000 \mathrm{cal} / \mathrm{mol}$ em 4 experimentos.

Apenas dois experimentos apresentaram ajuste maior que $23.000 \mathrm{cal} / \mathrm{mol}$.

A variável da quantidade total de peróxido $60 \%$ foi o que menos teve efeito na comparação entre modelos ajustados. $\mathrm{O}$ ajuste do modelo foi realmente influenciado de forma significativa pelas três outras variáveis do planejamento de experimentos. Temperatura e agitação, como foi discutido anteriormente, têm influência no tamanho de gotícula, e consequentemente influência potencial nas taxas de transferência de massa, que não é levada em conta no modelo. 
A quantidade de ácido fórmico também influenciou de maneira significativa. Isso pode ser atribuído a reações secundárias que não foram consideradas na cinética utilizada para a modelagem, que partiu de dados da literatura baseados em experimentos realizados com a concentração ideal de ácido fórmico (proporção mássica 1000:400:60 de óleo de soja, peróxido $60 \%$ e ácido fórmico $85 \%$ ).

$O$ fato de que o modelo simplificado requerer ajuste de parâmetros específicos para cada ensaio indica que o ajuste deste parâmetro está compensando outras simplificações adotadas no modelo. Dessa forma, isto claramente aponta para a necessidade de um esforço adicional para desenvolver um modelo matemático para este processo que não seja excessivamente simplificado como é o modelo aqui proposto. O modelo mais sofisticado deveria levar em conta de maneira explícita as complexidades inerentes a este processo, tais como a presença de duas fases, a transferência de massa de reagentes entre as fases, a presença de reações secundárias de degradação dos anéis oxirânicos. O desenvolvimento de tal modelo mais rigoroso e sofisticado está além do escopo do presente trabalho, mas os dados experimentais aqui obtidos podem ser de grande utilidade para 0 aperfeiçoamento do modelo e sua validação em condições operacionais mais amplas e variadas do que aquelas tipicamente usadas nos processos industriais convencionais. 


\section{CONCLUSÕES E RECOMENDAÇÕES}

\subsection{Conclusões}

Os ensaios e cálculos realizados demonstram que a proposta de adição única de todos os componentes é viável e apresenta vantagens para uma reação de epoxidação do óleo de soja com peróxido de hidrogênio e ácido fórmico, sem uso de catalisadores inorgânicos. A intensificação da troca de calor se apresentou como um caminho adequado para a intensificação desse processo reacional, reduzindo significativamente o tempo total de reação e melhorando a qualidade final do óleo de soja epoxidado.

O estudo mostrou que a adição gradual do peróxido é uma exigência apenas se a remoção do calor gerado pelo sistema reacional for insuficiente. No sistema proposto, a intensificação da remoção de calor permitiu a adição única de todos os componentes em diversas condições de operação e com diversas concentrações de reagentes. Apenas em duas condições mais extremas o sistema fugiu do controle.

Além da viabilidade, os estudos demonstraram que existem vantagens significativas com a adição única de componentes. O processo atingiu as especificações do óleo de soja epoxidado em menos da metade do tempo usual observado em operações industriais. Isso aponta para uma maior produtividade do processo e sugere que o investimento inicial em reatores pode ser reduzido. Além disso, o produto final apresentou qualidade superior a produtos comerciais, uma vez que as reações de formação do perácido e da formação do anel oxirânico ocorrem durante tempo total reduzido quando comparadas aos processos industriais atuais e reduz a exposição desses anéis oxirânicos às reações degradação que ocorrem em paralelo, confirmando a expectativa teórica desse efeito. Como vantagem de projeto, o sistema com adição única sugere a possibilidade de um controle mais simplificado do processo, uma vez que seria possível controlar o sistema apenas pela temperatura, sem necessidade de controles adicionais de agitação e dosagem do peróxido.

Ficou claro pelos experimentos realizados que a redução do tempo total de reação é limitada pela capacidade de remoção de calor do sistema. Isso confirma a suspeita inicial de que o caminho para melhorar a velocidade da epoxidação do óleo de soja em sistemas industriais está na intensificação da troca térmica. 
Os ensaios mostraram que a proporção de componentes (1000:400:60 de óleo de soja, peróxido de hidrogênio 60 \% e ácido fórmico 85 \%) hoje usada na indústria está muito próxima do valor ideal, uma vez que promove a velocidade adequada da reação e evita a quebra de anéis pelas reações de degradação. A temperatura de reação em $60^{\circ} \mathrm{C}$ (prática na indústria) proporcionou velocidade suficiente para obter OSE dentro da especificação em 3 horas. Isso sugere que a temperatura de processo hoje utilizada na indústria seria ideal. Porém, os ensaios (experimentos PE01 e PE03) mostraram que a reação não fugiu do controle mesmo ao chegar a temperaturas próximas de $100^{\circ} \mathrm{C}$, ao contrário do limite prático de $85^{\circ} \mathrm{C}$ adotado. Além de não haver perda de controle, o produto final obtido dessa reação que atingiu cerca de $100^{\circ} \mathrm{C}$ ficou com qualidade adequada, melhor até que os produtos comerciais disponíveis. Isso sugere que em condição de intensificação da troca térmica, temperaturas maiores de processo podem ser exploradas, potencialmente promovendo uma redução ainda maior do tempo de reação.

Os ensaios planejados, considerando a avaliação do efeito de quatro variáveis de operação (agitação, temperatura, ácido fórmico e peróxido), foram realizados e os dados de perfil de temperaturas foram comparados com o modelo matemático simplificado do processo que foi desenvolvido, gerando perfis calculados de temperatura ao longo da reação a partir dos parâmetros do processo.

Ficou claro pelos experimentos realizados que o coeficiente de troca térmica varia significativamente ao longo da reação. Com isso, a variação do coeficiente de troca térmica foi incluída no modelo para promover maior confiabilidade. O estudo apresentou resultados empíricos de $U$ e de viscosidade em diversas condições de operação e concentração de reagentes, permitindo que uma estimativa dos diversos valores de $U$ ao longo das reações dos ensaios planejados pudesse ser realizada.

Para o estudo da variação do coeficiente de troca térmica, foi necessário avaliar as variações de viscosidade aparente da mistura reacional, e para tanto foi desenvolvido um dispositivo simples, que se mostrou capaz de fornecer as medições experimentais da viscosidade aparente durante a reação.

Apesar de haver um bom ajuste para o ensaio com as proporções de reagentes normalmente adotadas pela indústria, foi observado que, mesmo com o ajuste de $U$, o modelo proposto não reflete de maneira adequada o perfil de temperaturas da maioria dos demais ensaios práticos, exigindo ajustes de parâmetros adicionais. De 
forma geral, porém, o modelo proposto permite uma avaliação parcial, não antes considerada, do comportamento da reação em diversas condições de operação e adição única de componentes.

Assim, as principais conclusões e contribuições do presente trabalho podem ser resumidas como segue:

(a) O presente trabalho mostrou que o processo de epoxidação de óleo de soja usando ácido fórmico e peróxido de hidrogênio, realizado industrialmente na forma de alimentações intermitentes, pode ser realizado sob condições de adição única de reagentes se o sistema de troca térmica for adequado;

(b) O processo realizado com adição única apresenta vantagens de menor tempo de processamento (o que representa maior produtividade) e menor degradação dos anéis oxirânicos (o que representa uma melhor qualidade do produto);

(c) Foi verificado que o coeficiente de troca térmica varia durante o processo e foi estudada a maneira pela qual este coeficiente varia, como função da temperatura do processo, da velocidade de rotação do agitador e das variações da viscosidade aparente da mistura reacional;

(d) Foi desenvolvido um dispositivo simples de viscosimetria capilar para uso acoplado ao reator, capaz de realizar medições da viscosidade aparente da mistura reacional durante o processo;

(e) Foi desenvolvido um modelo matemático simplificado, pseudo-homogêneo, para o processo de epoxidação de óleo de soja, que incorpora as variações de coeficiente de transferência de calor, mas que, por suas simplificações, ainda requer ajuste de parâmetros específicos, refletindo a necessidade de inclusão de maior detalhamento da descrição dos fenômenos de reação e transferência de massa entre as fases. 


\subsection{Recomendações}

A possibilidade de utilização de sistemas reacionais alternativos, como o ácido acético em substituição ao ácido fórmico, ou a adoção de catalisadores alternativos, oferece uma questão que merece ser explorada futuramente para a reação com adição única de componentes e intensificação da troca de calor.

Apesar do modelo proposto não ser completo e exigir ajustes, os dados experimentais obtidos podem ser levados em consideração para obter curvas de resposta empíricas que seriam úteis na simulação de processos, respeitando-se os limites dos experimentos realizados. Essa simulação poderia ser instrumental para a elaboração de projetos de reatores contínuos, com vasos em série ou mesmo de fluxo, que podem resultar em processos inovadores que utilizam a adição única de todos os componentes. $O$ desenho de um reator contínuo de fluxo acrescentaria às vantagens já citadas uma significativa melhora da segurança de processos, uma vez que minimizaria o risco de explosão ou de expansão repentina do meio reacional.

Novos estudos podem ser considerados para aprofundar e aperfeiçoar a modelagem do processo, incluindo a aplicação do modelo completo, com todas as reações envolvidas, suas cinéticas e entalpias, a variação do $c_{p}$ da mistura reacional e os efeitos de transporte de massa resultantes da variação de viscosidades e tamanho de gotícula em suspensão. Os resultados experimentais obtidos no presente trabalho sob diferentes condições operacionais poderiam ser úteis para a validação do modelo completo a ser desenvolvido. 
AKSE, H.; BEEK, W. J.; VAN BERKEL, F; DE GRAAUW, J. The local heat transfer at the wall of a large vessel agitated by turbine impellers. Chemical Engineering Science. 22.2, 1967, p. 135-146.

CAMPANELLA, A.; BALTANÁS, M. A. Degradation of the oxirane ring of epoxidized vegetable oils in liquid-liquid systems: Hydrolysis and attack by H2O2. Bahía Blanca: Lat. Am. appl. res. v.35 n.3, 2005.

CAMPANELLA, A.; FONTANINI, C.; BALTANÁS, M. A. High yield epoxidation of fatty acid methyl esters with performic. Chemical Engineering Journal, 2008, p. 466-475.

CHAVAN, V. P.; PATWARDHAN, A. V.; GOGATE, P. R. Intensification of epoxidation of soybean oil using sonochemical reactors. Chemical Engineering and Processing: Process Intensification 54, 2012, p. 22-28.

CHENG, W.; LIU, G.; WANG, X.; LIU, X.; JING, L. Kinetics of the epoxidation of soybean oil with $\mathrm{H} 2 \mathrm{O} 2$ catalyzed by phosphotungstic heteropoly acid in the presence of polyethylene glycol. European Journal of Lipid Science and Technology, 2015.

CHUANSHANG, $C$ et al. Studies on the kinetics of in situ epoxidation of vegetable oils. School of Chemistry and Environment, South China Normal University, Guangzhou, 2007.

DI SERIO, M.; TURCO, R.; PERNICE, P.; ARONNE, A.; SANNINO, F.; SANTACESARIA. Valuation of $\mathrm{Nb}_{2} \mathrm{O}_{5}-\mathrm{SiO}_{2}$ catalysts in soybean oil epoxidation. Catalysis Today 192.1, 2012, p. 112-116.

DIECKELMANN, G.; ECKWERT, K.; JEROMIN, L.; PEUKERT, E.; STE INBERNER, $U$. Continuous process for the catalytic epoxidation of olefinic double bonds with hydrogen peroxide and formic acid. Patente USA 4,584,390. Alemanha, 1986.

DINDA, S.; PATWARDHAN, A. V.; GOUD, V. V.; PRADHAN, N. C. Epoxidation of cottonseed oil by aqueous hydrogen peroxide catalysed by liquid inorganic acids. Bioresource technology 99.9, 2008, p. 3737-3744.

ENGESKAUG, R.; THORBJORNSEN, E.; SVENDSEN, H.F. Wall Heat Transfer in Stirred Tank Reactors, Ind. Eng. Chem. Res., 2005, 44 (14), pp 4949-4958.

ESTEBAN, B.; RIBA, J. R.; BAQUERO, G.; RIUS, A.; PUIG, R. Temperature dependence of density and viscosity of vegetable oils. Biomass and Bioenergy 42, 2012, p. 164-171.

GREENSPAN, F.; GALL, F. In situ epoxidation of organic esters with sulfuric and acetic acids. Patente USA 2,801,253. San Jose, CA, USA, 1957.

HAN, L.J. et al. Ultrasound-assisted epoxidation of soybean oil catalyzed by stearic acid. China Oils and Fats, 2010a.

HAN, L.J. et al. Preparation of epoxidized soybean oil catalyzed by sulfuric acid under ultrasonic conditions. Journal of Henan University of Technology (Natural Science Edition), $2010 \mathrm{~b}$. 
HANG, X.; YANG, $\mathrm{H}$ Model for a cascade continuous epoxidation process Journal of the American Oil Chemists' Society, Vol 76, no. 1, 1999

HE, X. P.; DENG, X.; WANG, S. S.; XIONG, J.; GU, Y. X. Catalytic epoxidation of soybean oil methyl esters. Advanced Materials Research. Vol. 396, 2012.

HE, W.; FANG, Z.; JI, D.; CHEN, K.; WAN, Z.; LI, X.; GUO, K. Epoxidation of Soybean Oil by Continuous Micro-Flow System with Continuous Separation. Organic Process Research \& Development, 2013, p. 1137-1141.

JIANG, J.; ZHANG, Y.; YAN, L.; JIANG, P. Epoxidation of soybean oil catalyzed by peroxo phosphotungstic acid supported on modified halloysite nanotubes. Applied Surface Science 258.17 , 2012, P. 6637-6642.

JOURDAN-LAFORTE, E. Process of epoxidation of oils. U.S. Patent No. 4,215,058, 1980.

KARMALM, P.; HJERTBERG, T.; JANSSON, A.; DAHL, R. Thermal stability of poly (vinyl chloride) with epoxidised soybean oil as primary plasticizer. Polymer Degradation and Stability 94.12, 2009, p. 2275-2281.

KRALISCH, D.; STRECKMANN, I.; OTT, D.; KRTSCHIL, U.; SANTACESARIA, E.; DI SERIO, M.; HESSEL, V. Transfer of the epoxidation of soybean oil from batch to flow chemistry guided by cost and environmental issues. ChemSusChem 5.2, 2012, p. 300-311.

LA SCALA, J.; WOOL, R. P. Effect of FA Composition on Epoxidation Kinetics of TAG. Journal of the American Oil Chemists' Society, Vol. 9, no 5, 2002.

LEHNEN, D. R.; GUZATTO, R.; DEFFERRARI, D.; ALBORNOZ, L. L.; SAMIOS, D. Solvent-free biodiesel epoxidation. Environmental Chemistry Letters 12.2, 2014, p. 335-340.

LEVENEUR, S.; ZHENG, J.; TAOUK, B.; BUREL, F.; WÄRNÅ, J.; SALMI, T. Interaction of thermal and kinetic parameters for a liquid-liquid reaction system: Application to vegetable oils epoxidation by peroxycarboxylic acid. Journal of the Taiwan Institute of Chemical Engineers 45.4, 2014, p. 1449-1458.

LIMA, R. M. F.; VASCONCELOS, J.A.; SILVA, G. R. Flotação aniônica de rejeito de minério de manganês. REM - Revista da Escola de Minas, Ouro Preto, 2008. p 337-342.

MARZZACCO, C.J. The enthalpy of decomposition of hydrogen peroxide: a general chemistry calorimetry experiment. Journal of chemical education 76 , no. 11, 1999, p. 1517.

MILCHERT, E.; SMAGOWICZ, A. Epoxidation of the Rapeseed Oil with Peracetic and Performic Acid. Czasopismo Techniczne, 2008.

MONONO, E. M.; HAAGENSON, D. M.; WIESENBORN, D. P. Characterizing the epoxidation process conditions of canola oil for reactor scale-up. Industrial Crops and Products 67, 2015. p. 364-372.

NIEDERHAUSER, W. D.; KOROLY,J. E. Process for the Epoxidation of Esters of Oleic and Linoleic Acids. Patente USA 2485 160, 1948.

PETROVIĆ, Z. S.; ZLATANIĆ, A.; LAVA, C. C.; SINADINOVIĆ-FIŠER, S. Epoxidation of Soybean Oil in toluene with peroxoacetic and peroxoformic 
acids - kinetics and side reactions. Eur. J. Lipid Sci. Technol. Volume 104, 2002, p. 293-299.

RAHMAN, M.;BRAZEL, C. S. The plasticizer market: an assessment of traditional plasticizers and research trends to meet new challenges. Progress in Polymer Science 29.12, 2004, p. 1223-1248.

RANGARAJAN, B. et al. Kinetic parameters of a twophase model for in-situ epoxidation of soybean oil. Journal American Oil Chemists' Society 72 p. 11611169, 1995.

RANGARAJAN, B.; HAVEY, A.; GRULKE, E. A.; CULNAN, P. D. Epoxidation of Soybean Oil in a Microemulsion-Assisted Environment. The 2005 Annual Meeting. Cincinnati, OH, USA, 2005.

RETHWISCH, D.; JAIN, K.; RASMUSSEN, P.; RETHWISCH, K.; PEEPLES, T.; SCRANTON, A.B. Epoxidation of Soybean Oil in a Microemulsion-Assisted Environment. The 2005 Annual Meeting. Cincinnati, OH, USA, 2005.

SANTACESARIA, R.; DI SERIO, E.; TESSER, M.; TURCO, R.; RUSSO, V. Epoxidation of soybean oil, a study on the possibilities of process intensification. University of Naples Federico II, Dpt. of Chemistry, 2010.

SANTACESARIA, E.; TESSER, R.; DI SERIO, M.; TURCO, R.; RUSSO, V.; VERDE, $D$. A biphasic model describing soybean oil epoxidation with $\mathrm{H}_{2} \mathrm{O}_{2}$ in a fedbatch reactor. Chemical Engineering Journal, v. 173, 2011a, p. 198-209.

SANTACESARIA, E.; RENKEN, A.; RUSSO, V.; TURCO, R.; TESSER, R.; DI SERIO, M. Biphasic model describing soybean oil epoxidation with $\mathrm{H}_{2} \mathrm{O}_{2}$ in continuous reactors. Industrial \& Engineering Chemistry Research 51.26, 2011b, p. 8760-8767.

SAURABH, T.; PATNAIK, M.; BHAGT, S. L.; RENGE, V. C. Epoxidation of vegetable oils: a review. International Journal of Advanced Engineering Technology 2.4, 2011, p. 491-501.

SEARS J. K.; DARBY J.R. The Technology of Plasticizers. Wiley, New York, 1982.

SWERN, D.; FINDLEY, T. W. Epoxidized Oils. Patente USA 2569 502, 1945.

The American Oil Chemists' Society (AOCS) Official Method Cd 1-25. Wijs Method for lodine Value. Revised 1988.

The American Oil Chemists' Society (AOCS) Official Method Cd 9-57. Oxirane Oxygen. Reapproved 2009.

TURCO, R. Industrial catalytic processes intensification through the use of microreactors. PhD Thesis in Chemical Sciences, University of Naples Federico II, Dpt. of Chemistry, 2011.

TURCO, R.; VITIELLO, R.; RUSSO, V.; TESSER, R.; SANTACESARIA, E.; DI SERIO, M. Selective epoxidation of soybean oil with performic acid catalyzed by acidic ionic exchange resins. Green Processing and Synthesis 2.5, 2013, p. 427-434.

WOODS, M. E.; KRIEGER, I. M. Rheological studies on dispersions of uniform colloidal spheres I. Aqueous dispersions in steady shear flow. Journal of Colloid and Interface Science 34.1, 1970, p. 91-99. 
ZAHER, F. A.; EL-SHAMI S. M. Oxirane ring opening by formic acid. Grasas y Aceites, 1990, p. 361-365.

ZAHER, F. A.; EL-MALLAH M. H.;EL-HEFNAWY M. M. Kinetics of oxirane cleavage in epoxidized soybean oil. Journal of the American Oil Chemists' Society Volume 66, Number 5, 1989, p. 698-700. 


\section{APÊNDICE I}

Gráficos com ajustes de curvas do modelo aos dados experimentais:

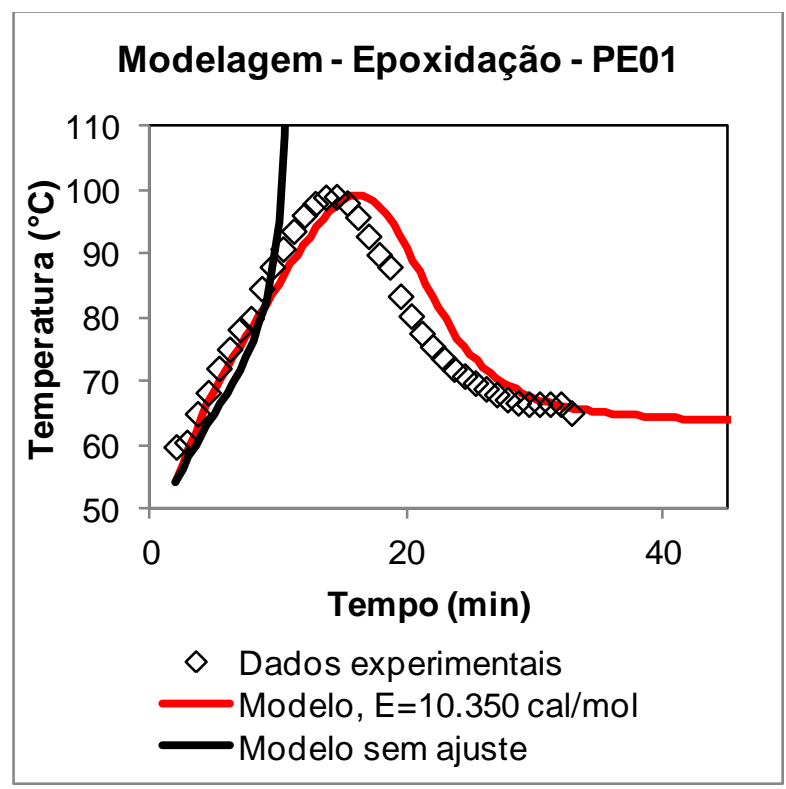

\section{Modelagem - Epoxidação - PE03}

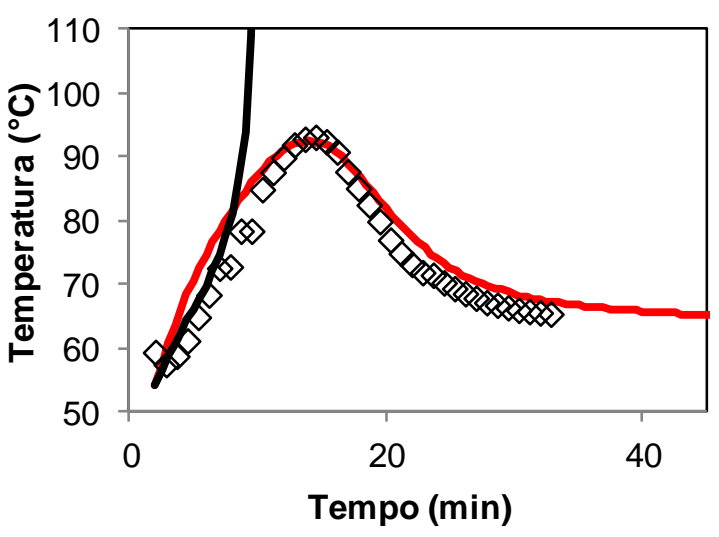

$\diamond$ Dados experimentais

Modelo, $\mathrm{E}=8.700 \mathrm{cal} / \mathrm{mol}$

-Modelo sem ajuste

\section{Modelagem - Epoxidação - PE05}

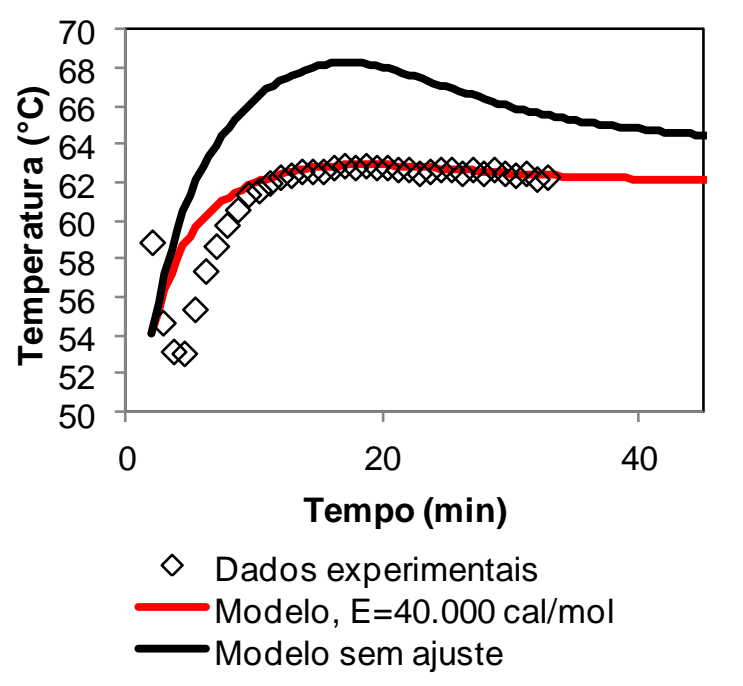

Modelagem - Epoxidação - PE07

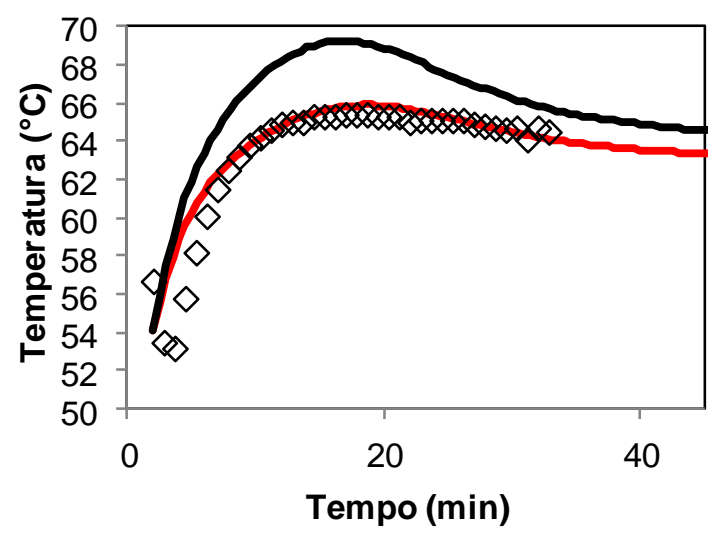

$\diamond$ Dados experimentais

Modelo, $\mathrm{E}=30.000 \mathrm{cal} / \mathrm{mol}$ Modelo sem ajuste 

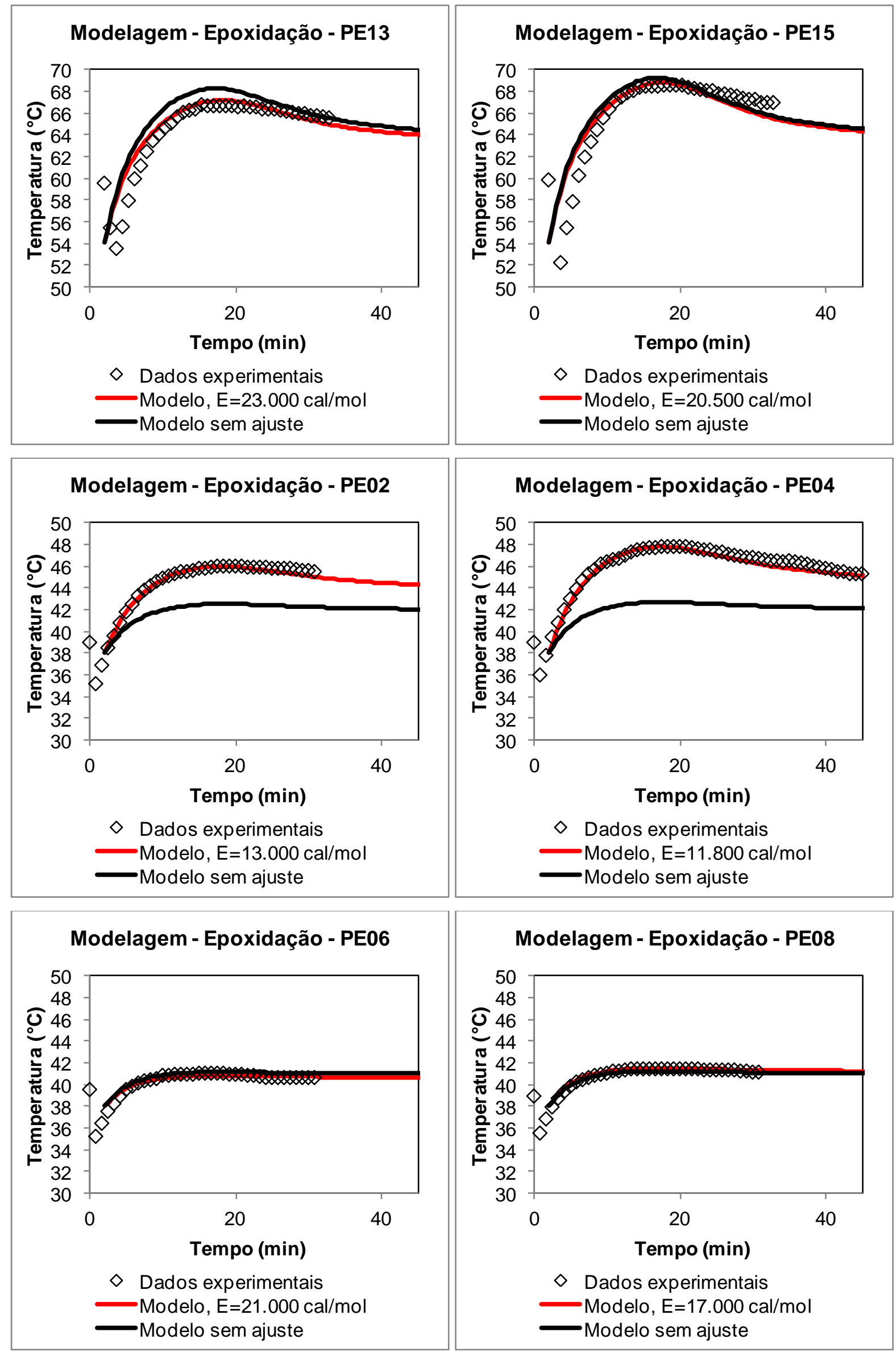

\section{Modelagem - Epoxidação - PE08}

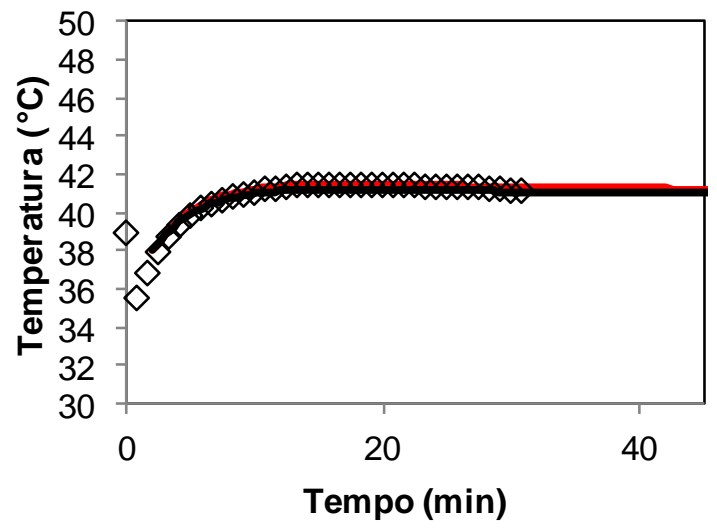

$\diamond$ Dados experimentais

Modelo, $\mathrm{E}=17.000 \mathrm{cal} / \mathrm{mol}$

Modelo sem ajuste 

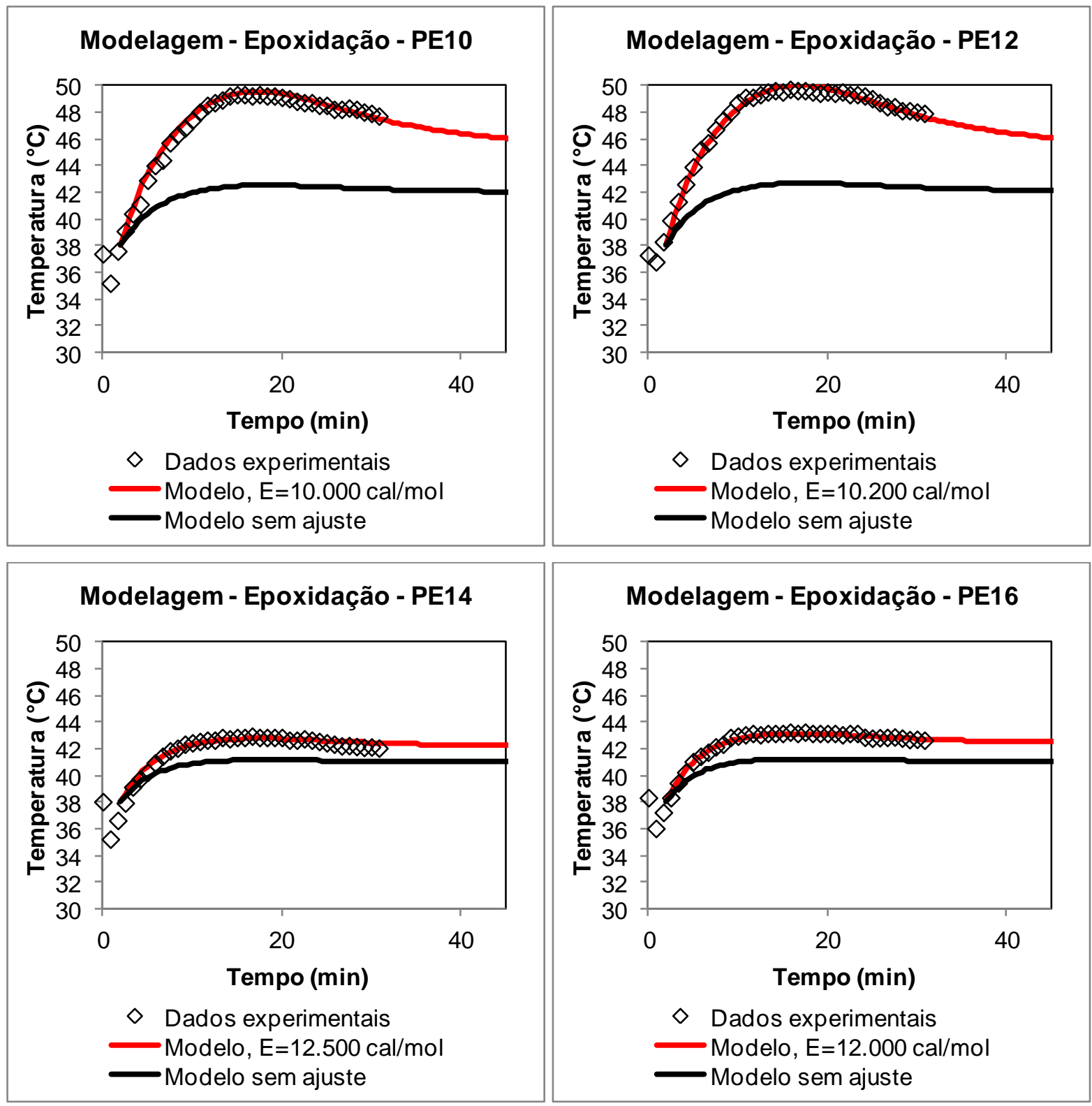


\section{ANEXO I}

Especificações comerciais, óleo de soja epoxidado:

Oxigênio Oxirânico $(\% \mathrm{~m} / \mathrm{m}) \ldots \ldots \ldots \ldots \ldots \ldots \ldots \ldots \ldots \ldots$ Min 6,50

Índice de Iodo ( $\left.\mathrm{g} \mathrm{I}_{2} / 100 \mathrm{~g}_{\text {amostra }}\right) \ldots \ldots \ldots \ldots \ldots \ldots \ldots \ldots$ Máx 5,0

Índice de Acidez $(\mathrm{mg} \mathrm{KOH} / \mathrm{g})$.......................... Máx 0,7

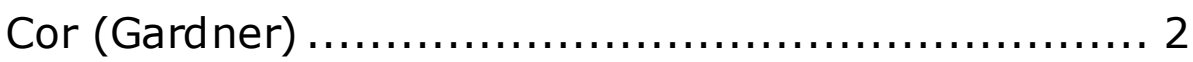

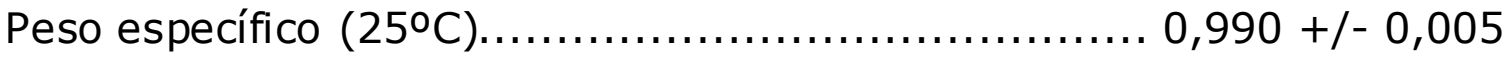




\begin{abstract}
ANEXO II
SUMÁRIO - Método AOCS (American Oil Chemists' Society) Cd 9-57

\section{Insumos e Reagentes}

- Solução de Ácido perclórico $0,1 \mathrm{~N}$ em ácido acético glacial

- Solução violeta cristal $1 \%$ em ácido acético glacial

- Reagente TEAB (Brometo de Amônio tetraetila) em ácido acético glacial

- Clorofórmio
\end{abstract}

\title{
Materiais e equipamentos
}

\begin{tabular}{|l|l|}
\hline Bureta de $25 \mathrm{~mL}$ & Erlenmeyer de $250 \mathrm{~mL}$ com rol ha de vidro \\
\hline Balança Analítica & Pipeta graduada $15 \mathrm{~mL}$ \\
\hline Pipeta graduada $10 \mathrm{~mL}$ & \\
\hline
\end{tabular}

\section{Procedimentos experimentais}

- Em um erlenmeyer, pesar $\pm 0,15$ a $0,20 \mathrm{~g}$ da amostra, utilizar balança analítica.

- Adicionar $10 \mathrm{~mL}$ de Clorofórmio.

- Adicionar $15 \mathrm{~mL}$ de reagente TEAB neutralizado. Agite bem.

- Adicionar 2 gotas de violeta cristal $1 \%$.

- Titule com Ácido Perclórico 0,1N

- Ponto de viragem verde (a cor deve permanecer por 15 segundos)

- Cálculos de expressão dos resultados e algarismos significativos

$\% \mathrm{O}_{2}$ Oxirânico $=\underline{(\mathrm{Va}) \times \mathrm{N} \times 1,6}$

$\mathrm{m}$

Onde:

$\mathrm{Va}=$ volume gasto de Ácido Perclórico

$\mathrm{m}=$ massa da amostra em gramas

$\mathrm{N}=$ normalidade do Ácido Perclórico

\section{Preparo da solução de Brometo de Amônio tetraetila (TEAB):}

\section{Insumos e Reagentes}

- Reagente TEAB(Brometo de Amônio tetraetila)

- Ácido acético glacial P.A

- Solução violeta cristal a 1 \% em ácido acético glacial

- Solução de Acetato de sódio $0,1 \mathrm{~N}$ em ácido acético glacial 


\section{Procedimentos}

- Em um béquer, pesar $100 \mathrm{~g}$ de TEAB (98 - $99 \%)$, utilizar balança analítica.

- Diluir em $420 \mathrm{~mL}$ de ácido acético glacial, em constante agitação.

- Adicione 4 gotas de indicador violeta cristal $1 \%$

- Neutralizar com solução de Acetato de sódio $0,1 \mathrm{~N}$ em ácido acético glacial.

\section{Preparo da solução de Acetato de Sódio 0,1N}

- Pesar 1,3657 g de acetato de sódio, utilizar balança analítica.

- Diluir com ácido acético glacial e avolumar para $100 \mathrm{~mL}$

\section{Preparo da solução de violeta cristal $1 \%$}

- $10 \mathrm{~g}$ de ácido acético

- $1 \%$ de violeta cristal 


\section{SUMÁRIO - Método AOCS (American Oil Chemists' Society) Cd 1-25}

\section{Insumos e Reagentes}

- Solução de Tiossulfato de Sódio 0,1 N

- Solução de WIJS

- Solução de lodeto de Potássio $15 \%$

- Solução de amido a 1 \%

- Clorofórmio

Materiais e equipamentos

\begin{tabular}{|l|l|}
\hline Bureta de $50 \mathrm{~mL}$ & Erlenmeyer de $250 \mathrm{~mL}$ com rol ha de vidro \\
\hline Balança Analítica & Pipeta graduada $25 \mathrm{~mL}$ \\
\hline Pipeta graduada $20 \mathrm{~mL}$ & Proveta de $50 \mathrm{~mL}$ \\
\hline
\end{tabular}

\section{Procedimentos experimentais}

- Em um erlenmeyer, pesar amostra de acordo com a tabela AP1, utilizar balança analítica.

- Adicionar $50 \mathrm{~mL}$ de Clorofórmio e agitar bem.

- Adicionar $25 \mathrm{~mL}$ da solução WIJS, agitar bem

- Deixe em abrigo da luz por 1 hora

- Adicionar $20 \mathrm{~mL}$ de lodeto de Potássio e $50 \mathrm{~mL}$ de água destilada

- Titule lentamente com Tiossulfato de Sódio $0,1 \mathrm{~N}$, quando a coloração estiver próxima do amarelo, adicionar $1,5 \mathrm{~mL}$ de solução indicadora de amido a $1 \%$

- Ponto de viragem branco (a cor deve permanecer por 15 segundos)

- A cada lote de análise realizar a titulação de um branco

Tabela AP1

Cálculo do resultado

$\begin{array}{cc}\begin{array}{c}\text { Índice de lodo esperado } \\ <=1\end{array} & \begin{array}{c}\text { Massa de amostra em gramas } \\ 10,00\end{array} \\ 3 & 5,00 \text { a } 6,00 \\ 7 & 3,00 \text { a } 4,00 \\ 10 & 2,50 \text { a } 3,00 \\ 20 & 0,80 \text { a } 1,50 \\ 30 & 0,60 \text { a } 0,80 \\ 80 & 0,30 \text { a } 0,40 \\ 100 & 0,20 \text { a } 0,30 \\ 130 & 0,20 \text { a } 0,25 \\ 150 & 0,17 \text { a } 0,20\end{array}$

$$
\text { Índice de Iodo }=\frac{(V b-V a) \times 1,269 \times F c}{m}
$$

Onde:

$\mathrm{Va}=$ volume do titulante gasto na amostra

$\mathrm{Vb}=$ volume do titulante gasto no branco

$\mathrm{Fc}=$ fator de correção do titulante, indicado pelo fabricante

$M=$ massa da amostra em gramas 